\title{
A systematic review on silica-, carbon-, and magnetic materials-supported copper species as efficient heterogeneous nanocatalysts in "click" reactions
}

\author{
Pezhman Shiri ${ }^{*}$ and Jasem Aboonajmi
}

\author{
Review \\ Address: \\ Department of Chemistry, Shiraz University, Shiraz, Iran \\ Email: \\ Pezhman Shiri* - pezhmanshiri@yahoo.com \\ * Corresponding author \\ Keywords: \\ "click" reaction; copper complexes; reusable catalysts; \\ Sharpless-Meldal C-N bond-forming reaction; silica/carbon/magnetic \\ materials
}

Beilstein J. Org. Chem. 2020, 16, 551-586. doi:10.3762/bjoc. 16.52

\author{
Received: 05 September 2019 \\ Accepted: 11 March 2020 \\ Published: 01 April 2020 \\ Associate Editor: M. Rueping \\ (C) 2020 Shiri and Aboonajmi; licensee Beilstein-Institut. \\ License and terms: see end of document.
}

\begin{abstract}
In recent years, many inorganic silica/carbon-based and magnetic materials have been selected to arrest copper ions through a widespread range of anchoring and embedding methodologies. These inorganic supported nanocatalysts have been found to be efficient, environmentally friendly, recyclable, and durable. In addition, one of the vital issues for expanding new, stable, and reusable catalysts is the discovery of unique catalysts. The basis and foundation of this review article is to consider the recently published developments (2014-2019) in the synthesis and catalytic applications of copper supported by silica nanocomposites, carbon nanocomposites, and magnetic nanocomposites for expanding the "click" chemistry.
\end{abstract}

\section{Introduction}

Heterocycles are a class of organic compounds with significant biological activities [1-10], including antimicrobial [2], antibacterial [3], anti-HIV [4], antiviral [5], antiparkinsonian [6], and anticancer [10] properties.

Particularly, triazoles illustrate distinguished moieties well distributed in natural products with biological properties [2-4,9,10], including antimicrobial [2], antibacterial [3], antifungal [3], anti-HIV [4], and anticancer [10] activities.

One of the employed procedures for the creation of triazole products is the Huisgen azide-alkyne cycloaddition, and the reaction selectively forms one type of triazole products. Many of the alkyne and azide substrates are commercially available, many others can easily be prepared with a good range of functional groups. The intramolecular reaction of an alkyne as a dipolarophile with an azide as a 1,3-dipole to produce the desired 1,2,3-triazole motif is a model of "click" chemistry. The concept of "click" chemistry is an idiom that was developed by Sharpless and Meldal and later by others to describe organic reactions that are stereospecific, high-yielding, modular, wide in scope, executable under simple reaction conditions, conductable in safe or easily removable solvents, and that generate only nonoffensive byproducts. Of course, the classical 
Huisgen 1,3-dipolar cycloaddition does not fit into the above definition and fails as a real "click" reaction. Although this cyclization reaction requires elevated temperatures and often yields both the 1,4- and 1,5-regioisomers, the $\mathrm{Cu}$ or $\mathrm{Ru}$ alkyne-azide cycloaddition falls exactly into the above definition [11].

In this respect, the copper-catalyzed cycloaddition reaction proceeds under mild conditions, is effective, efficient, and requires no column purification in many cases. The $\mathrm{Cu}$ alkyne-azide cycloaddition (CuAAC) version also gives only 1,2,3-triazole products substituted at the 1- and 4-positions in an aqueous medium even at room temperature and requires no protecting groups [12]. Later, ruthenium complexes-catalyzed alkyne-azide cycloadditions (RuAACs) regioselectively produced the opposite form of the disubstituted triazoles. Thus, a wide range of azides was reacted with diverse nonactivated terminal alkyne substrates using ruthenium complexes to generate 1,2,3-triazole products substituted at the 1- and 5-positions [13]

A range of copper(I) species (copper(I) iodide, copper(I) bromide, $\left[\mathrm{Cu}\left(\mathrm{CH}_{3} \mathrm{CN}\right)_{4}\right] \mathrm{PF}_{6}$, (EtO) $)_{3} \mathrm{P} \cdot \mathrm{CuI}$, and $\left.\left[\mathrm{Cu}\left(\mathrm{PPh}_{3}\right)_{3}\right] \mathrm{Br}\right)$ has been applied in the prementioned reaction [14]. Generally, $\mathrm{Cu}(\mathrm{I})$ species are not thermodynamically stable and can be oxidized to $\mathrm{Cu}(\mathrm{II})$ species. Without using a ligand or a reducing agent, $\mathrm{Cu}(\mathrm{II})$ can oxidize alkynes to produce an undesired byproduct. Active copper catalysts can be prepared by reducing copper(II) sources, oxidizing copper metal, comproportionation of $\mathrm{Cu}(\mathrm{II})$ and $\mathrm{Cu}(0)$, or combination of copper salts and suitable ligands [14].

Ligands serve to increase and modulate the reactivity of copper salts. In the first attempt, tris((1-benzyl-1H-1,2,3-triazol-4yl)methyl)amine (TBTA) considerably speds up the copper-catalyzed cyclization [15]. Many structurally diverse ligands, such as nitrogen-, phosphorus-, carbon-, oxygen-, and sulfur-containing ligands were investigated soon after the disclosure of the auxiliary effect of ligands on copper-catalyzed alkyne-azide cycloaddition reactions $[16,17]$.

Heterogeneous catalysts are safer than their homogeneous counterparts. They also offer some advantages, such as the ease of product separation, catalyst recovery, simplifying the production process, and cleaner operation conditions [18-20].

Thus far, several heterogeneous catalysts have been explored for CuAAC and RuAAC processes. The catalytic activities of heterogeneous copper catalysts as novel catalysts are wellrecognized with respect to their benefits, such as easy work-up, simple separation of catalysts from products, and economically viable usage in laboratory processes [21-23].
A new and systematic review of the recently published procedures for constructing copper supported by silica nanocomposite, carbon nanocomposite, and magnetic nanocomposites and their catalytic uses in CuAACs will be helpful to the community of scientists working in industry and scholarly laboratories, respectively.

This review aims to cover recently published reports from 2014 to 2019 presenting synthetic routes and applications that focused on the title catalysts in $\mathrm{CuAAC}$ reactions.

\section{Review \\ Copper anchored on functionalized silica materials: efficient and recyclable catalysts for CUAAC reactions}

In recent years, silica or silicon dioxide nanomaterials have received much attention from researchers and industry and have been used in a wide spectrum of applications. Silica nanomaterials have the empirical formula $\mathrm{SiO}_{2}$ in which one silicon atom covalently links to four oxygen atoms, and most of the oxygen bond to two silicon atoms. Hence, their atoms are randomly oriented to produce amorphous structures. These materials, with a high surface area, could be employed as electronic devices, thermal or electronic insulators, catalysts, and humidity sensors [24].

Moreover, mesoporous silica nanomaterials benefit from unique properties, including a large surface area, uniform pore size and distribution, high chemical/thermal/mechanical stability, and good adsorption capacity. They also contain an ordered porous network that is appropriate for the free diffusion of reactants and reaction products [24].

In this regard, various functionalized $\mathrm{SiO}_{2}$ nanoparticles were employed in diverse organic reactions, including Suzuki-Miyaura reactions, Ugi-Smiles reactions, Mizoroki-Heck reactions, aldol reactions, oxidation and dehydration reactions, Mannich reactions, and multicomponent reactions. Because of the mentioned reasons as well as due to the low toxicity of silica nanoparticles, they are often a good option [24]. For this review article, we have provided an overview on the synthesis and functionalization of $\mathrm{SiO}_{2}$ nanoparticles and on the investigation on their catalytic applications in $\mathrm{CuAAC}$ reactions.

Rhee et al. immobilized $\mathrm{Cu}(\mathrm{I})$ and $\mathrm{Cu}(\mathrm{II})$ species onto reversephased silica gel [25]. In this work, a 2-pyridinecarboxaldehyde ligand was attached on reversed-phase 3-aminopropylfunctionalized silica gel (APSi) in dichloromethane as a solvent. The complexation reaction of the resulting Schiff base, named 
iminopropyl-functionalized silica gel (IPSi), with $\left[\mathrm{Cu}\left(\mathrm{CH}_{3} \mathrm{CN}\right)_{4}\right] \mathrm{PF}_{6}$ and $\mathrm{CuSO}_{4}$ produced $\mathrm{Cu}(\mathrm{I}) @ \operatorname{IPSi}(\mathbf{1 a})$ and Cu(II)@IPSi (1b), respectively (Scheme 1). The catalysts were characterized by a series of analytical techniques. The solidstate ${ }^{13} \mathrm{C}$ NMR of IPSi showed nine peaks at 10, 24, 43, 63, $121,136,148,155$, and $162 \mathrm{ppm}$, respectively. SEM analysis displayed an irregular shape for $\mathbf{1 a}$ and $\mathbf{1 b}$.

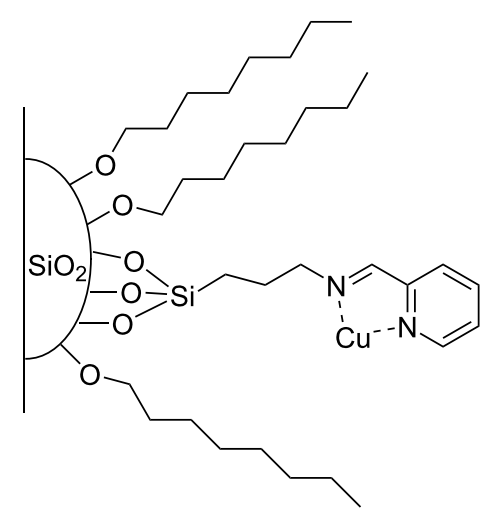

Cu(I)@IPSi (1a) or Cu(II)@IPSi (1b)

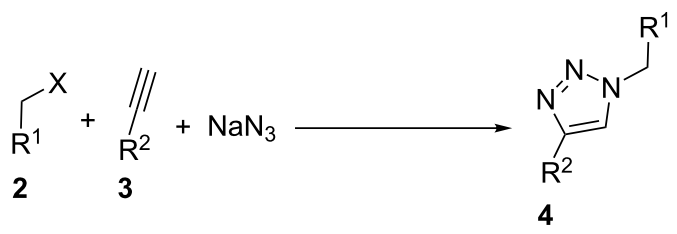

conditions for the triazole syntheses: 1 a $(2.5 \mathrm{~mol} \%$ of $\mathrm{Cu})$

or $1 \mathbf{b}(5.0 \mathrm{~mol} \%$ of $\mathrm{Cu}), 60^{\circ} \mathrm{C}, \mathrm{H}_{2} \mathrm{O}(2 \mathrm{~mL})$

reaction time for $1 \mathrm{a}: 2-6 \mathrm{~h} ; 1 \mathbf{b}: 2-6 \mathrm{~h}$

yield for 1a: 76-97\%; 1b: 74-96\%

$\mathrm{X}=\mathrm{Br} ; \mathrm{R}^{1}=\mathrm{Ph}, 4-\mathrm{NO}_{2} \mathrm{C}_{6} \mathrm{H}_{4}, 4-\mathrm{CF}_{3} \mathrm{C}_{6} \mathrm{H}_{4}$,

4- $\mathrm{ClC}_{6} \mathrm{H}_{4}, 3-\mathrm{MeOC}_{6} \mathrm{H}_{4}, 4-\mathrm{MeC}_{6} \mathrm{H}_{4}$

$\mathrm{R}^{2}=\mathrm{Ph}, 4-\mathrm{MeC}_{6} \mathrm{H}_{4}, 4-\mathrm{MeOC}_{6} \mathrm{H}_{4}, 4-\mathrm{BrC}_{6} \mathrm{H}_{4}$,

4- $\mathrm{NH}_{2} \mathrm{C}_{6} \mathrm{H}_{4}, 4-\mathrm{CF}_{3} \mathrm{C}_{6} \mathrm{H}_{4}, 3,4-\mathrm{diClC}_{6} \mathrm{H}_{3}, 4-t-\mathrm{BuC}_{6} \mathrm{H}_{4}$

Scheme 1: Chemical structure of the catalysts $1 \mathrm{a}$ and $\mathbf{1 b}$ and their catalytic application in CuAAC reactions.

The catalytic activity of Cu(I)@IPSi (1a) and Cu(II)@IPSi (1b) was investigated in the one-pot three-component condensation of various benzyl bromides, various phenylacetylenes, and sodium azide (Scheme 1). The authors stated that benzyl azide was formed in situ by the nucleophilic addition of the benzyl bromide and sodium azide. Subsequently, the desired triazole products were generated through the $[3+2]$ cycloaddition of the azide and alkyne. The recyclability analysis of these IPSi-supported $\mathrm{Cu}(\mathrm{I})$ and $\mathrm{Cu}(\mathrm{II})$ catalysts indicated seven consecutive runs with almost equivalent performances.

In 2018, silica modified with a benzimidazole-salen $\mathrm{Cu}(\mathrm{II})$ complex, 11, was synthesized in several steps [26]. Initially, 5-(chloromethyl)-2-hydroxybenzaldehyde (6) was prepared by the reaction of 2-hydroxybenzaldehyde (5) and paraformaldehyde in concentrated $\mathrm{HCl}$ at a temperature between 5 and 10 ${ }^{\circ} \mathrm{C}$. At the same time, benzimidazole-substituted phenol 8 was generated by the reaction of 2-hydroxybenzaldehyde (5) and $o$-phenylenediamine (7) at rt using a cobalt catalyst. In the next step, a benzimidazole-containing aldehyde $\mathbf{9}$ was obtained by the reaction of $\mathbf{6}$ with benzimidazole-substituted phenol $\mathbf{8}$. This ligand was immobilized on propylamine-functionalized nanosilica. Finally, the complexation reaction of $\mathrm{Cu}(\mathrm{II})$ with a supported ligand on propylamine-functionalized nanosilica, 10, was performed to produce a $\mathrm{Cu}(\mathrm{II})$ benzimidazole-salen complex supported by imine-functionalized silica (BS-Cu(II)@SiO 2 (11), Scheme 2).

The nanocatalyst $\mathbf{1 1}$ was used to synthesize benzimidazole-triazole derivatives through a one-pot sequence of activation of the alkyne, $[3+2]$ condensation, cyclization, and aromatization under mild reaction conditions (Scheme 2). Moreover, the BS-Cu(II)@SiO 2 (11) catalyst could be recovered and recycled for seven cycles without a notable loss of catalytic activity.

Using a multistep solid-phase procedure, Shantz et al. reported on SBA-15 functionalized with melamine-based dendrons (Scheme 3) [27]. The $\mathrm{Cu}$ and $\mathrm{Cu} / \mathrm{Au}$ nanoparticles were then supported on this new composite to generate a nanocatalyst. The catalytic application of this nanocatalyst was investigated as well. The amine-functionalized SBA-15, 19, was added to a THF solution of cyanuric chloride and DIPEA. After being stirred in a closed vessel at $\mathrm{rt}$ for $24 \mathrm{~h}$, the produced material was filtered off and then washed with methanol, dichloromethane, and THF. The sample was again reacted with 4-aminomethylpiperidine (AMP, 21) or piperazine (PIP) to afford $G_{1}$-AAA-SBA-15 (G 1 -AMP-SBA-15, 22, or $\mathrm{G}_{2}$-PIP-SBA-15, 23) materials (Scheme 3). The resulting solid product was then filtrated and washed with methanol, dichloromethane, and tetrahydrofuran. The organic part of the $\mathrm{G}_{1}$-AAA-SBA-15 was grown one or two times by repeating the above-mentioned process to generate $\mathrm{G}_{2}$-AAA-SBA-15 and $\mathrm{G}_{3}$-AAA-SBA-15 composites, respectively. Generally, $x$ and AAA in $\mathrm{G}_{\mathrm{X}}$-AAA-SBA-15 refer to the dendron generation and diamine (AMP for dendrons containing 4-aminomethylpiperidine and PIP for dendrons containing piperazine), respectively. In the next step, $\mathrm{G}_{\mathrm{X}}$-AAA-SBA-15 was dispersed in an aqueous solution of $\mathrm{HAuCl}_{4}$ and stirred for a short time. The reduction of $\mathrm{Au}$ was accomplished using an aqueous solution of $\mathrm{NaBH}_{4}$. The obtained material was then centrifuged and washed with deionized water. The resulting solid was dispersed in an aqueous solution of $\mathrm{CuCl}_{2} \cdot 3 \mathrm{H}_{2} \mathrm{O}$ for $10 \mathrm{~min}$. The copper species was reduced with an aqueous solution of $\mathrm{NaBH}_{4}$. The metal-dendron SBA-15 material was filtrated, washed with de- 
<smiles>O=Cc1ccccc1O</smiles>

5<smiles>Nc1ccccc1[NH2+]C=O</smiles><smiles>O=Cc1cc(CCl)ccc1O</smiles>

6

Co catalyst<smiles>CCc1ccc(-c2nc3ccccc3[nH]2)c(O)c1</smiles>

$\mathrm{HO}$<smiles>O=Cc1cc(Cn2c(-c3ccccc3O)nc3ccccc32)ccc1O</smiles>

9

8

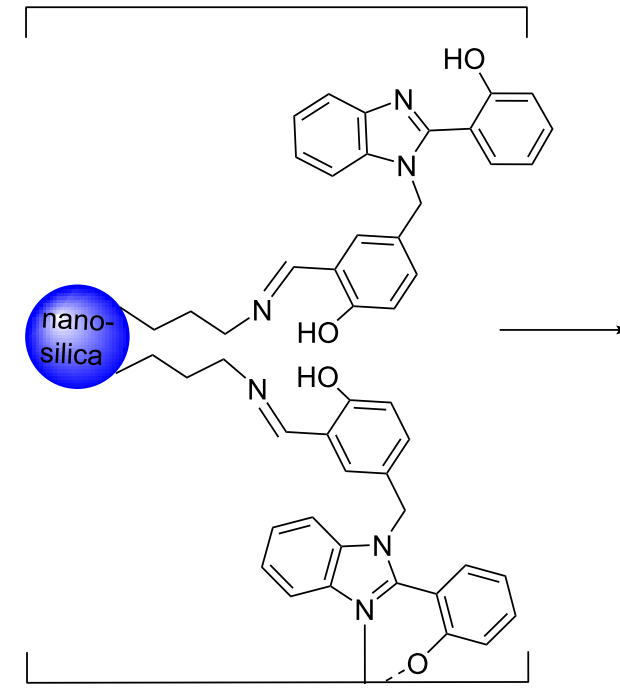

10

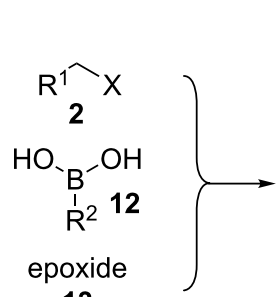

13<smiles>C#CCOc1[R]cc(C=O)cc1</smiles>

O
15

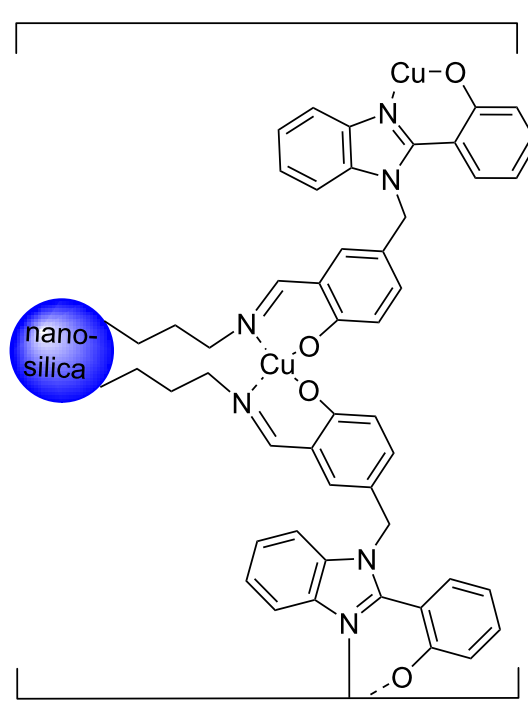

11<smiles></smiles>

conditions: 11 (5.0 mol \% of $\mathrm{Cu})$, rt, alcohol $/ \mathrm{H}_{2} \mathrm{O}$ reaction time: 11 and $18 \mathrm{~h}$, yield: $87-94 \%$

$\mathrm{X}=\mathrm{Cl}, \mathrm{Br} ; \mathrm{R}^{1}=\mathrm{Ph}, \mathrm{R}^{2}=\mathrm{Ph} ; \mathrm{R}^{3}=\mathrm{H}, \mathrm{OMe} ; \mathrm{R}^{4}=\mathrm{H}, \mathrm{Cl}, \mathrm{Me}, \mathrm{PhCO}$<smiles>[R]c1ccc(-c2nc3cc[R1]([H])cc3[nH]2)cc1</smiles>

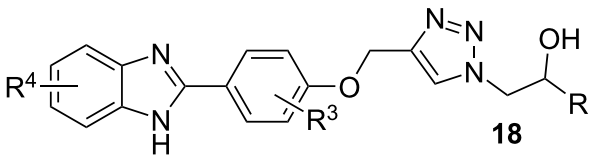
epoxide $=$ 2-phenyloxirane, 2-(phenoxymethyl)oxirane, 7-oxabicyclo[4.1.0]heptane

Scheme 2: Synthetic route to the catalyst 11 and its catalytic application in CuAAC reactions.

ionized water, and dried to produce $\mathrm{x}$ wt $\% \mathrm{Cu}_{\mathrm{Y}} \mathrm{Au}-\mathrm{G}_{\mathrm{X}}-$ AAA-SBA-15 ( $\mathrm{x}$ wt $\%$ = weight percent loading of $\mathrm{Cu}, \mathrm{Y}=\mathrm{Cu} /$ $\mathrm{Au}$ molar ratio, $\mathrm{G}_{\mathrm{x}}=$ dendrimer generation, and $\mathrm{AAA}=$ dendron type).

After the preparation and characterization of the $\mathrm{Cu}_{\mathrm{Y}} \mathrm{Au}-\mathrm{G}_{\mathrm{X}^{-}}$ AAA-SBA-15 catalyst, the material was employed in a triazole synthesis, and it was established that the catalyst was efficient in the Sharpless-Meldal $\mathrm{C}-\mathrm{N}$ bond formation reaction in Scheme 4.

Different ratios of $\mathrm{Cu} / \mathrm{Au}$ were explored for the reaction. As expected, the SBA-15, G $\mathrm{G}_{2}$ AMP-SBA-15, and $2 \mathrm{wt} \% \mathrm{Au}-\mathrm{G}_{2-}$ SBA-15 materials were not catalytically active in the reactions. However, the reactions proceeded well using $2 \mathrm{wt} \% \mathrm{Cu}-\mathrm{SBA}-$ 15 and 2 wt $\% \mathrm{Cu}-\mathrm{G}_{2}$-AMP-SBA- 15 materials. 


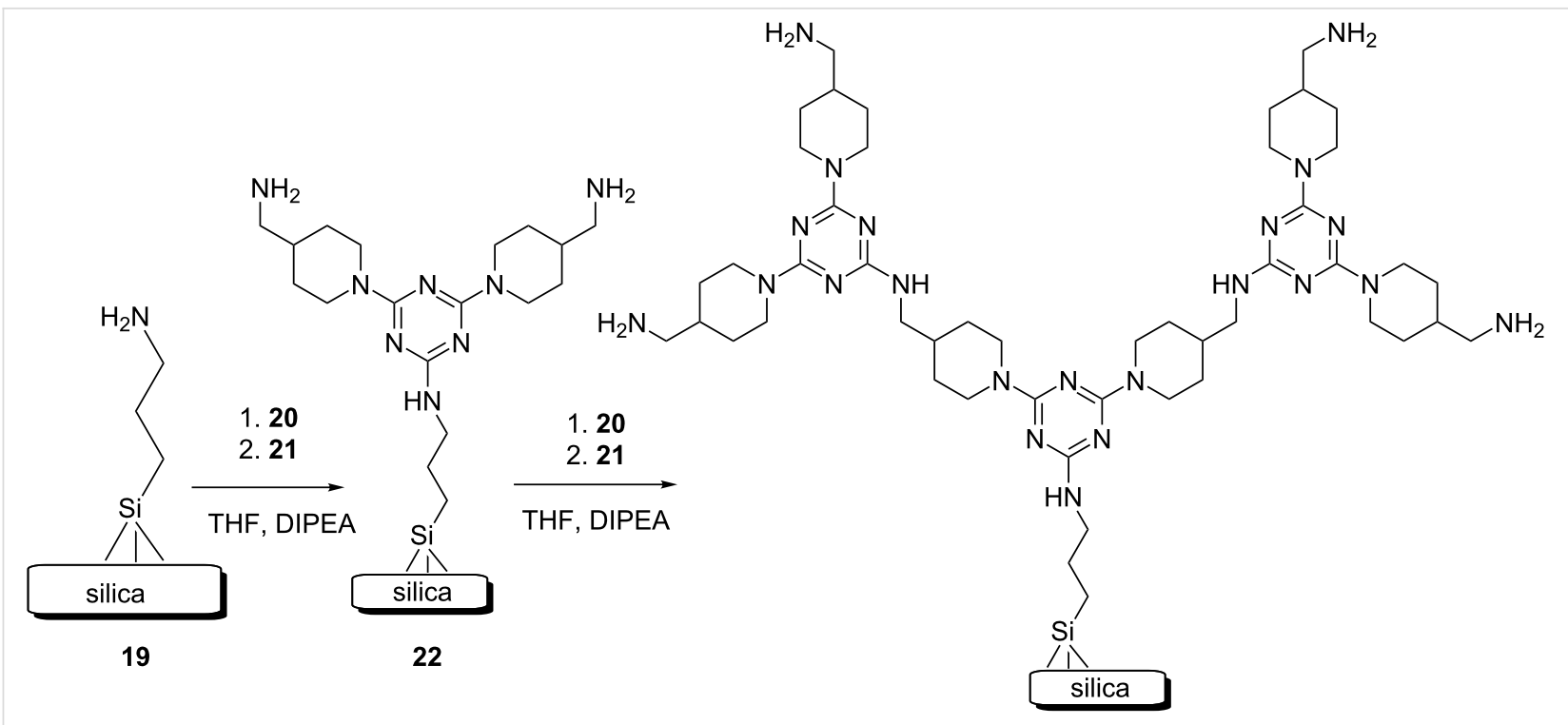

23

Scheme 3: Synthetic route of dendrons, illustrated using $\mathrm{G}_{2}-\mathrm{AMP} 23$.

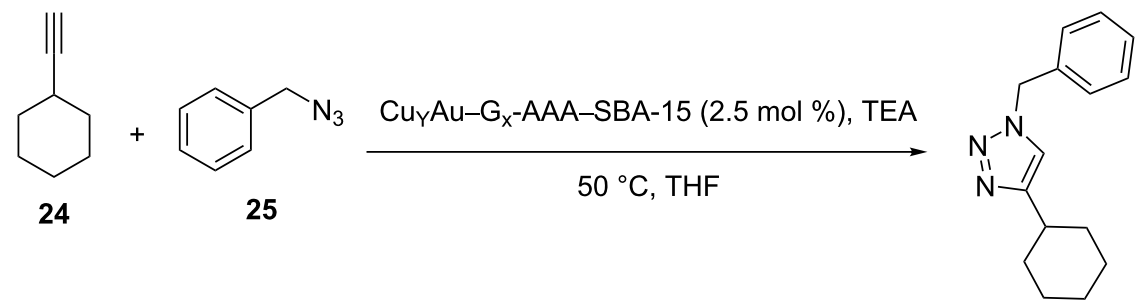

26

Scheme 4: The catalytic application of $C u_{Y} A u-G_{x}-A A A-S B A-15$ in a CuAAC reaction.

Different ratios of $\mathrm{Cu} / \mathrm{Au}(1: 1,3: 1$, and 5:1) were studied for the coupling reaction of a nonactivated terminal alkyne with an organic azide. Control measurements showed that 1:1 and 3:1 samples were more efficient than a 5:1 sample. The authors stated that increasing the $\mathrm{Cu} / \mathrm{Au}$ ratio caused the formation of thicker layers of $\mathrm{Cu}$ on $\mathrm{Au}$ nanoparticles. Other findings in this study were: a) copper leaching decreased using gold nanoparticles, b) increasing the dendron generation increased the diffusion resistance.

As shown in Scheme 5, a silica nanomaterial was decorated with a novel copper complex of poly(N-heterocyclic carbene) in multiple steps [28]. Initially, imidazole (28) was immobilized on the silica nanomaterial $\mathbf{2 7}$ by a nucleophilic attack of $\mathbf{2 8}$ on the iodopropylated silica nanomaterial $\mathbf{2 7}$ in acetonitrile under reflux for $48 \mathrm{~h}$. The obtained 1-propylimidazole-nanosilica compound $\mathrm{ImP}-\mathrm{nSiO}_{2}$ (29) was filtered, washed with acetonitrile, and dried. The catalyst $\mathbf{2 9}$ was treated with pentaerythri- tol tetrabromide (PETB, 30) using NaI in anhydrous toluene under reflux for $24 \mathrm{~h}$. The obtained composite PETB-ImP- $\mathrm{nSiO}_{2}$ (31) was filtrated, washed with anhydrous toluene, and dried. Then, $\mathbf{2 8}, \mathbf{3 1}$, and NaI were added to acetonitrile, and this was stirred under reflux for $48 \mathrm{~h}$. The obtained nanomaterial $\mathrm{G}_{1}-\mathrm{nSiO}_{2}$ (32) was filtrated, washed with acetonitrile, and dried. Then, $\mathbf{3 2}$ was reacted with $\mathbf{3 0}$ and $\mathrm{NaI}$ in dry toluene as a solvent at $120{ }^{\circ} \mathrm{C}$ for $24 \mathrm{~h}$ to yield the nanomaterial PETB $-\mathrm{G}_{1}-\mathrm{nSiO}_{2}(\mathbf{3 3})$. The solid product was gathered by filtration and then dried. The material $\mathrm{G}_{2}-\mathrm{nSiO}_{2}(\mathbf{3 5})$ was prepared by the nucleophilic attack of 1-methylimidazole (34) to PETB $-\mathrm{G}_{1}-\mathrm{nSiO}_{2}(\mathbf{3 3})$ in refluxing acetonitrile for $48 \mathrm{~h}$. $\mathrm{G}_{2}-\mathrm{nSiO}_{2}(35)$ was then filtrated, washed with acetonitrile, and dried. $\mathrm{Cu}(\mathrm{II})$ was immobilized on $\mathbf{3 5}$ by stirring in acetonitrile at $60{ }^{\circ} \mathrm{C}$ for $5 \mathrm{~h}$ and then at $100{ }^{\circ} \mathrm{C}$ for 40 minutes. The obtained poly(N-heterocyclic carbine-Cu complex) immobilized on nanosilica, ( $\mathrm{Cu}(\mathrm{II})-\mathrm{NHCs})_{\mathrm{n}} @ \mathrm{nSiO}_{2}(\mathbf{3 6})$, was filtrated, washed with acetonitrile/methanol, and dried. 


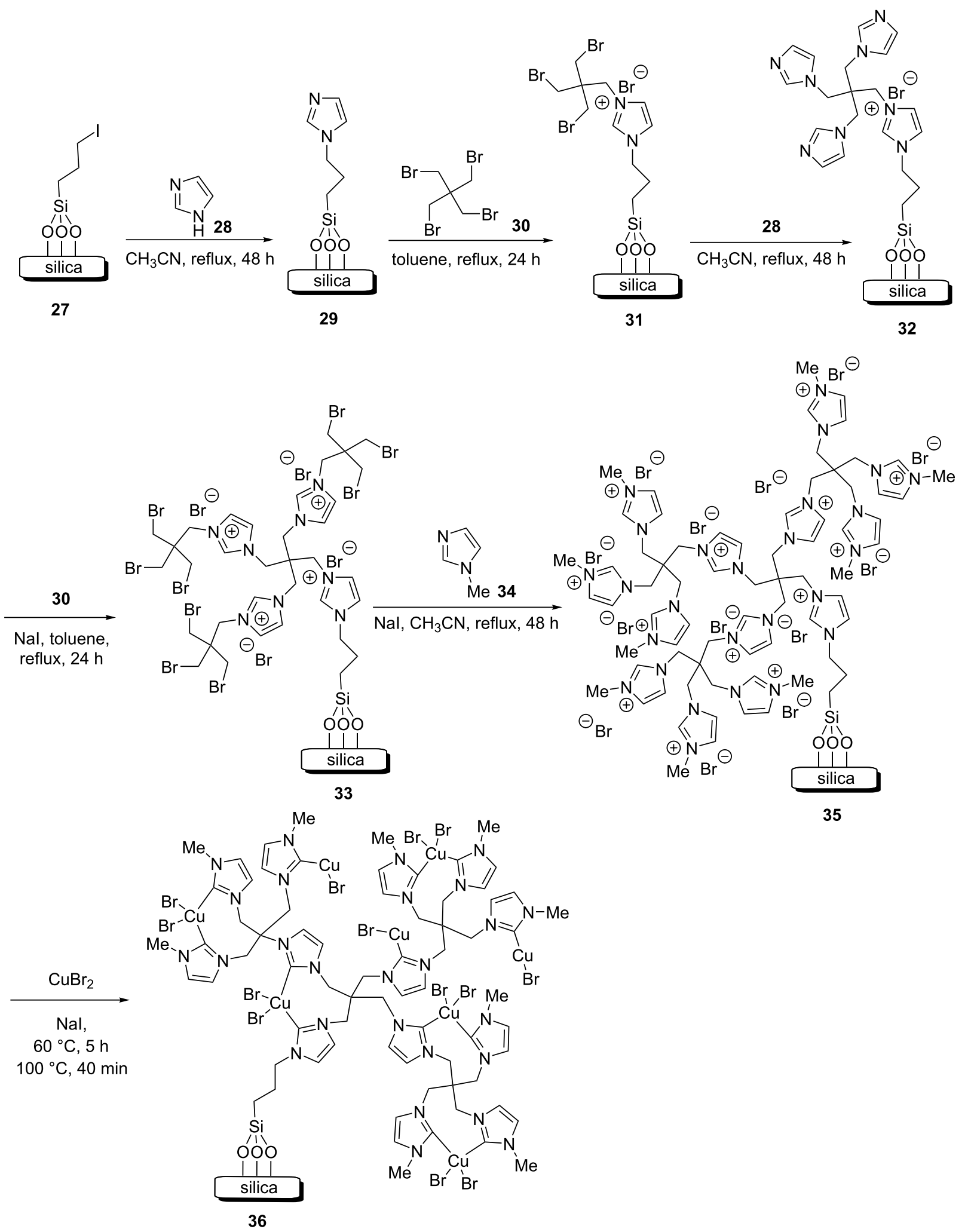

Scheme 5: Synthetic route to the catalyst 36. 


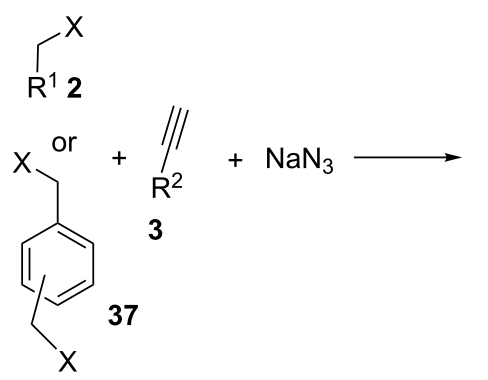<smiles>[R]Cn1cc([R])nn1</smiles>

38 conditions:

$36(0.02 \mathrm{~mol} \%$ of $\mathrm{Cu})$, sodium ascorbate $(10 \mathrm{mg})$, rt, $\mathrm{H}_{2} \mathrm{O} / \mathrm{EtOH}(2: 1)$ reaction time: $15-30 \mathrm{~min}$, yield: $85-96 \%$ $\mathrm{X}=\mathrm{Cl}, \mathrm{Br} ; \mathrm{R}^{1}=\mathrm{Ph}, 4-\mathrm{BrC}_{6} \mathrm{H}_{4}, 2-\mathrm{ClC}_{6} \mathrm{H}_{4}$, $2-\mathrm{NO}_{2} \mathrm{C}_{6} \mathrm{H}_{4}, 4-\mathrm{NO}_{2} \mathrm{C}_{6} \mathrm{H}_{4} ; \mathrm{R}^{2}=\mathrm{Ph}$

Scheme 6: Application of the catalyst 36 in CuAAC reactions.

The catalyst $(\mathrm{Cu}(\mathrm{II})-\mathrm{NHCs})_{\mathrm{n}} @ \mathrm{nSiO}_{2}$ catalyst (36) showed outstanding activity and selectivity, and mono- and bistriazole products were formed using a very low amount of the catalyst 36 and sodium ascorbate in a mixture of water and ethanol as the solvent system at room temperature, with good to high yields being achieved within short reaction times (Scheme 6).
Furthermore, compound $\mathbf{3 6}$ could be recycled and used in seven subsequent cycles.

A further example of a silica-supported CuAAC catalyst was reported by Moghadam et al. (Scheme 7) [29]. In this study, the bis(benzothiazole)-substituted pyridine ligand BTP (41) was

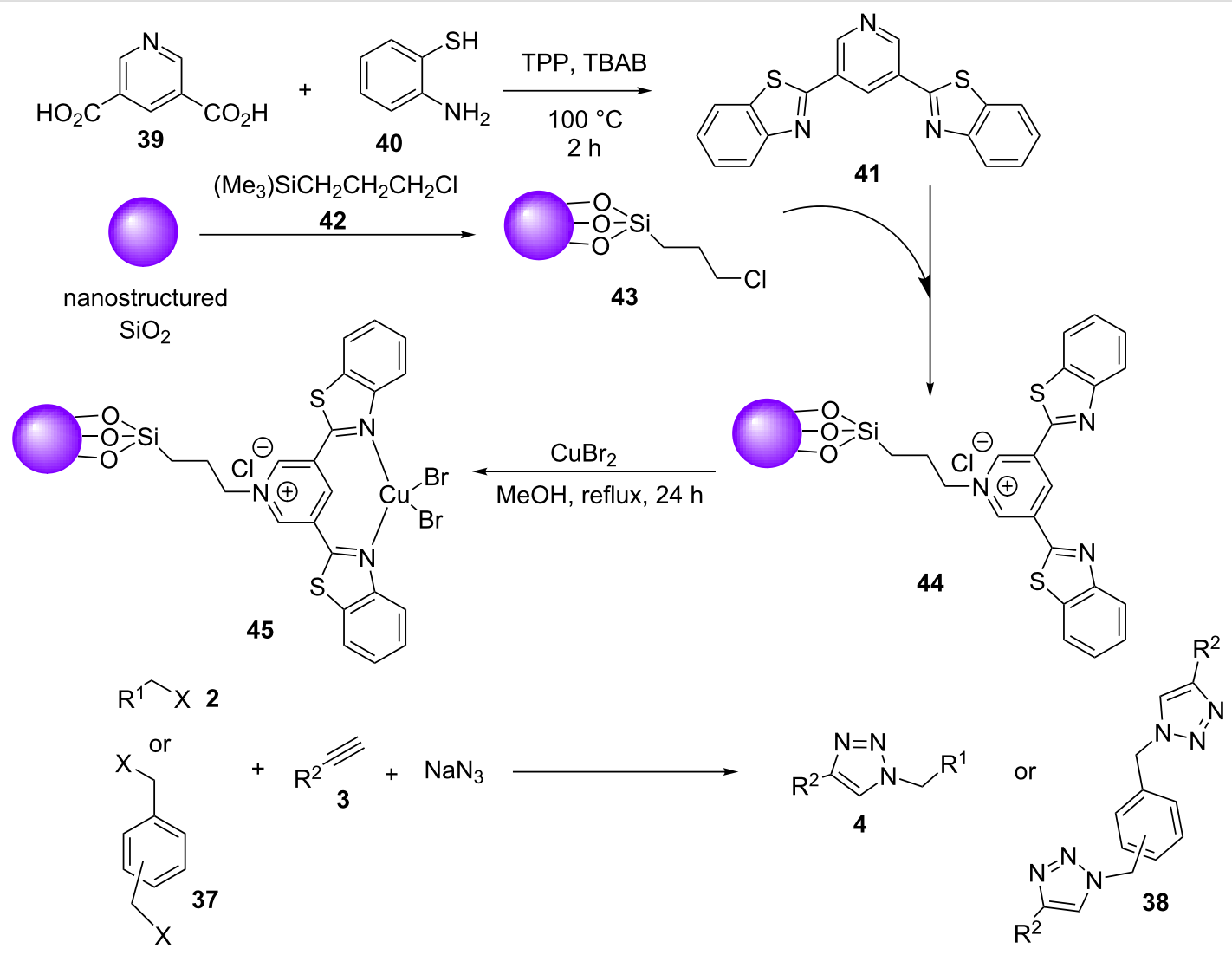

conditions for monotriazoles: 45 (0.2 mol \%), sodium ascorbate $(5 \mathrm{mg}), 85^{\circ} \mathrm{C}, \mathrm{EtOH} / \mathrm{H}_{2} \mathrm{O}(3: 1)$ conditions for bistriazoles: 45 (0.4 mol \%), sodium ascorbate $(10 \mathrm{mg}), 85^{\circ} \mathrm{C}, \mathrm{EtOH} / \mathrm{H}_{2} \mathrm{O}(3: 1)$ reaction time: $25-90 \mathrm{~min}$, yield: $70-98 \%, \mathrm{X}=\mathrm{Br}$

$\mathrm{R}^{1}=\mathrm{Ph}, 4-\mathrm{BrC}_{6} \mathrm{H}_{4}, 4-\mathrm{NO}_{2} \mathrm{C}_{6} \mathrm{H}_{4}, 3,5-\left(\mathrm{CH}_{3}\right)_{2} \mathrm{C}_{6} \mathrm{H}_{3}, 4-\mathrm{BrC}_{6} \mathrm{H}_{4} \mathrm{CO}$,

4- $\mathrm{NO}_{2} \mathrm{C}_{6} \mathrm{H}_{4} \mathrm{CO}, 4-\mathrm{FC}_{6} \mathrm{H}_{4} \mathrm{CO}, 3-\mathrm{MeOC}_{6} \mathrm{H}_{4} \mathrm{CO}$, 4-cyclohexyl- $\mathrm{C}_{6} \mathrm{H}_{4} \mathrm{CO}$,

2-furyl-CO; $\mathrm{R}^{2}=\mathrm{Ph}, \mathrm{C}_{6} \mathrm{H}_{13}, \mathrm{C}_{5} \mathrm{H}_{11}$ 
synthesized through the condensation of 2-aminothiophenol (40) with pyridine-3,5-dicarboxylic acid (39) using $\mathrm{P}\left(\mathrm{OC}_{6} \mathrm{H}_{5}\right)_{3}$ (TPP). The ligand 41 was immobilized on 3-chloropropyltrimethoxysilane (CPTMS, 43) to afford $\mathrm{TMSP}-\mathrm{nSiO}_{2}(\mathbf{4 4})$. Material 44 was then reacted with $\mathrm{CuBr}_{2}$ in methanol at reflux for $24 \mathrm{~h}$ to produce the heterogeneous catalyst $\mathrm{Cu}(\mathrm{II}) \mathrm{Br}_{2}-\mathrm{BTP} @ \mathrm{TMSP}-\mathrm{nSiO}_{2}(\mathbf{4 5}$, Scheme 7). X-ray photoelectron spectroscopy (XPS) analysis displayed a $\mathrm{Cu} 2 \mathrm{p}_{3 / 2}$ peak of the $\mathrm{Cu}(\mathrm{II}) \mathrm{Br}_{2}-\mathrm{BTP} @ \mathrm{TMSP}-\mathrm{nSiO}_{2}$ catalyst at $933.5 \mathrm{eV}$ attributed to a $\mathrm{Cu}(\mathrm{II})$ species.

Monotriazoles were obtained using $0.2 \mathrm{~mol} \%$ of $\mathrm{Cu}(\mathrm{II}) \mathrm{Br}_{2}-\mathrm{BTP} @ \mathrm{TMSP}-\mathrm{nSiO} \mathrm{S}_{2}(\mathbf{4 5})$ and a catalytic amount of sodium ascorbate as a reducing agent in a mixture of water and ethanol as the solvent at $85{ }^{\circ} \mathrm{C}$. In continuation, bistriazoles have been produced using $0.4 \mathrm{~mol} \%$ of $\mathbf{4 5}$ and $10 \mathrm{mg}$ sodium ascorbate as a reducing agent in an ethanol/water mixture at $85{ }^{\circ} \mathrm{C}$. All triazole products were produced in good to high yield (Scheme 7). The ICP analysis of $\mathbf{4 5}$ revealed a strong attachment of the copper species to the functionalized nanosilica. Furthermore, the composite $\mathbf{4 5}$ demonstrated good catalytic activity in five consecutive cycles.

Recently, the synthesis and catalytic application of a copper(II)-2-imino-1,2-diphenylethan-1-ol complex supported on nanosilica (Cu(II)-ID@silica, 48) was described by our research group [30]: The silica-supported complex 48 was obtained in two steps (Scheme 8). First, 2-hydroxy-1,2diphenylethan-1-one (47) and copper acetate were stirred and heated to reflux. In the next step, the amino-functionalized silica $\mathbf{4 6}$ was added to the mixture, and this was heated to reflux to generate the catalyst $\mathbf{4 8}$. Several organic halides or epoxides,

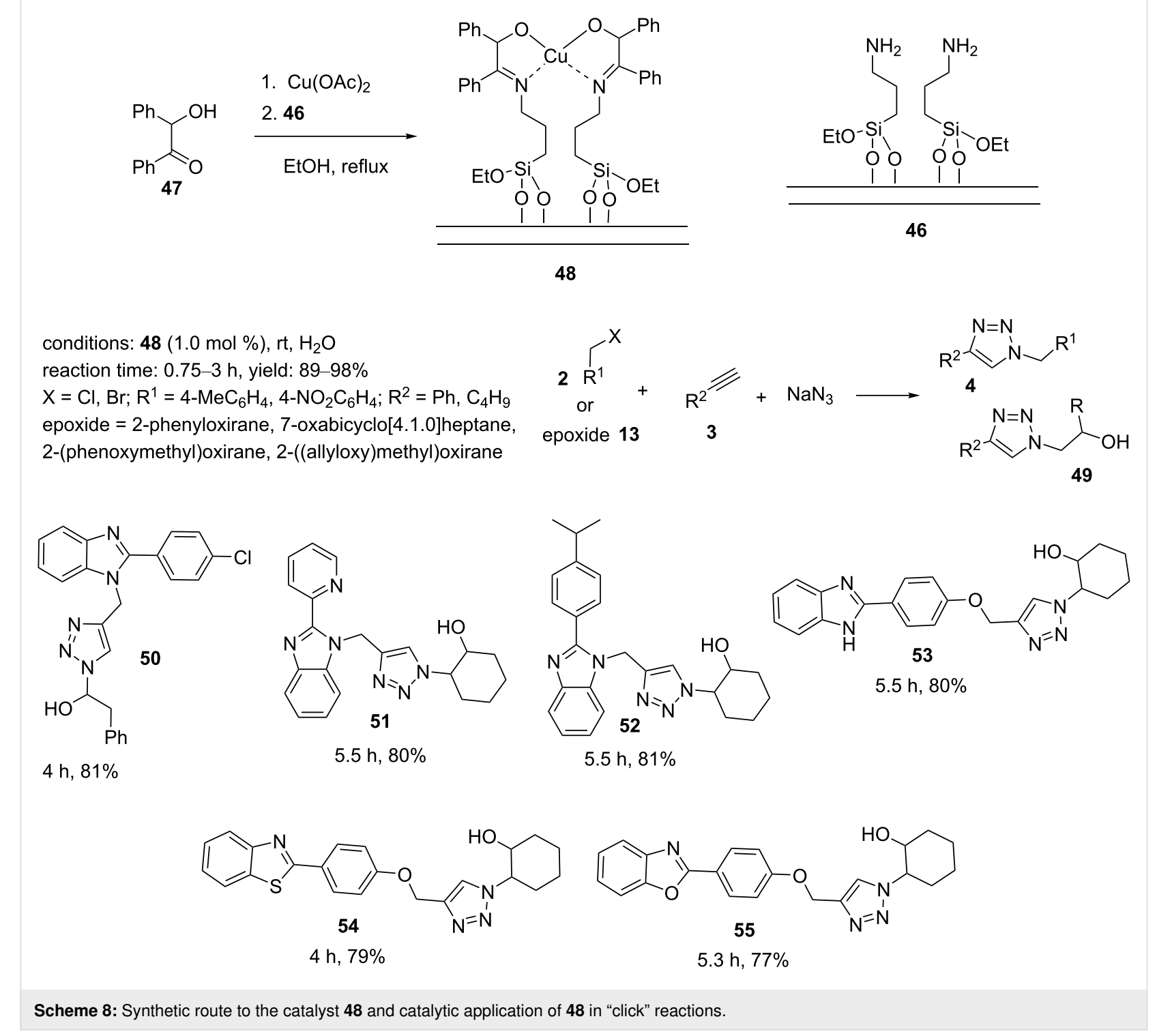


nonactivated alkynes, and sodium azide were reacted in an aqueous medium to provide triazoles or $\beta$-hydroxytriazoles using $1.0 \mathrm{~mol} \%$ catalyst loading at $25{ }^{\circ} \mathrm{C}$. Subsequently, a range of hybrid molecules, including triazole-benzimidazoles 50-53, triazole-benzothiazole 54, and triazole-benzoxazole 55, was prepared under the above-mentioned conditions (Scheme 8). The benefits of this catalytic system were mild reaction conditions, low catalyst loadings, a diverse set of triazole products, excellent reusability, short reaction times, and good to high yields.

Further, Dufauda et al. reported a copper(II)-phenanthroline complex supported on the SBA-15 architecture, Cu(II)phen@SBA-15 (58) [31]. The preparation is outlined in Scheme 9: Initially, phen-functionalized mesoporous SBA-15 silica (phen@SBA-15, 57)was prepared via dissolving pluronic $\mathrm{P} 123$ in acidic water at $35^{\circ} \mathrm{C}$. A mixture of phen-Si (56) and tetraethyl orthosilicate (TEOS) was added with stirring, followed by heating at $35{ }^{\circ} \mathrm{C}$ for $24 \mathrm{~h}$. After transferring to a teflon bottle sealed in an autoclave and heating for 2 days at $100{ }^{\circ} \mathrm{C}$, a solid was obtained, which was then filtered off, washed with distilled water, and dried. In the next step, the surfactant pluronic P123 was removed by the Soxhlet extraction method to produce a white solid. Then, $\mathbf{5 8}$ was synthesized using $\mathbf{5 7}$ and copper(II) acetate in methanol at reflux conditions for one day. The resulting powder was filtered off, washed with methanol, and dried. Finally, excess copper was removed by the Soxhlet extraction method (Scheme 9).

The 1,3-dipolar reaction of organic alkynes, organic bromides (or aryldiazonium salts or epoxides), and sodium azide proceeded well using a catalytic amount of the synthesized catalyst 58 in water at $70{ }^{\circ} \mathrm{C}$ to create 1,4-disubstituted 1,2,3-triazole products in good to high yields (Scheme 9). In terms of<smiles>CCO[SiH2]CCCNC(=O)N(C(=O)NCCC[SiH2]CC)c1cc2cccnc2c2ncccc12</smiles>

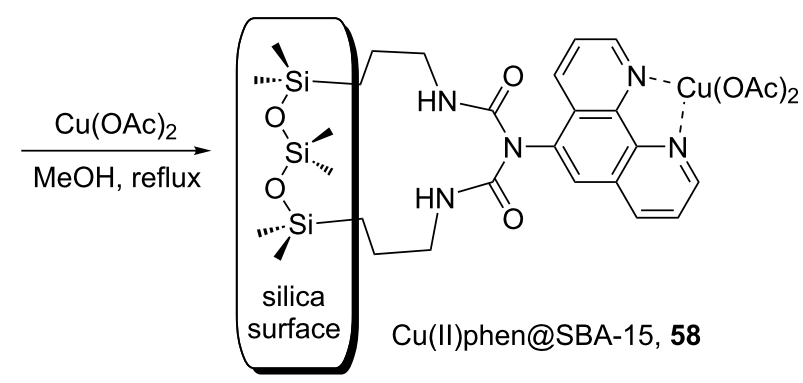

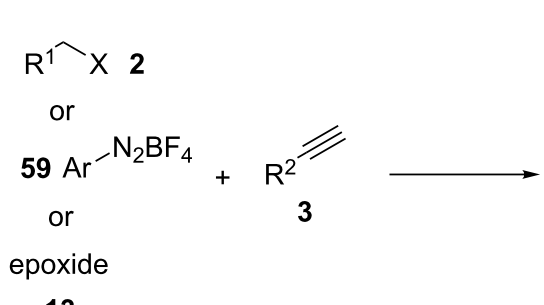

13

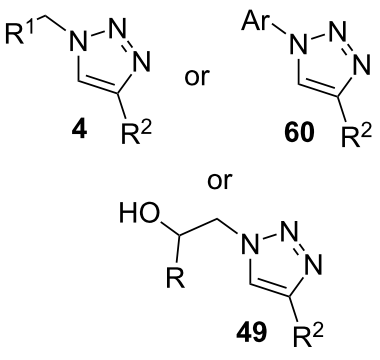

conditions for the triazole syntheses: $58(0.5 \mathrm{~mol} \%), 70{ }^{\circ} \mathrm{C}, \mathrm{H}_{2} \mathrm{O}$

reaction time: $6-14 \mathrm{~h}$, yield: $61-98 \%$

$\mathrm{Ar}=4-\mathrm{BrC}_{6} \mathrm{H}_{4} ; \mathrm{R}^{1}=\mathrm{Ph}, \mathrm{PhCHCH}, \mathrm{PhCO}, \mathrm{CO}_{2} \mathrm{Et}$

$\mathrm{R}^{2}=\mathrm{Ph} ;$ epoxide $=$ 2-phenyloxirane 
recyclability, there was a continuous decrease in the catalytic activity of $\mathbf{5 8}$ from the first to the second to the third cycle of 98 to 55 to $26 \%$. The deactivation of the catalyst was probably related to the remarkable decrease in pore volume and surface area that were proved by XPS surface analysis.

1,2-Bis(4-pyridylthio)ethane (62) was covalently grafted on the functionalized silica nanoparticles $\mathbf{6 1}$ by the reaction in DMF at $80{ }^{\circ} \mathrm{C}$ for $24 \mathrm{~h}$. Through this, ionic liquid (IL)-supported silica nanoparticles were generated [32]. The resulting material was centrifuged, washed with methanol, and dried. Subsequently, the obtained nanoparticles and methyl iodide were reacted in dry toluene at room temperature. The resulting silica nanoparticles containing ionic liquid (SNIL, 63) were centrifuged, washed with ether, and dried. The SNIL (63) were treated with $\mathrm{Cu}(\mathrm{OTf})_{2}$ in ethanol as a solvent at reflux for one day. Finally, this solid material was centrifuged, washed with methanol, and dried to produce the catalyst SNIL-Cu(II) (64) (Scheme 10) [32].

An interesting aspect of the heterogeneous catalyst SNIL-Cu(II) $(64)$ is its successful application in the $[3+2]$

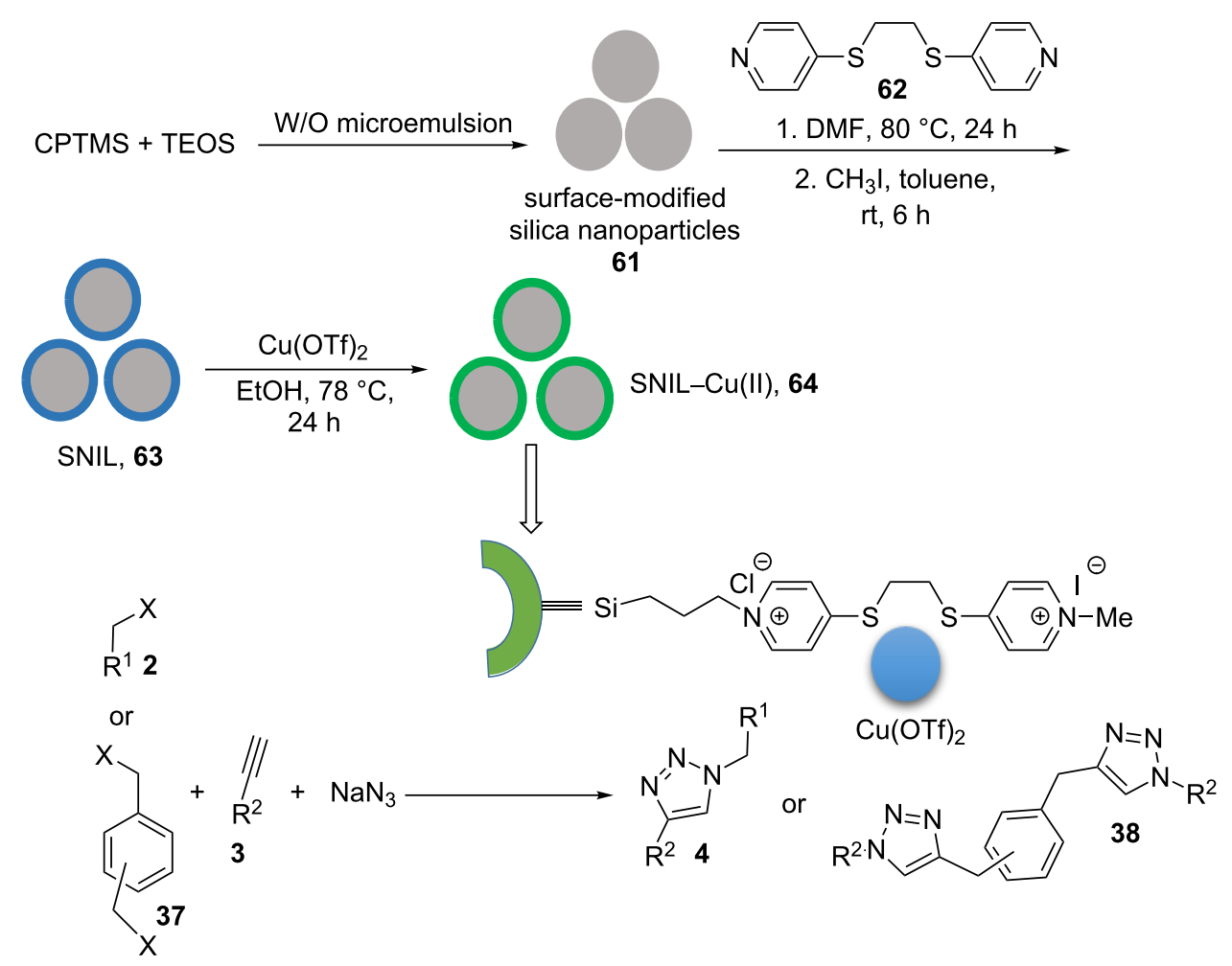

conditions for the triazole syntheses: $64(0.05 \mathrm{~mol} \%)$, sodium ascorbate $(2.0 \mathrm{~mol} \%)$, rt, $\mathrm{H}_{2} \mathrm{O} / \mathrm{PEG} 400$ (1:1) reaction time: $15-45 \mathrm{~min}$, yield: $72-80 \%$

$\mathrm{X}=\mathrm{Br} ; \mathrm{R}^{1}=\mathrm{Ph}, 4-\mathrm{BrC}_{6} \mathrm{H}_{4}, 4-\mathrm{NO}_{2} \mathrm{C}_{6} \mathrm{H}_{4}, 3,5-\mathrm{Me}_{2} \mathrm{C}_{6} \mathrm{H}_{3} ; \mathrm{R}^{2}=\mathrm{Ph}, \mathrm{C}_{6} \mathrm{H}_{13}, \mathrm{C}_{5} \mathrm{H}_{11}$
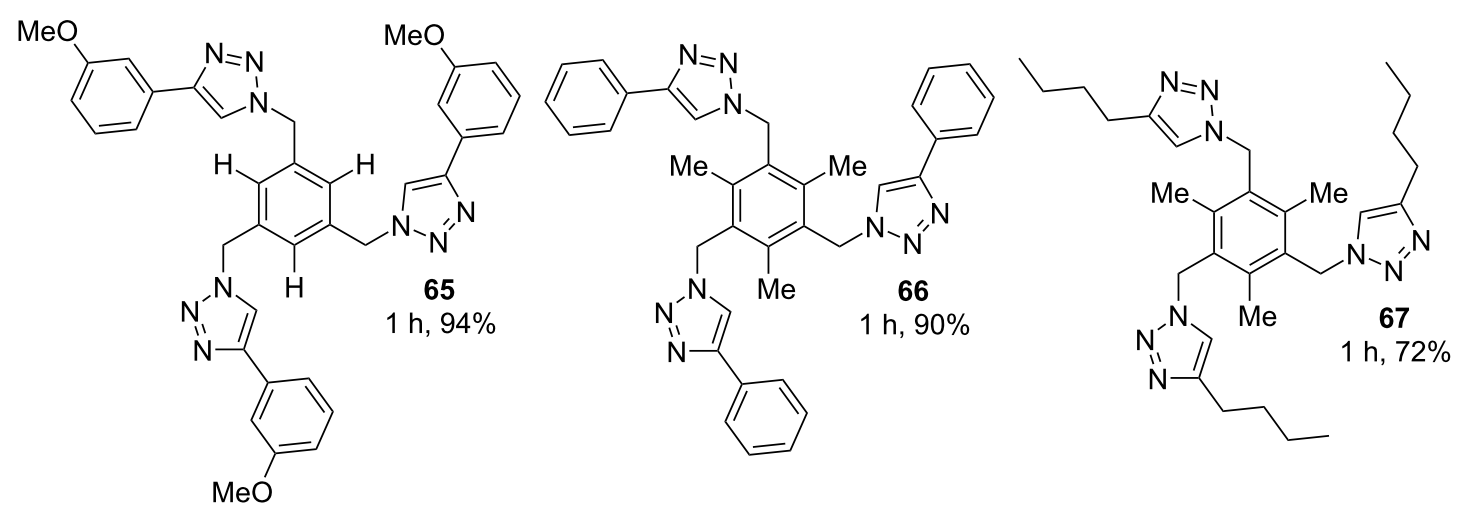

Scheme 10: Synthetic route to the catalyst 64 and catalytic application of 64 in "click" reactions. 
cyclization synthesis of "click" products under mild reaction conditions. $0.05 \mathrm{~mol} \%$ of $\mathbf{6 4}$ and $2 \mathrm{~mol} \%$ of sodium L-ascorbate were used to prepare a range of multitriazole products in polyethylene glycol as a green solvent at room temperature (Scheme 10). The authors proposed that sodium L-ascorbate acted as a reducing agent in the reduction of $\mathrm{Cu}(\mathrm{II})$ to $\mathrm{Cu}(\mathrm{I})$. Aromatic/aliphatic terminal acetylenes and benzyl bromides bearing electron-rich and electron-deficient substitutions were efficiently transformed to the corresponding products in excellent yields. To show the high efficiency of this catalytic system, bis"click" and tris-"click" reactions were also effectively performed (Scheme 10). The heterogeneous catalyst $\mathbf{6 4}$ could be used for six consecutive cycles without serious decline of the catalytic activity. The FTIR spectrum of the recovered catalyst $\mathbf{6 4}$ was almost the same as that of the freshly prepared catalyst. The high catalyst stability was confirmed by ICP analysis and a hot filtering test.

Heravi reported a procedure for the deposition of copper on (3-aminopropyl)triethoxysilane (APTES)/KIT-5 (CuI/AK, 68) using $\mathrm{CuI}$ as the copper source [33]. The APTES/KIT-5, as a solid support, was added to a vessel containing $\mathrm{CuI}$ in aceto- nitrile. After stirring under reflux and a nitrogen atmosphere for $5 \mathrm{~h}$, the solid product $\mathbf{6 8}$ was collected by filtration. The solid was washed with acetonitrile and dried before being used in "click" reactions. CuI/AK (68) furnished the desired products of the reaction of phenacyl halides (with $\mathrm{Me}, \mathrm{Br}$, and $\mathrm{Cl}$ substituents), benzyl halides or methyl iodide, and phenylacetylene or propargyl alcohol as substrates using a catalytic amount of this nanocatalyst in water as a green solvent under reflux. The triazoles were generated in short reaction times in good yields (Scheme 11). Finally, the heterogeneous catalyst $\mathbf{6 8}$ showed the benefits of good yields, short reaction times, high efficiency, not requiring chromatographic purification, and high reusability.

In another method, sol-gel-entrapped copper in a silica matrix, the catalyst $\mathrm{SiO}_{2}-\mathrm{Cu}$, was synthesized through a modified Stöber method [34]. $\mathrm{NH}_{4} \mathrm{OH}$, water, and absolute ethanol were mixed and stirred. Afterwards, TEOS was slowly added to the mixture. After obtaining a white mixture, different amounts of $\mathrm{CuI}$ as the copper source were slowly added to the above mixture. Then, this was stirred at room temperature for $12 \mathrm{~h}$. After centrifugation, the produced solid was washed with ethanol and

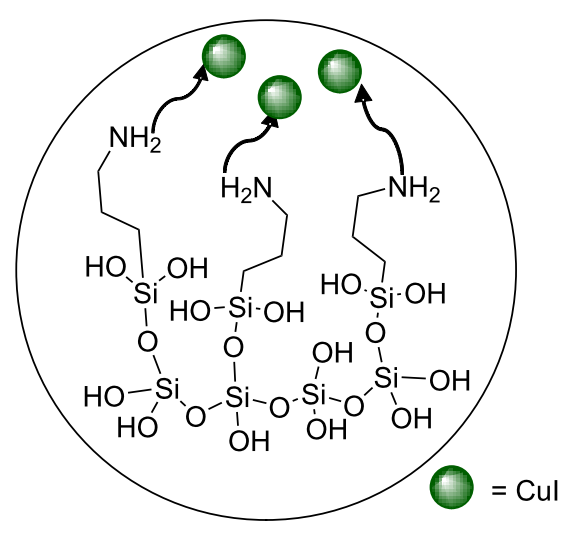

68

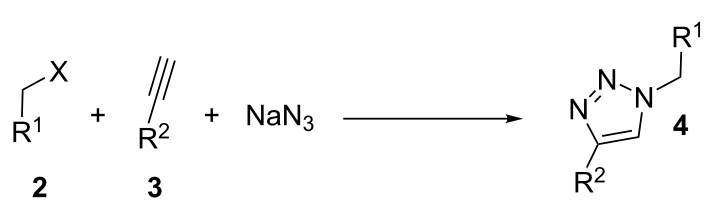

conditions for the triazole syntheses: 68 (0.03 g),

reflux, $\mathrm{H}_{2} \mathrm{O}$

reaction time: $15-150 \mathrm{~min}$, yield: $69-95 \%$

$\mathrm{X}=\mathrm{Cl}, \mathrm{Br} ; \mathrm{R}^{1}=\mathrm{PhCO}, 4-\mathrm{MeC}_{6} \mathrm{H}_{4} \mathrm{CO}, 4-\mathrm{ClC}_{6} \mathrm{H}_{4} \mathrm{CO}$,

4- $\mathrm{BrC}_{6} \mathrm{H}_{4} \mathrm{CO}, \mathrm{CO}_{2} \mathrm{Me}, \mathrm{Ph}$

$\mathrm{R}^{2}=\mathrm{Ph}, \mathrm{CH}_{2} \mathrm{OH}, \mathrm{C}(\mathrm{Me})_{2} \mathrm{OH}$ 
water and then dried to create a fine blue powder. In order to reduce the oxidation state of the copper component, the resulting powder was added to an aqueous solution of sodium ascorbate. Finally, the solid material was filtered off, washed with water and diethyl ether, and dried.

The catalyst was also used in the synthesis of 1,2,3-triazole products substituted at the 1- and 4-position through two-component or three-component "click" reactions. In the two-component reaction, acetylene compounds and organic azides were stirred in dimethylformamide or in a mixture of $t-\mathrm{BuOH} / \mathrm{H}_{2} \mathrm{O}$, $3: 1, \mathrm{v} / \mathrm{v}$ as the solvent using diethylisopropylamine and $\mathrm{SiO}_{2}-\mathrm{Cu}$. In the three-component example, acetylene species and organic halides as well as sodium azide were stirred in a mixture of $t-\mathrm{BuOH} / \mathrm{H}_{2} \mathrm{O}, 3: 1, \mathrm{v} / \mathrm{v}$ as the solvent in the presence of diethylisopropylamine and $\mathrm{SiO}_{2}-\mathrm{Cu}$. In both cases, the $\mathrm{SiO}_{2}-\mathrm{Cu}$ catalyst was filtered off and then, the triazole products were purified.

In another approach, 2-pyridine carboxaldehyde was reacted with 3-aminopropyl-functionalized SBA-15 in dry ethanol at $60{ }^{\circ} \mathrm{C}$ for one day to afford the SBA-15-supported imine ligand 69 (Scheme 12) [35]. The solid product was filtered off, washed with toluene/ethanol, and dried. The SBA-15-supported imine composite was added to an ethanolic solution of $\mathrm{Cu}(\mathrm{OAc})_{2}$, and the mixture was heated at reflux for $12 \mathrm{~h}$. Finally, the material $\mathrm{Cu} @ I m P y-S B A-15$ (69) was collected, washed with ethanol, and dried. The catalyst was applied in the synthesis of triazole products via the reaction of in situ-prepared arylazides from anilines with aryl-/alkyl-alkynes in $\mathrm{HCl} / \mathrm{H}_{2} \mathrm{O}$ using $0.1 \mathrm{~mol} \%$ of Cu@PyIm-SBA-15 (69, Scheme 12).

\section{Copper anchored on functionalized carbon materials: efficient and recyclable catalysts for CuAAC reactions}

Carbon nanomaterials have attracted the interest of researchers due to the high electrical and thermal conductivities, low production cost, oxidation stability, and low density, and diverse forms, such as graphene, fibers, horns, buds, onions, helices, etc. exist [36-55]. In addition, they are rather stable in strongly acidic and strongly basic solutions and capable to perform over a wide temperature range, increases the attractiveness of carbon nanomaterials [56]. Carbon materials have been used in different areas, including water purification, gas separation, fuel cells, photocatalysis, catalyst supports, etc. [57-62].

Different types of carbon nanomaterials, including a) zerodimensional nanoparticles (NPs), b) one-dimensional nanotubes, c) two-dimensional graphene sheets, and d) three-dimensional mesoporous carbon have been reported in the literature [63].

In this regard, various functionalized carbon nanomaterials were employed in diverse organic reactions, including Suzuki reactions [64], Sonogashira reactions [65], transesterifications of triglycerides [66], hydrogenation reactions [67], N-heterocycle syntheses [68], cleavage of propargyl phenol ethers [69], etc. [70-75]. In this review article, we provide an overview on the synthesis and functionalization of carbon nanomaterials the catalytic application of these materials in $\mathrm{CuAAC}$ reactions.

Very recently, $\mathrm{CuCl}_{2}$ on fabricated graphitic polymeric $\mathrm{C}_{3} \mathrm{~N}_{4}$ supported $\mathrm{CuCl}_{2}\left(\mathrm{Cu} @ \mathrm{~g}-\mathrm{C}_{3} \mathrm{~N}_{4}, 74\right)$ was prepared as an off-
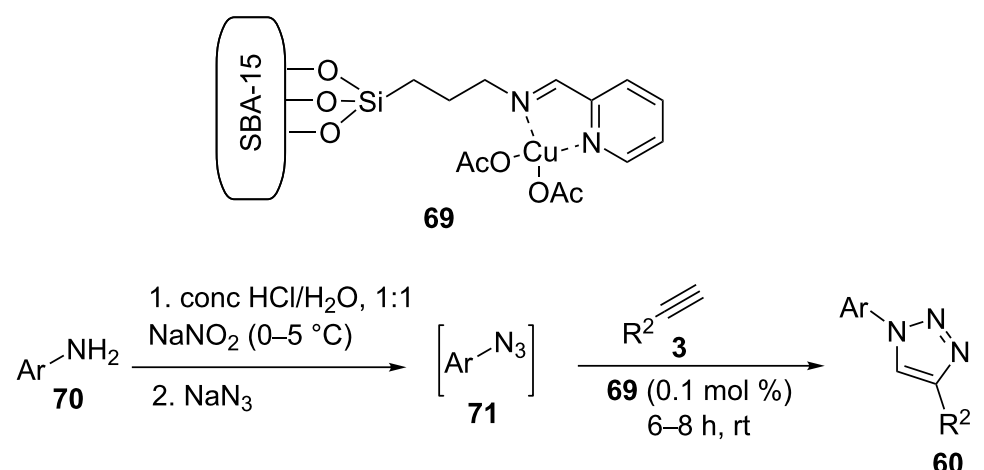

reaction time: $6-8 \mathrm{~h}$, yield: $90-98 \%$

$\mathrm{Ar}=\mathrm{Ph}, 4-\mathrm{NO}_{2} \mathrm{C}_{6} \mathrm{H}_{4}, 2-\mathrm{IC}_{6} \mathrm{H}_{4}, 4-\mathrm{MeOC}_{6} \mathrm{H}_{4}, \mathrm{PhCH}_{2}, 3-\mathrm{ClC}_{6} \mathrm{H}_{4}, 2-\mathrm{NO}_{2} \mathrm{C}_{6} \mathrm{H}_{4}$

$\mathrm{R}^{2}=\mathrm{Ph}, 4-\mathrm{CNC}_{6} \mathrm{H}_{4}, 4-\mathrm{FC}_{6} \mathrm{H}_{4}, 4-\mathrm{PhC}_{6} \mathrm{H}_{4}$, 4-ethynyl- $\mathrm{C}_{6} \mathrm{H}_{4}$, pyridyl, $\mathrm{CH}_{2} \mathrm{OH}$ 
white bluish solid in two simple steps [76]. Generally, urea (72) was calcined and then, $\mathrm{CuCl}_{2}$ was immobilized using sonication (Scheme 13).

The nanopolymeric catalyst was applied as a reusable nanocatalyst for promoting the 1,3-dipolar cycloaddition of nitroolefins/ phenylacetylenes and sodium azide in water at ambient temperature. High yields of the 4-aryl-1,2,3-triazole 76 were obtained in short reaction times. The results indicated that B-nitrostyrenes/phenylacetylenes containing electron-rich and -deficient groups could participate in the 1,3-dipolar cycloaddition reaction. Notably, the reaction was also extended to bistriazole derivatives (Scheme 14). The synthesized copper-catalyst 74 could be reused in up to ten consecutive cycles, and only very little leaching $(0.08 \%)$ was observed.

A novel and reusable, synergistic and dual catalyst $\mathrm{Pd}-\mathrm{Cu} @ \mathrm{rGO}$ (78) was designed and synthesized by Naeimi and Ansarian through the decoration of reduced graphene oxide (rGO) with copper and palladium species (Scheme 15) [77].

In this study, graphite oxide (GO) was generated according to the modified Hummer's method. Copper(II) was anchored on GO via ultrasonication. In the next step, copper ions were

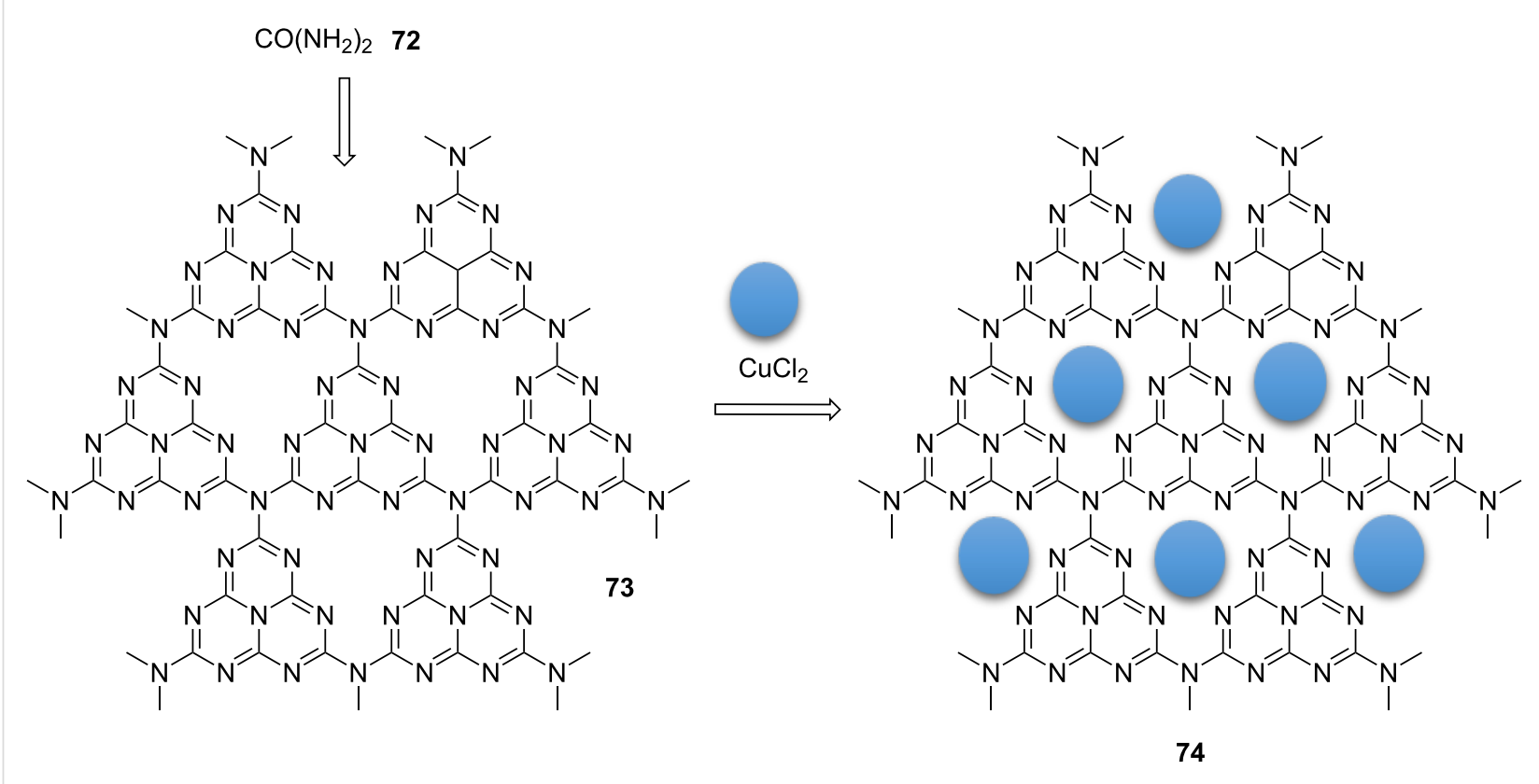

Scheme 13: Synthetic route to, and chemical structure of the catalyst 74

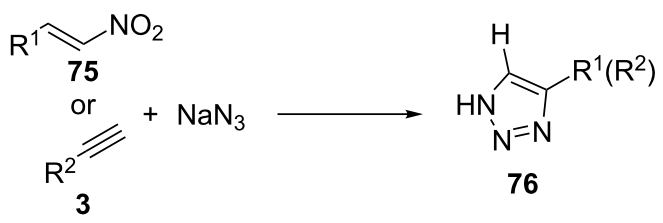

conditions for the triazole syntheses: $74(15 \mathrm{mg}), 100{ }^{\circ} \mathrm{C}, \mathrm{H}_{2} \mathrm{O}$

reaction time: $30-45 \mathrm{~min}$, yield: $84-99 \%$

$\mathrm{R}^{1}=\mathrm{Ph}, 4-\mathrm{MeC}_{6} \mathrm{H}_{4}, 4-\mathrm{MeOC}_{6} \mathrm{H}_{4}, 4-\mathrm{NO}_{2} \mathrm{C}_{6} \mathrm{H}_{4}$,

3- $\mathrm{ClC}_{6} \mathrm{H}_{4}, 3-\mathrm{MeC}_{6} \mathrm{H}_{4}, 2,3-\mathrm{diClC}_{6} \mathrm{H}_{3}, 3-\mathrm{MeOC}_{6} \mathrm{H}_{4}, 2-\mathrm{NO}_{2} \mathrm{C}_{6} \mathrm{H}_{4}, 2-\mathrm{MeOC}_{6} \mathrm{H}_{4}$,

2,4-diClC $6 \mathrm{H}_{3}, 4-\mathrm{HOC}_{6} \mathrm{H}_{4}, 2,3,4-$ triMeOC $_{6} \mathrm{H}_{2}$

$\mathrm{R}^{2}=\mathrm{Ph}, 4-\mathrm{MeC}_{6} \mathrm{H}_{4}, 4-\mathrm{NO}_{2} \mathrm{C}_{6} \mathrm{H}_{4}, 4-\mathrm{PhC}_{6} \mathrm{H}_{4}, 4-n-\mathrm{PnC}_{6} \mathrm{H}_{4}, 4-n-\mathrm{BuC}_{6} \mathrm{H}_{4}$,

$2-\mathrm{NO}_{2} \mathrm{C}_{6} \mathrm{H}_{4}, 2-\mathrm{MeOC}_{6} \mathrm{H}_{4}, 2-n-\mathrm{BuC}_{6} \mathrm{H}_{4}, \mathrm{C}_{8} \mathrm{H}_{17}$ 


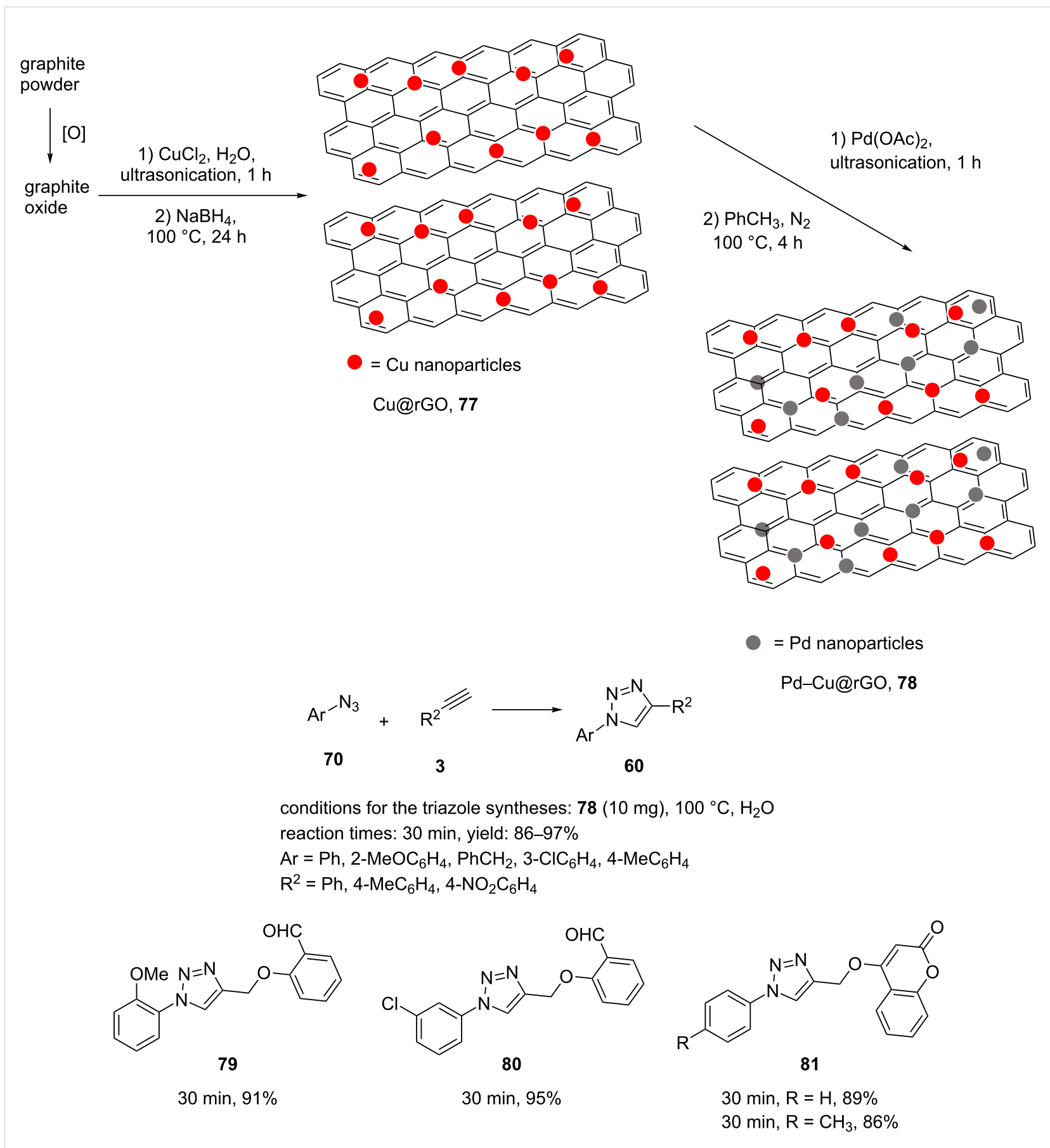

Scheme 15: Synthetic route to, and chemical structure of the catalyst 78 and catalytic application of 78 in "click" reactions.

reduced by adding $\mathrm{NaBH}_{4}$. The mixture was then heated at $100{ }^{\circ} \mathrm{C}$ for one day, cooled, and filtered. The material $\mathrm{Pd}-\mathrm{Cu} @ \mathrm{rGO}(\mathbf{7 8})$, as heterogeneous nanocatalyst, was prepared by anchoring $\mathrm{Pd}(\mathrm{OAc})_{2}$ on $\mathrm{Cu} @ \mathrm{rGO}$ in toluene via pyrolysis.

The catalyst was highly active in one-pot condensations of alkyl/aryl-substituted triazole heterocycles with cycloadditions and in "click" reactions of organic halides, terminal alkynes, and sodium azide. High yields of various triazole products were obtained when using $10 \mathrm{mg}$ of the catalyst $\mathbf{7 8}$ in water at reflux for $30 \mathrm{~min}$ (Scheme 15). Moreover, this synergistic dual catalyst was also investigated in the stepwise generation of biaryl products with triazole. For this, 4-bromoaryl derivatives were initially treated with phenylboronic acid. The biaryl derivatives were then reacted with phenylacetylene to give triazole-contain- 
ing biaryl compounds in high yields. Stilbenes were also applied in the reaction under similar conditions to obtain triazoles containing stilbenes. The nanocatalyst $\mathbf{7 8}$ could be readily recovered seven times without a significant loss of catalytic activity.

Naeimi and Ansarian reported a new, effective, and reusable catalyst comprised of a polytriazole copper(I) complex sup-

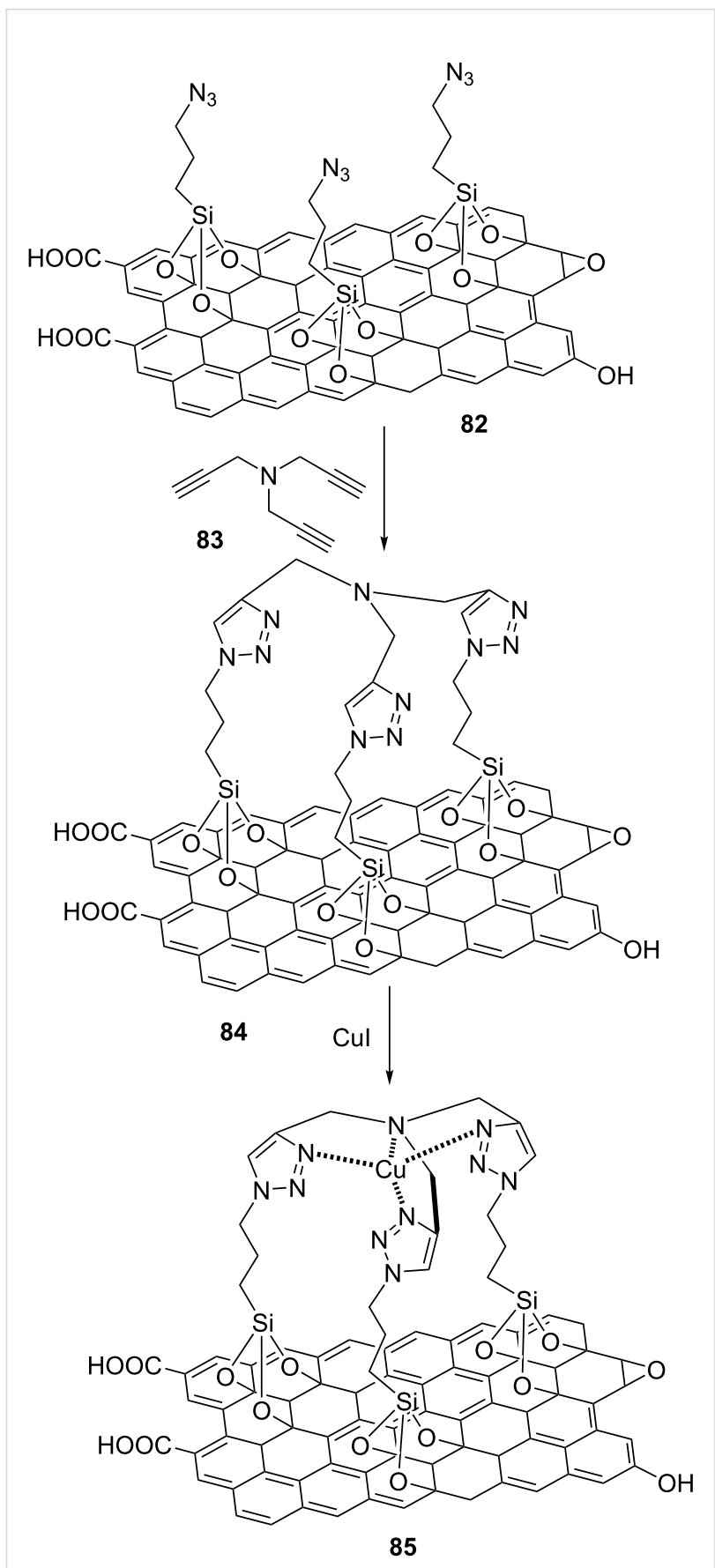

Scheme 16: Synthetic route to the catalyst 85 . ported on graphene oxide, GO@polytriazole-Cu (85), as outlined in Scheme 16 [78].

For this, 3-chloropropyltrimethoxysilane (CTS) was added to dispersed graphene oxide in dry toluene, and the mixture was refluxed for 2 days under a nitrogen atmosphere to afford chloro-functionalized GO (GO@CTS).The GO@CTS was sonicated in water for $5 \mathrm{~min} . \mathrm{NaN}_{3}$ and $\mathrm{KI}$ were added to the reaction mixture, and this was heated at $60{ }^{\circ} \mathrm{C}$ for two days to afford the azido-functionalized GO GO@ $\mathrm{N}_{3}(\mathbf{8 2})$. In the next time, tripropargylamine $(\mathbf{8 3}), \mathrm{CuSO}_{4}$, and sodium ascorbate were added to dispersed $\mathbf{8 2}$. The azide/alkyne "click" reaction proceeded well at rt over two days to produce the "click"-functionalized GO GO@PTA (84).CuI as a copper source was added to dispersed $\mathbf{8 4}$ in dry acetonitrile. The mixture was stirred at reflux for one day to give a copper complex supported by GO, GO@polytriazole-Cu (85, Scheme 16).

The obtained species $\mathbf{8 5}$ was then applied as a heterogeneous nanocatalyst in "click" reactions for the multicomponent synthesis of triazole products in water with ultrasound irradiation and $0.017 \mathrm{~mol} \%$ catalyst loading. As such, a series of aryl/ alkyl-substituted oxiranes was treated with sodium azide and nonactivated terminal alkynes, giving 1,2,3-triazole products substituted at the 1- and 4-position in good to high yields and with short reaction times (Scheme 17).

The nanocatalyst GO@polytriazole-Cu (85) could easily be recovered from the reaction mixture and was reused in five cycles, with no decline of its performance.

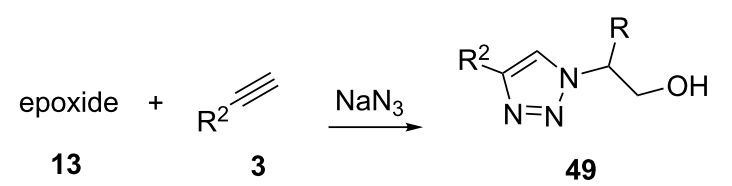

reaction conditions: $85(0.017 \mathrm{~mol} \%)$, sonication at $45 \mathrm{kHz}$, rt, $\mathrm{H}_{2} \mathrm{O}$

reaction time: 7-20 min, yield: $82-95 \%$

$\mathrm{R}^{2}=\mathrm{Ph}, \mathrm{C}_{3} \mathrm{H}_{7}$

epoxide $=2$-phenyloxirane, 2-( $p$-tolyl)oxirane, 2-ethyloxirane, 2-(phenoxymethyl)oxirane, 2-(isopropoxymethyl)oxirane, 7-oxabicyclo[4.1.0]heptane, oxiran-2-ylmethyl acrylate, oxiran-2-ylmethyl 4-methylbenzenesulfonate,

2-(chloromethyl)oxirane, 2-butyloxirane 


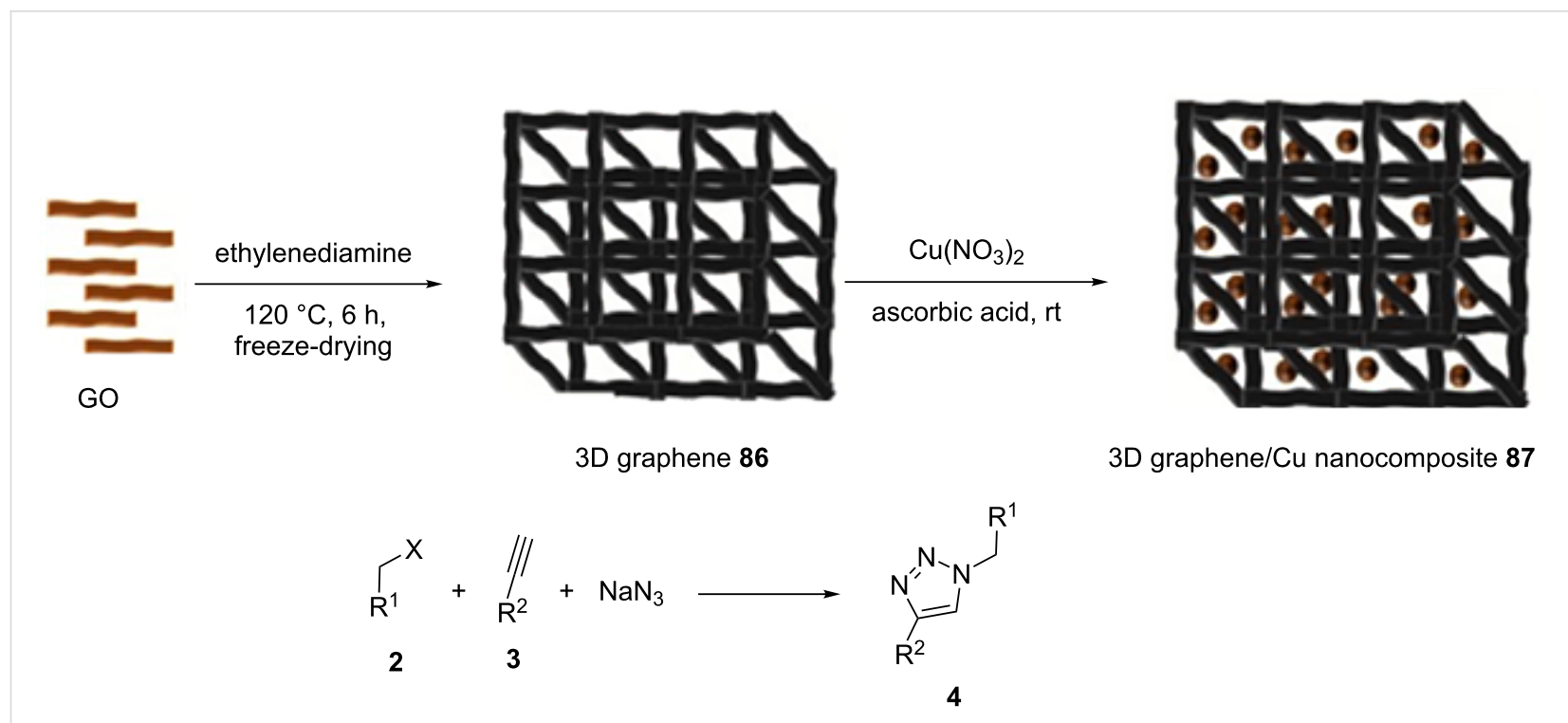

conditions for the triazole syntheses: $87(5 \mathrm{~mol} \%), 70{ }^{\circ} \mathrm{C}, \mathrm{EtOH} / \mathrm{H}_{2} \mathrm{O}, 1: 1$

reaction time: 3 and $7 \mathrm{~h}$, yield: $81-97 \%$

$\mathrm{X}=\mathrm{Br}, \mathrm{Cl} ; \mathrm{R}^{1}=\mathrm{Ph}, 4-\mathrm{BrC}_{6} \mathrm{H}_{4}, 4-\mathrm{NO}_{2} \mathrm{C}_{6} \mathrm{H}_{4}, \mathrm{C}_{9} \mathrm{H}_{19}$

Scheme 18: Synthetic route to the catalyst 87 and catalytic application of 87 in "click" reactions.

The design and synthesis of carbon nitride-supported copper nanoparticles was disclosed by Islam and co-workers (Scheme 18) $[79,80]$. The nanocatalyst 87 was successfully used as a high-performance photoreactor promoting "click" reactions of alkynes with organic azides under light irradiation in the absence of basic condition.

In the first step, photon energy caused an electron transition from the valence to the conduction band in $\mathrm{gCN}$. In the next step, hot electron acted as a scavenger of the terminal proton of the alkyl-/arylacetylenes in order to facilitate the construction of the copper acetanilide species.

In the next example, copper nanoparticles-decorated threedimensional graphene (3D graphene/Cu nanocomposite 87) was reported as a catalyst to perform Huisgen 1,3-dipolar cycloadditions. Therein, the GO material was mixed with EDA to produce a stable suspension that was transferred to a teflon-lined autoclave. After heating at $120^{\circ} \mathrm{C}$ for $6 \mathrm{~h}$ and then freeze-drying, a 3D graphene hydrogel was produced. After dissolving the 3D graphene $\mathbf{8 6}$ in water by ultrasonication, $\mathrm{CuNO}_{3} \cdot 3 \mathrm{H}_{2} \mathrm{O}$ was added into the solution, and this was ultrasonicated for $3 \mathrm{~h}$. L-Ascorbic acid as a reducing agent was added into the solution and stirred for $24 \mathrm{~h}$ to produce a precipitate that was gathered and washed with water and ethanol (Scheme 18). It should be noted that $5.0 \mathrm{~mol} \%$ of the 3D graphene/Cu nanocomposite $\mathbf{8 7}$ were sufficient to generate a high yield of the desired products in $\mathrm{EtOH} / \mathrm{H}_{2} \mathrm{O}(1: 1)$ at $70{ }^{\circ} \mathrm{C}$. To screen the recyclability of $\mathbf{8 7}$, the condensation of phenylacetylene and 1-azido-4-nitrobenzene on a $4 \mathrm{mmol}$ scale in $\mathrm{EtOH} / \mathrm{H}_{2} \mathrm{O}(1: 1)$ using $5 \mathrm{~mol} \%$ of $\mathbf{8 7}$ was performed. After completion of the reaction, the heterogeneous catalyst was centrifuged and washed with ethyl acetate/water. This nanocatalyst could be reused in up to ten cycles.

A microwave-assisted method was developed for the preparation of 1,2,3-triazole products, substituted at the 1- and 4-positions, from benzyl halides, sodium azide, and nonactivated alkynes in a mixture of water and ethanol using a $\mathrm{Cu}(\mathrm{I})$ complex supported on graphene oxide, 88 [81], and the synthesis of "click" products by this new catalyst was successfully accomplished.

To synthesize the catalyst, first, $\mathrm{GO}-\mathrm{COCl}$ was created by the reaction of GO with thionyl chloride in DMF at reflux for $24 \mathrm{~h}$. Then, the resulting GO-COCl compound was treated with 1,7diaminoheptane to afford amino-modified graphene oxide (GO-CO- $\mathrm{NH}_{2}$ ), and this was subsequently reacted with isatoic anhydride (IA) in EtOH under reflux conditions for $24 \mathrm{~h}$. GO-CO-NH-IA was then reacted with copper iodide under reflux conditions to obtain GO-NH-IA-Cu(I) (88, Scheme 19).

Gopidas et al. explored the catalytic activity of copper nanoparticles linked to organic frameworks $(\mathrm{CNOF}, 90)$ for the prepara- 


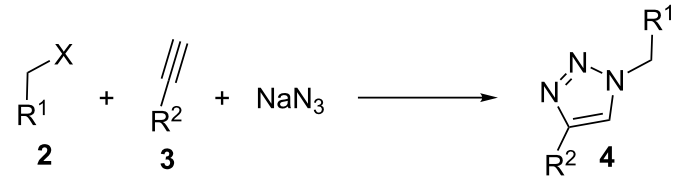

conditions for the triazole syntheses: $88(0.01 \mathrm{~g}), 70{ }^{\circ} \mathrm{C}$, $\mathrm{EtOH} / \mathrm{H}_{2} \mathrm{O}(1: 1)$, reaction time: $1-8 \mathrm{~h}$, yield: $78-94 \%$ $\mathrm{R}^{1}=\mathrm{Ph}, 4-\mathrm{BrC}_{6} \mathrm{H}_{4}, 3-\mathrm{ClC}_{6} \mathrm{H}_{4}, 2-\mathrm{ClC}_{6} \mathrm{H}_{4}, 2-\mathrm{Cl}-6-\mathrm{FC}_{6} \mathrm{H}_{3}$, 2,4-diNO ${ }_{2} \mathrm{C}_{6} \mathrm{H}_{3} ; \mathrm{R}^{2}=\mathrm{Ph}, 4-\mathrm{MeC}_{6} \mathrm{H}_{4}, \mathrm{C}_{3} \mathrm{H}_{7}$

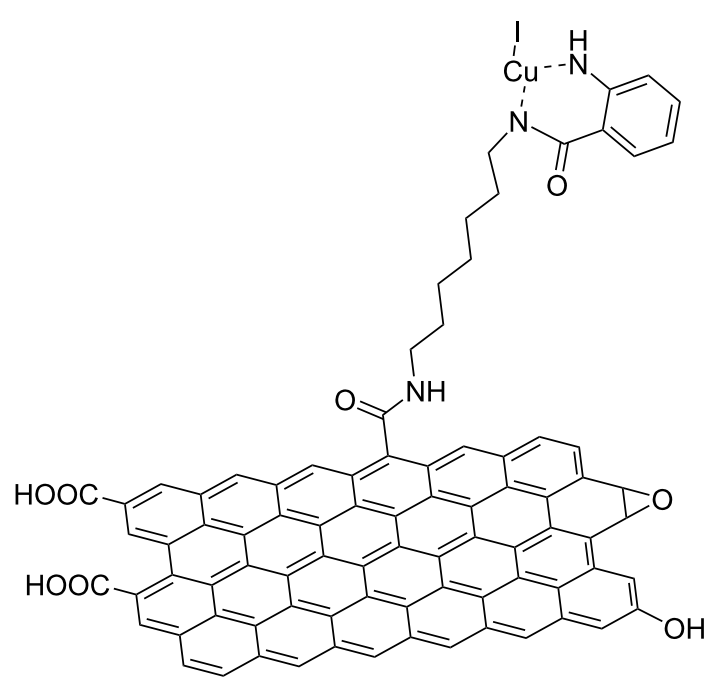

88

Scheme 19: Chemical structure of the catalyst 88 and catalytic application of 88 in "click" reactions.

tion of 1,2,3-triazole derivatives substituted at the 1- and 4-positions under green reaction conditions [82]. The CNOF (90) worked well as catalyst for the Huisgen cycloaddition of benzyl azides and aromatic azides (generated from benzyl halides and diazonium salts, respectively) with aromatic and aliphatic alkynes (Scheme 20).

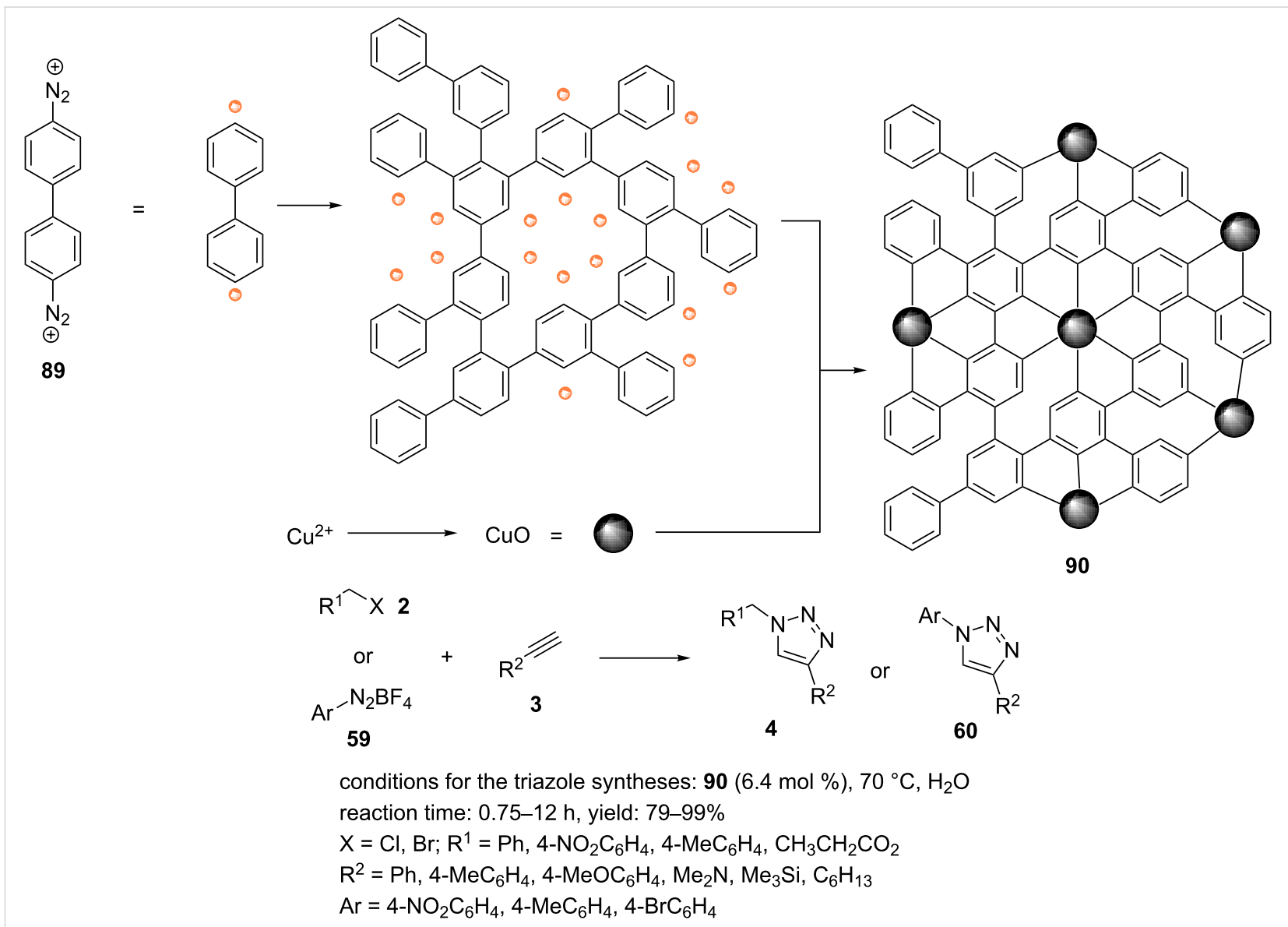

Scheme 20: Synthetic route to the catalyst $\mathbf{9 0}$ and catalytic application of $\mathbf{9 0}$ in "click" reactions. 
In the first step, 4,4'-biphenylbisdiazonium tetrafluoroborate (BPBDT, 89) and $\mathrm{CuCl}_{2} \cdot 2 \mathrm{H}_{2} \mathrm{O}$ were added to a water/toluene solvent system. Then, a methanolic solution of $\mathrm{NaBH}_{4}$ was added, and this was stirred for $6 \mathrm{~h}$. The toluene layer was separated, washed with water, and subsequently diluted with methanol. The solid was filtered and washed with $\mathrm{MeOH}$ and was finally dried to afford the catalyst CNOF (90, Scheme 20). The nanocatalyst provided outstanding selectivity in the production of the 1,4-disubstituted 1,2,3-triazole products in an aqueous medium under aerobic conditions at $70{ }^{\circ} \mathrm{C}$ (Scheme 20).

In another example, $\mathrm{GO}$ was effectively modified with $\mathrm{CuO}$ nanoparticles through a facile pathway that can be seen below [83]. In the next step, GO was sonicated in isopropyl alcohol for $0.5 \mathrm{~h}$ to produce a black dispersion. After, copper acetate mono- hydrate was added to the GO to afford a brown dispersion that was stirred at $83{ }^{\circ} \mathrm{C}$ for $0.5 \mathrm{~h}$. After the addition of water, the reaction mixture was stirred at $83{ }^{\circ} \mathrm{C}$ for $0.5 \mathrm{~h}$ and then cooled to ambient temperature. The solid product $\mathrm{CuO}-\mathrm{GO}$ was centrifuged, washed with ethanol, and dried. It was demonstrated that the $\mathrm{CuO}$ nanoparticles-graphene hybrids could act as an effective catalyst for the "click" reaction in aqueous medium under aerobic conditions. The reusability of the catalyst $\mathrm{CuO}-\mathrm{GO}$ was screened as well: the catalyst was recycled by simple filtration and washing with ethyl acetate, followed by water and acetone. The CuO-GO composite was reused five times without noticeable loss of catalytic performance.

The carbon-supported copper nanomaterial 96 (Scheme 21) was prepared by trapping copper species on carbon graphene and

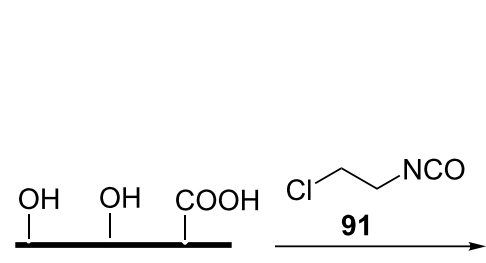<smiles>O=C(O)NCCCl</smiles><smiles>CC(OC(=O)NCCCl)C(=O)O</smiles>

\section{$\mathrm{NaN}_{3}$}

92<smiles></smiles><smiles></smiles>

96<smiles>[R]C#CCCC</smiles>

conditions for the triazole syntheses: $96(2 \mathrm{~mol} \%), 40^{\circ} \mathrm{C}$, THF reaction time: $72 \mathrm{~h}$, yield: $85-99 \%$ $\mathrm{R}^{1}=\mathrm{Ph} ; \mathrm{R}^{2}=\mathrm{Ph}, \mathrm{Cl}\left(\mathrm{CH}_{2}\right)_{4}, \mathrm{CH}_{3}\left(\mathrm{CH}_{2}\right)_{4}(\mathrm{OH}), \mathrm{CH}_{3} \mathrm{CH}_{2} \mathrm{C}(\mathrm{Me})(\mathrm{OH})$ 
carbon nanotubes [84]. This catalyst was found to be highly active in $[3+2]$ cycloaddition reactions of halides, nonactivated terminal alkynes, and sodium azide (Scheme 21).

Copper(I) ions were attached to the surface of carbon graphene as outlined in Scheme 21. Therein, GO was generated by Hummer's method, and ascorbic acid was used to produce chemically reduced graphene oxide (CRGO)-OH. The CRGO-OH and 2-chloroethyl isocyanate (91) were magnetically stirred in anhydrous DMF under nitrogen atmosphere to afford $\mathrm{Cl}$-graphene (92). The azide-functionalized GO 93 was synthesized by the reaction of $\mathbf{9 2}$ with sodium azide in DMSO and heating for $48 \mathrm{~h}$. The $\mathrm{Cu}(\mathrm{I})$-catalyzed cyclization between CRGO-N 3 (93) and 1-propargyl-3-methylimidazolium bromide (94) was used to attach the imidazolium moiety to the surface of the CRGO. Finally, a graphene-containing copper complex of $\mathrm{N}$-heterocyclic carbene, (NHC)-Cu (96), was produced via proton exchange of the imidazolium scaffold with a $\mathrm{Cu}(\mathrm{I})$ (Scheme 21). The reaction between benzyl azide and alkynes proceeded in deuterated THF at $40{ }^{\circ} \mathrm{C}$ within $72 \mathrm{~h}$ using $2.0 \mathrm{~mol} \%$ of the catalyst to obtain the desired products with good to high yields (Scheme 21). The nanocatalyst 96 could be readily recycled for use in more than 10 cycles.

A mixture of GO, 1-vinylimidazole (98), and cross-linker 99 in ethanol was sonicated for $20 \mathrm{~min}$ [85]. Afterwards, the mixture was deoxygenated in an Ar atmosphere for $20 \mathrm{~min}$. In the next step, polymerization was generated by adding AIBN (3 wt \%). This was then heated at $70{ }^{\circ} \mathrm{C}$ for $24 \mathrm{~h}$. This solid material was washed with $\mathrm{MeOH}$ and dried. The resulting GO/intrinsically microporous polymer (Pim) material and $\mathrm{CuSO}_{4}$ were added into water and heated at $50{ }^{\circ} \mathrm{C}$ overnight to afford the material $\mathrm{GO} / \mathrm{Pim} / \mathrm{Cu}$ (100, Scheme 22). The powder was collected by filtration and washed by water/methanol. The "click" reactions of alkyl halide, $\mathrm{NaN}_{3}$, and acetylene were performed successfully in the presence of $\mathbf{1 0 0}(1.0 \mathrm{~mol} \%)$ as the catalyst and $10 \mathrm{~mol} \%$ of sodium ascorbate as a reducing agent in water at $50{ }^{\circ} \mathrm{C}$ (Scheme 22). Further, the nanocatalyst $\mathbf{1 0 0}$ was durable and could be recycled eight times without any significant loss of catalytic activity [85].

Chattopadhyay et al. prepared the nanocomposite $\mathrm{rGO} / \mathrm{Cu}_{2} \mathrm{O}$ (102) via an in situ method [86]. Lactulose, a disaccharide, was used to reduce GO and the copper(II) source under alkaline conditions. Initially, the GO material was prepared from natural graphite powder via a modified Hummer procedure. Graphite powder, $\mathrm{NaNO}_{3}$, and concentrated sulfuric acid were mixed and vigorously stirred in an ice bath. After converting to a black slurry, $\mathrm{KMnO}_{4}$ was added and then, this was stirred for $4 \mathrm{~h}$. The resulting mixture was diluted with water and stirred at room temperature for $2 \mathrm{~h}$. The mixture was also diluted with hot

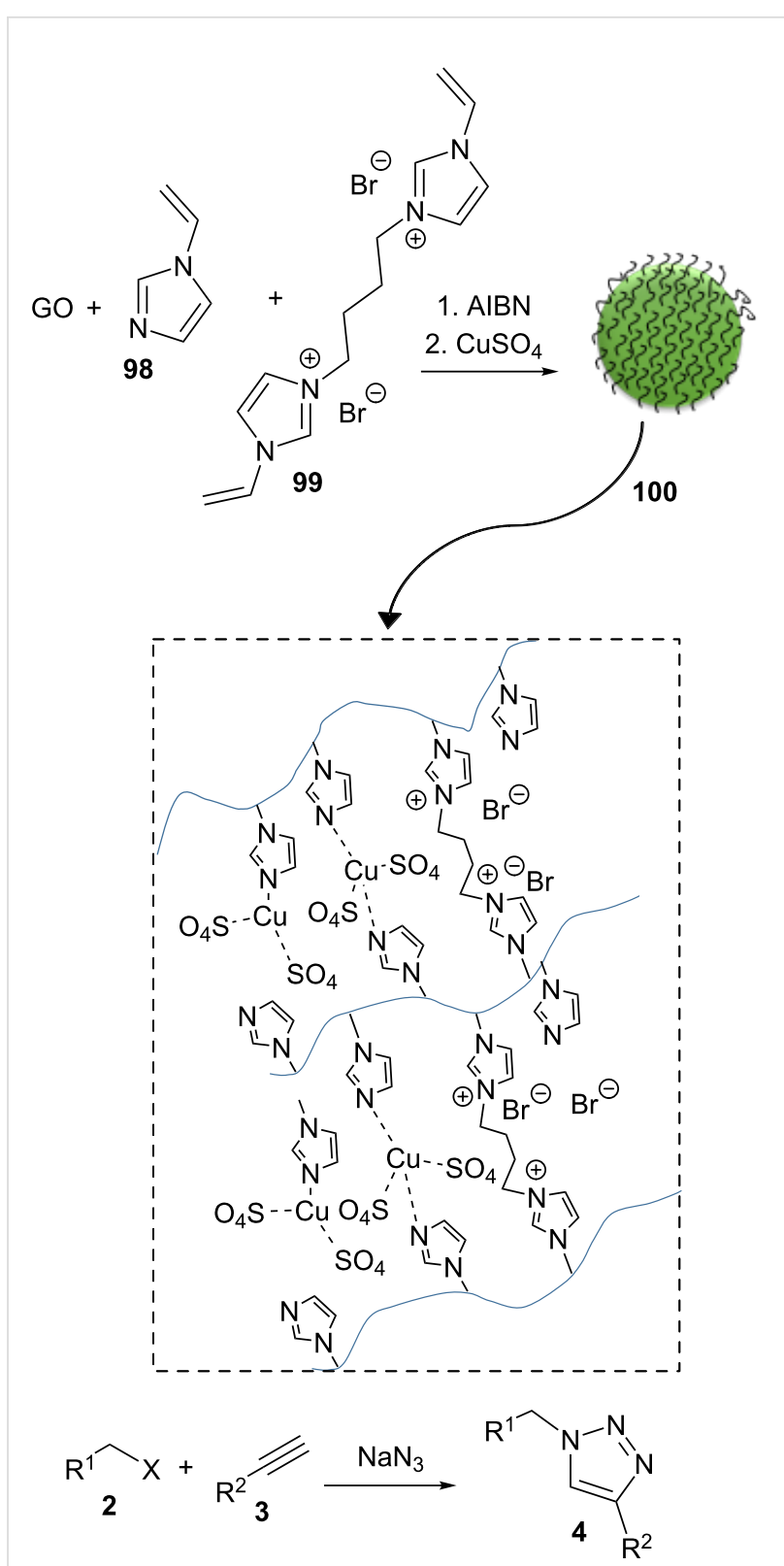

conditions for the triazole syntheses: 100 (1 mol \%), sodium ascorbate $(10 \mathrm{~mol} \%), 50{ }^{\circ} \mathrm{C}, \mathrm{H}_{2} \mathrm{O}$ reaction time: $0.5-3.5 \mathrm{~h}$, yield: $80-96 \%$ $\mathrm{X}=\mathrm{Cl}, \mathrm{Br}$, OTs; $\mathrm{R}^{1}=$ benzyl/alkyl groups $\mathrm{R}^{2}=\mathrm{Ph}, 4-\mathrm{NO}_{2} \mathrm{C}_{6} \mathrm{H}_{4}, 4-\mathrm{MeOC}_{6} \mathrm{H}_{4}, \mathrm{CO}_{2} \mathrm{Et}, \mathrm{C}_{5} \mathrm{H}_{11}, \mathrm{CH}_{2} \mathrm{OH}$

Scheme 22: Synthetic route to the catalyst 100 and catalytic application of $\mathbf{1 0 0}$ in "click" reactions.

water and then, $\mathrm{H}_{2} \mathrm{O}_{2}$ was added to adjust the $\mathrm{pH}$ value and to terminate the reaction. In the next step, the resulting mixture was washed with distilled water, and the pure graphene oxide powder was gathered by centrifugation and dried. The GO was dispersed in distilled water by ultrasonication. Subsequently, an aqueous solution of $\mathrm{CuSO}_{4}$ was added and stirred for $2 \mathrm{~h}$. The 
$\mathrm{pH}$ value was increased to $>10$ by adding aqueous $\mathrm{NaOH}$. An aqueous solution of lactulose was added as the reducing agent to the mixture to reduce GO and copper(II). After sonication for 10 minutes at $120^{\circ} \mathrm{C}$ and $15 \mathrm{psi}, \mathrm{rGO} / \mathrm{Cu}_{2} \mathrm{O}(\mathbf{1 0 2})$ was obtained. The nanoparticles of $\mathrm{Cu}_{2} \mathrm{O}$ with an average size of $5 \mathrm{~nm}$ were homogeneously dispersed throughout the rGO sheets (Scheme 23).

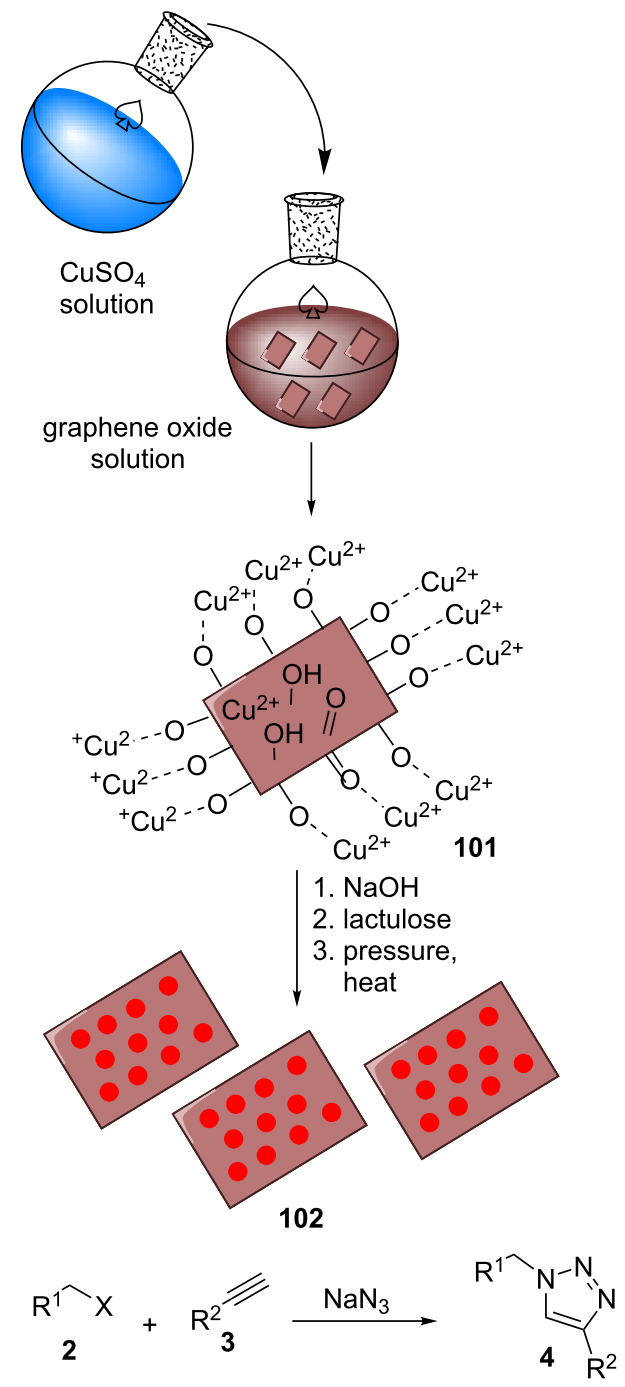

conditions for the triazole syntheses: $102(20 \mathrm{mg}), 55^{\circ} \mathrm{C}, \mathrm{H}_{2} \mathrm{O}$ reaction time: $2-2.5 \mathrm{~h}$, yield: $91-95 \%$

$\mathrm{X}=\mathrm{Br} ; \mathrm{R}^{1}=\mathrm{Ph}, 4-\mathrm{NO}_{2} \mathrm{C}_{6} \mathrm{H}_{4}, 4-\mathrm{MeOC}_{6} \mathrm{H}_{4} ; \mathrm{R}^{2}=\mathrm{Ph}$

Scheme 23: Synthetic route to the catalyst 102 and catalytic application of $\mathbf{2 3}$ in "click" reactions.

A mixture of phenylacetylene, benzyl bromides containing methoxy and nitro substitutions, and sodium azide was stirred using a catalytic amount of $\mathrm{rGO} / \mathrm{Cu}_{2} \mathrm{O}(\mathbf{1 0 2})$ in water at $55^{\circ} \mathrm{C}$ for $2 \mathrm{~h}$ to obtain 1,2,3-triazole derivatives substituted at the 1and 4 position with high yields (Scheme 23). The catalyst 102 could be readily reused in six cycles [86].

In another study, charcoal-supported palladium and copper as a multitask nanocatalyst was used for one-pot Sonogashira"click"/“click"-Heck sequences [87]. Palladium(II) acetate, copper(II) acetate, and charcoal were dispersed in methanol. In order to remove oxygen from the reaction mixture, hydrogen gas was passed through the medium. Then, the solution was stirred at ambient temperature for $12 \mathrm{~h}$ under a hydrogen atmosphere. Finally, the $\mathrm{Pd}-\mathrm{Cu} / \mathrm{C}$ catalyst was collected by filtration, washed with methanol, and dried.

An efficient one-pot sequential Sonogashira-"click" reaction toward heterocyclic structures was disclosed using the same catalyst. In this regard, trimethylsilylacetylene (TMSA) was selected for coupling with aryl iodides in the presence of a catalytic amount of $\mathrm{Pd}-\mathrm{Cu} / \mathrm{C}$ and $\mathrm{PPh}_{3}$ using $\mathrm{Et}_{2} \mathrm{NH}$ as a base in methanol at $120^{\circ} \mathrm{C}$ under microwave irradiation for $20 \mathrm{~min}$. In the next step, the azide derivative was added to the reaction mixture. Finally, the reaction mixture was irradiated at $120{ }^{\circ} \mathrm{C}$ for $10 \mathrm{~min}$ to the provide the triazole derivatives.

Binder et al. reported highly dispersed copper nanoparticles supported by graphene nanosheets [88]. After the preparation of GO by Hummer's method, the GO was dispersed in water. In the next step, copper acetate was added under vigorous stirring, and this was reacted overnight to afford $\mathrm{Cu}(\mathrm{II}) / \mathrm{GO}$. Finally, the reduction of the $\mathrm{Cu}(\mathrm{II}) / \mathrm{GO}$ composite was realized at $600{ }^{\circ} \mathrm{C}$ under an argon atmosphere to produce $\mathrm{TRGO} / \mathrm{Cu}(\mathrm{I})$. According to STEM-EDXS, the quantities of copper and oxygen were in a ratio of 2:1, indicating the presence of $\mathrm{Cu}_{2} \mathrm{O}$ nanoparticles. The $\mathrm{TRGO} / \mathrm{Cu}(\mathrm{I})$ catalyst $(2 \mathrm{~mol} \%$ ) was applied in the synthesis of triazole derivatives by the reaction of benzyl azide with different alkynes at $40{ }^{\circ} \mathrm{C}$ for $48 \mathrm{~h}$. In this protocol, the TRGO/Cu(I) species could be simply recovered and recycled four times without any significant loss of catalytic activity.

\section{Copper anchored on functionalized magnetic nanoparticles (MNPs): efficient and recyclable catalysts for $\mathrm{CuAAC}$ reactions}

MNPs are of significant interest to chemists owing to a number of unique features, including their high structural diversity, large surface area, superparamagnetic behavior, ease of separation, and high safety. Indeed, materials including silica, carbon, etc. were combined with MNPs to produce new compositions that illustrated unique efficiency in the areas of catalysis [89], sensors [90], water purification [91], bioimaging [92], energy storage [92], drug delivery [93], and cancer detection [94]. 
In this regard, various functionalized MNPs were employed in diverse organic reactions, including Suzuki-Miyaura reactions, Sonogashira reactions, Ullmann coupling, hydrogenation reactions, oxidation reactions, hydroformylation reactions, and "click" reactions [89]. Because of the mentioned reasons, as well as due to the low toxicity and the magnetically reusability of these nanoparticles, they were also used in organic reactions. As such, in this review, we provide an overview on the synthesis and functionalization of MNPs and on investigations on their catalytic application in CuAAC reactions.

Turkowicz, Wilczewska, and co-workers were the first to covalently immobilized a range of NHC-copper(I) and NHC-copper(II) complexes on MNPs [95]. The synthetic process for NHC-copper@MNPs 108-111 can be seen in Scheme 24. Initially, the magnetic nanoparticles were synthesized by heating a mixture of $\mathrm{FeCl}_{2} \cdot 4 \mathrm{H}_{2} \mathrm{O}$ and $\mathrm{FeCl}_{3} \cdot 6 \mathrm{H}_{2} \mathrm{O}$ in water at $80{ }^{\circ} \mathrm{C}$ in an ultrasonic bath. The $\mathrm{pH}$ value of the solution was increased to 11 by adding concentrated ammonia. In the next step, the MNPs were dispersed in EtOH by ultrasonication and diluted with EtOH. Then, the resulting mixture was reacted. After $15 \mathrm{~min}$ of stirring under argon, concentrated ammonia was added, and this was stirred for another $5 \mathrm{~min}$. (3-Aminopropyl)trimethoxysilane (APTMS) was added dropwise to the mixture, and this was stirred at $\mathrm{rt}$ for $4 \mathrm{~h}$. The silanecoated MNPs were magnetically separated. These nanoparticles were dispersed in triethylorthoformate and some drops of formic acid were added. The mixture was heated at reflux for $20 \mathrm{~h}$ to receive the new functionalized nanoparticles $\mathbf{1 0 3}$.

The nanoparticles $\mathbf{1 0 3}$ were dispersed in 1,6-diisopropylaniline (104) by ultrasonication. The mixture was heated at $120^{\circ} \mathrm{C}$ for about $20 \mathrm{~h}$ and then magnetically separated. After dispersing the resulting nanoparticles in 1,2-dichloroethane, $\mathrm{N}, \mathrm{N}$-diisopropylethylamine (DIPEA) was added. The mixture was heated

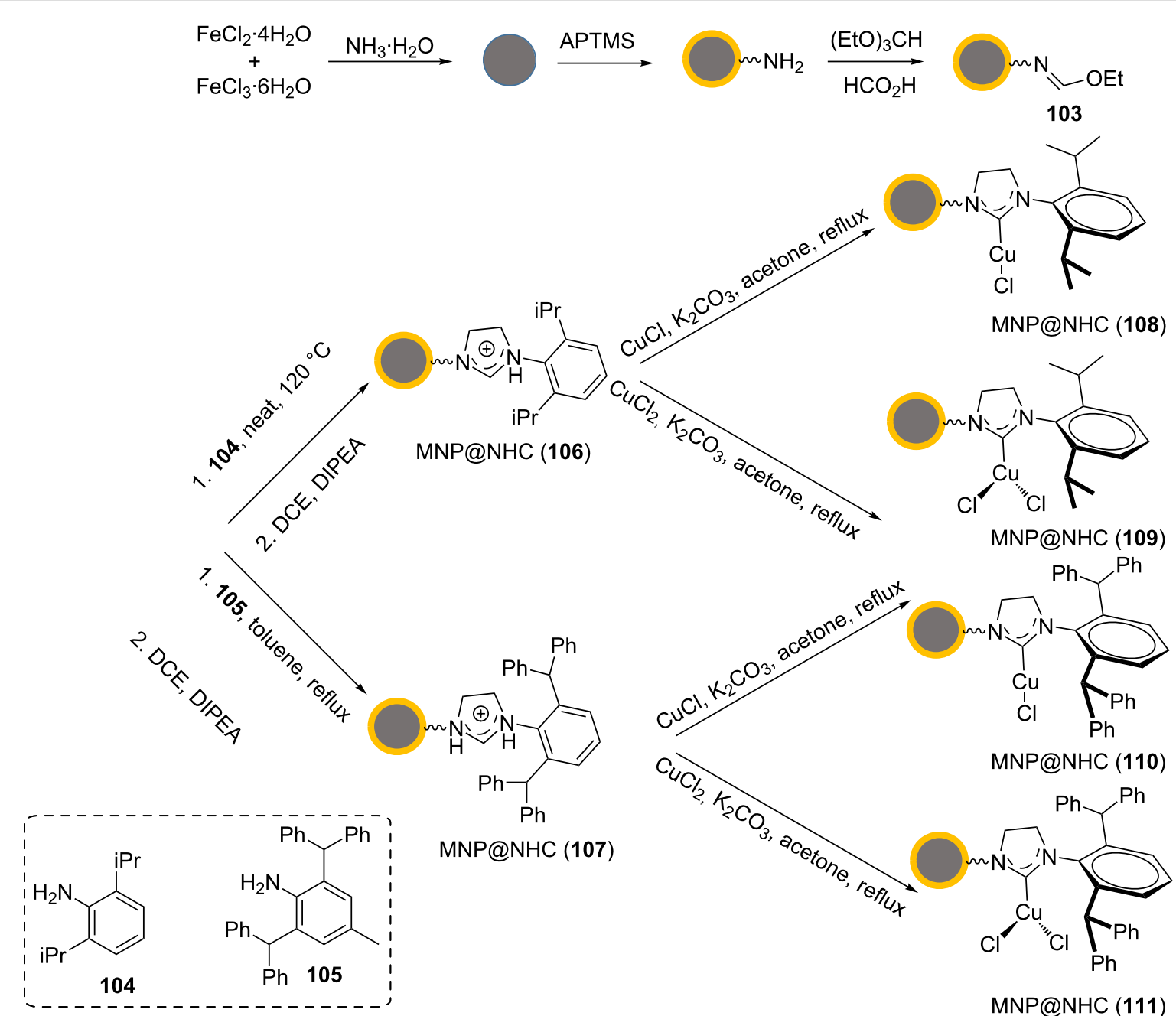


under reflux conditions for $20 \mathrm{~h}$ to obtain the nanoparticles $\mathbf{1 0 6}$, which were magnetically separated.

The nanoparticles $\mathbf{1 0 7}$ were also synthesized in multiple steps: The nanoparticles $\mathbf{1 0 3}$ were dispersed in toluene by ultrasonication. Then, 2,6-bis(diphenylmethyl)-4-methylaniline (105) was added to the mixture, and this was stirred at reflux over $20 \mathrm{~h}$ The resulting material was magnetically separated. These nanoparticles were dispersed in 1,2-dichloroethane by ultrasonication. After adding $N, N$-diisopropylethylamine, the mixture was heated at reflux for $20 \mathrm{~h}$. The nanoparticles 107 were magnetically separated and finally, the corresponding complexes of copper(I) and copper(II) with the NHC ligands, 108-111, were prepared as shown in Scheme 24.

The catalysts 108-111 were found to be effective in CuAAC reactions to form triazole products under mild conditions. The best results for NHC-copper(I) complexes were accomplished in $\mathrm{THF}$ at $50{ }^{\circ} \mathrm{C}$. For the NHC-Cu(II) complexes 109 and 111, the best yields were obtained in $\mathrm{MeOH}$. Importantly, the $\mathrm{NHC}-\mathrm{Cu}(\mathrm{II})$ complexes $\mathbf{1 0 8}$ and $\mathbf{1 1 0}$ required the addition of sodium ascorbate to reduce the oxidation state of $\mathrm{Cu}(\mathrm{II})$. In summary, the NHC-Cu(II) complexes 109 and 111 displayed higher catalytic activities than the NHC-Cu(I) complexes $\mathbf{1 0 8}$ and 110. The catalyst 111 presented the best catalytic activity, high stability, and high selectivity (Scheme 25).

Recently, Heydari et al. reported a $\mathrm{Cu}(\mathrm{I})$-caffeine complex supported on silica-coated magnetite nanoparticles, $\mathrm{Fe}_{3} \mathrm{O}_{4} @ \mathrm{SiO}_{2}$-caffeine-Cu(I) (121), for "click" reactions in aqueous medium [96]. The heterogeneous catalyst $\mathbf{1 2 1}$ was prepared as outlined in Scheme 26. The salts $\mathrm{FeCl}_{3} \cdot 6 \mathrm{H}_{2} \mathrm{O}$ and $\mathrm{FeCl}_{2} \cdot 4 \mathrm{H}_{2} \mathrm{O}$ were dissolved in water, and the $\mathrm{pH}$ value was increased to 11 by adding an aqueous ammonia solution. The mixture was stirred at $\mathrm{rt}$ for $1 \mathrm{~h}$ and heated under reflux conditions for $1 \mathrm{~h}$. The resulting magnetic nanoparticles were magnetically colleted from the aqueous solution and washed with water and ethanol. The $\mathrm{Fe}_{3} \mathrm{O}_{4}$ nanoparticles were dispersed in an ethanol/water mixture, and concentrated aqueous ammonia was added to the mixture to adjust the $\mathrm{pH}$ to approximately 10 , and this was subsequently sonicated for $20 \mathrm{~min}$. Then, TEOS was added to the mixture, and this was stirred at $40{ }^{\circ} \mathrm{C}$ for $12 \mathrm{~h}$. The silica-coated magnetite nanoparticles $\mathrm{Fe}_{3} \mathrm{O}_{4} @ \mathrm{SiO}_{2}$ were magnetically separated from the aqueous solution and washed with water and ethanol. The $\mathrm{Fe}_{3} \mathrm{O}_{4} @ \mathrm{SiO}_{2}$ nanoparticles were then reacted with (3-chloropropyl)triethoxysilane in toluene. After that, the mixture was heated at reflux for $18 \mathrm{~h}$ to obtain new nanoparticles. The resulting nanoparticles were magneti-

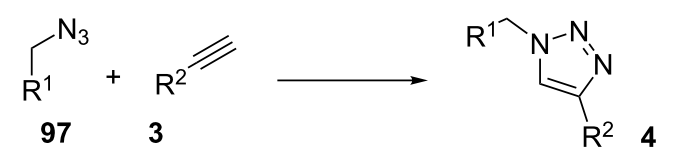
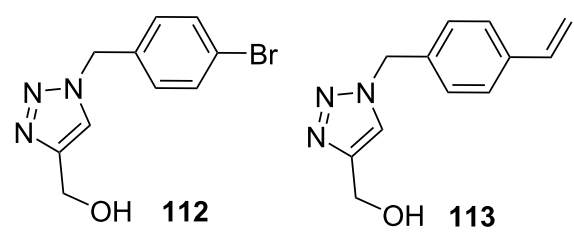<smiles>C=Cc1ccc(Cn2cc(C(O)C(c3ccccc3)c3ccccc3)nn2)cc1</smiles><smiles>C=Cc1ccc(Cn2cc(CC(C(C)=O)C(C)=O)nn2)cc1</smiles><smiles>CC(=O)C(Cc1cn(Cc2ccc(Br)cc2)nn1)C(=O)N1CCCC1</smiles><smiles>CC(=O)OCCc1cn(Cc2ccc(Br)cc2)nn1</smiles>

conditions for the triazole syntheses:

108 and 110: $\left(0.2 / 5 \mathrm{mmol} / \mathrm{mg}\right.$ benzyl azide derivative/catalyst), sodium ascorbate $(0.04 \mathrm{mmol}), 50^{\circ} \mathrm{C}, \mathrm{THF}$ 109 and 111: $(0.2 / 5 \mathrm{mmol} / \mathrm{mg}$ benzyl azide derivative/catalyst), sodium ascorbate $(0.04 \mathrm{mmol}), \mathrm{reflux}, \mathrm{MeOH}$ TON and TOF for the triazole syntheses in the presence of 108: 12 and 0.5; 110 : 38 and 15.5; 109: 12 and $0.5 ; 111: 27$ and 9 yield for the triazole syntheses in the presence of 108 and $110: 0-82 \% ; 109$ and $111: 19-93 \%$ 


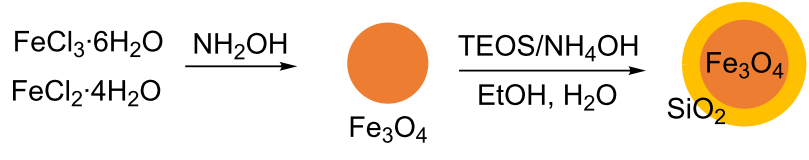

1. $(\mathrm{EtO})_{3} \mathrm{Si} \frown \widehat{C l}_{\mathrm{Cl}}$

toluene, $18 \mathrm{~h}$

2.<smiles>Cn1c(=O)c2c(ncn2C)n(C)c1=O</smiles>
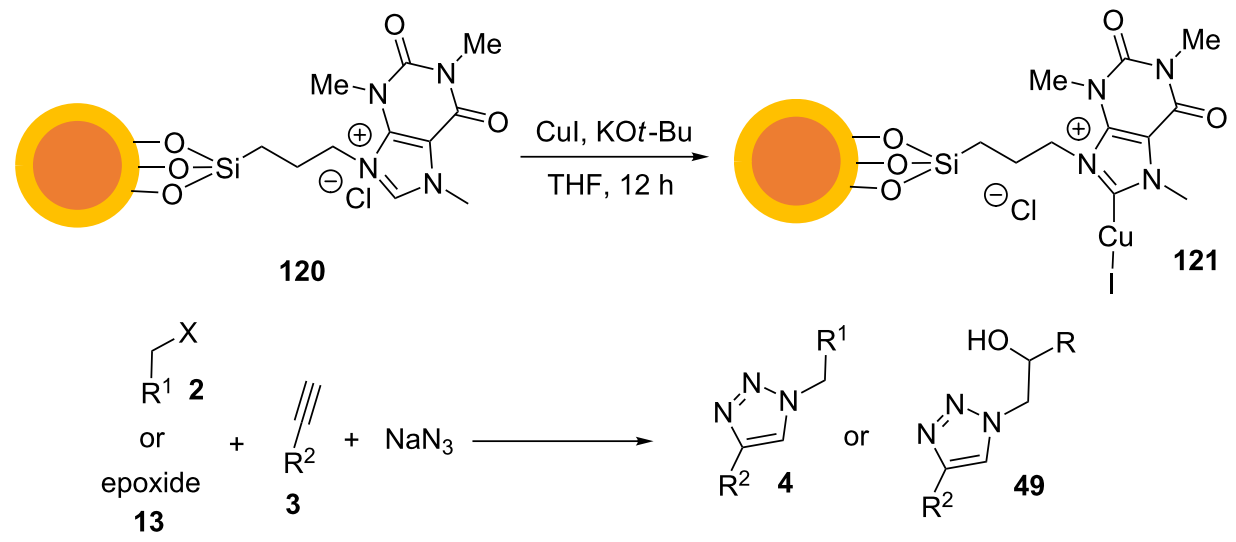<smiles>[R]Cn1cc([R])nn1</smiles>

conditions for the triazole syntheses: $121(0.3 \mathrm{~mol} \%), 70{ }^{\circ} \mathrm{C}, \mathrm{H}_{2} \mathrm{O}$ reaction time: $20-50 \mathrm{~min}$, yield: $83-96 \%$

$\mathrm{X}=\mathrm{Cl}, \mathrm{Br}$

$\mathrm{R}^{1}=\mathrm{Ph}, 4-\mathrm{BrC}_{6} \mathrm{H}_{4}, 4-\mathrm{NO}_{2} \mathrm{C}_{6} \mathrm{H}_{4}, \mathrm{PhCO}, 4-\mathrm{ClC}_{6} \mathrm{H}_{3} \mathrm{CO}, 4-\mathrm{NO}_{2} \mathrm{C}_{6} \mathrm{H}_{3} \mathrm{CO}, \mathrm{CH}_{2} \mathrm{CH}$

$\mathrm{R}^{2}=\mathrm{Ph}, 4-\mathrm{FC}_{6} \mathrm{H}_{4}, 4-\mathrm{MeC}_{6} \mathrm{H}_{4}, \mathrm{CH}_{2} \mathrm{OH}, \mathrm{CO}_{2} \mathrm{H},\left(\mathrm{CH}_{2}\right)_{5} \mathrm{CHOH}$

epoxide $=2$-phenyloxirane, aliphatic epoxide derivatives

Scheme 26: Synthetic route to the catalyst 121 and catalytic application of 121 in "click" reactions.

cally collected and washed with toluene, methanol, and diethyl ether. These new nanoparticles were treated with caffeine (119) in dry acetone under reflux conditions for $48 \mathrm{~h}$. The resulting nanoparticles 120 were magnetically collected and washed with methanol and acetone. Finally, the nanoparticles $\mathrm{Fe}_{3} \mathrm{O}_{4} @ \mathrm{SiO}_{2}-$ caffeine- $\mathrm{Cu}(\mathrm{I})(\mathbf{1 2 1})$ were prepared by the reaction of the nanoparticles $\mathrm{Fe}_{3} \mathrm{O}_{4} @ \mathrm{SiO}_{2}$-caffeine (120), CuI, and $\mathrm{KO} t$-Bu in dry THF at $\mathrm{rt}$ for $12 \mathrm{~h}$. The final nanoparticles $\mathbf{1 2 1}$ were magnetically collected, washed with THF and dichloromethane, and dried.

Different organic halides (benzyl bromides, benzyl chloride, allyl bromide, aliphatic epoxides, and aromatic epoxides) were treated with sodium azide and phenylacetylene in the presence of a catalytic amount of the copper catalyst $\mathbf{1 2 1}$ in water at $70{ }^{\circ} \mathrm{C}$ (Scheme 26). These magnetically retrievable nanoparticles could be recycled five times.

Copper(II) was supported by carboxylic acid-rich $\mathrm{Fe}_{3} \mathrm{O}_{4}$-pectin (124) to afford copper(II)-supported $\mathrm{Fe}_{3} \mathrm{O}_{4}$-pectin,
$\mathrm{Cu}(\mathrm{II}) @ \mathrm{Fe}_{3} \mathrm{O}_{4}$-pectin (125), as a superparamagnetic nanobiopolymer (Scheme 27) [97].

Briefly, 125 was synthesized by adding a methanolic solution of copper(II) sulfate to $\mathbf{1 2 4}$, and this was allowed to stir for $2 \mathrm{~h}$. The resulting nanoparticles were collected from the solution by centrifugation and washed/sonicated with methanol. Finally, 125 was dried before use in the reactions (Scheme 27).

Pectin (122) is a polymer that contains many carboxylate groups. These functional groups can chelate $\mathrm{Fe}_{3} \mathrm{O}_{4}$ nanoparticles (i.e., pectin includes the $\mathrm{Fe}_{3} \mathrm{O}_{4}$ nanoparticles as a shell). Generally, $\mathbf{1 2 2}$ is a branched macromolecule that is found broadly in nature. The promising aspects associated with pectin are biodegradability, nontoxicity, and inexpensiveness.

The catalytic application of $\mathrm{Cu}(\mathrm{II}) @ \mathrm{Fe}_{3} \mathrm{O}_{4}$-pectin (125) was screened in the "click" reaction of phenylacetylene, benzyl bromide, and sodium azide to synthesize 1,4-disubstituted 1,2,3-triazole derivatives. Water was the best solvent for this reaction, 


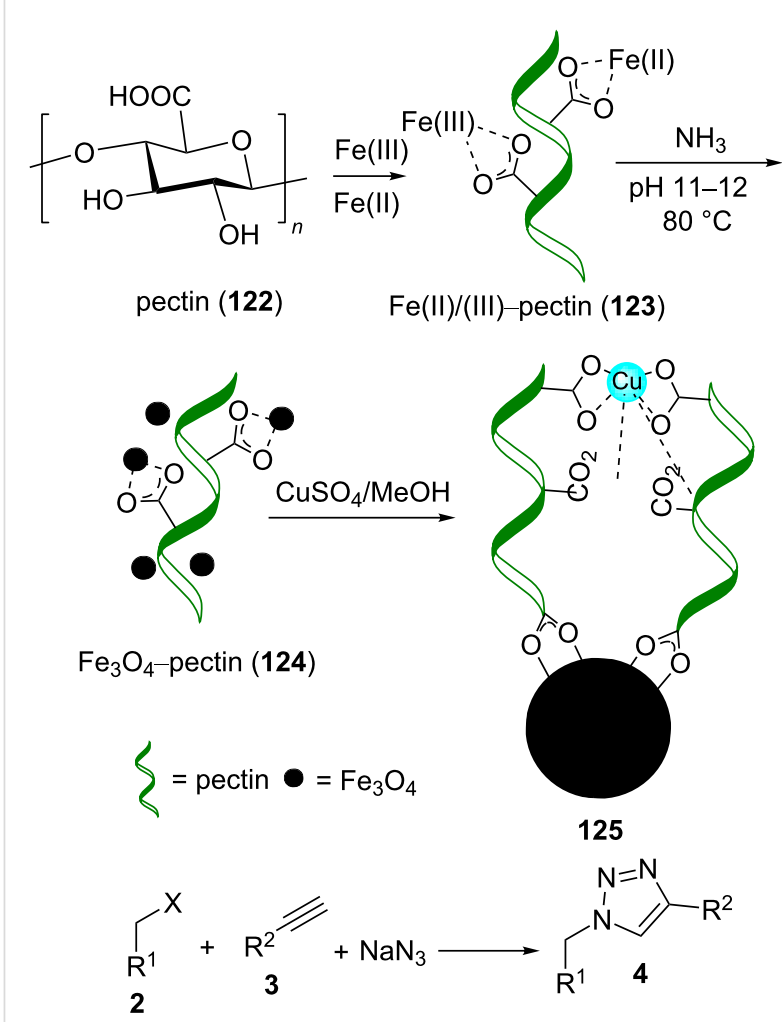

conditions for the triazole syntheses: $125(10 \mathrm{mg}), \mathrm{rt}, \mathrm{H}_{2} \mathrm{O}$ reaction time: ca. $4 \mathrm{~h}$, yield: $>95 \%$

$\mathrm{X}=\mathrm{Br} ; \mathrm{R}^{1}=\mathrm{Ph}, \mathrm{R}^{2}=\mathrm{Ph}$

Scheme 27: Synthetic route to 125 and application of 125 in "click" reactions.

and the temperature had a direct effect on the rate of the reaction. By increasing the reaction temperature to $70^{\circ} \mathrm{C}$, the reaction rate could be increased. The triazole product was generated at $\mathrm{rt}$ within $4 \mathrm{~h}$ (Scheme 27).

$\mathrm{Cu}(\mathrm{II}) @ \mathrm{Fe}_{3} \mathrm{O}_{4}$-pectin (125) was reusable several times, and the results displayed good efficiency for up to 7 cycles. According to the TEM image obtained after the eigth cycle, the collapse of the catalyst was the reason for decreased activity of the catalyst at that stage.

Gholinejad et al. reported the synthesis of copper ferrite nanoparticles-modified starch $\left(\mathrm{CuFe}_{2} \mathrm{O}_{4} @\right.$ starch, 131) as a highly reusable nanomagnetic catalyst for "click" reactions and tandem syntheses of 1,2,3-triazoles substituted at the 1- and 4-position in water [98]. The synthetic approach to $\mathbf{1 3 1}$ is shown in Scheme 28.

First, magnetic $\mathrm{CuFe}_{2} \mathrm{O}_{4}$ nanoparticles $\mathbf{1 2 6}$ were treated with (3-chloropropyl)triethoxysilane in dry toluene to produce the magnetic nanoparticles $\mathrm{Cl} @ \mathrm{CuFe}_{2} \mathrm{O}_{4}$ (127). Subsequently,

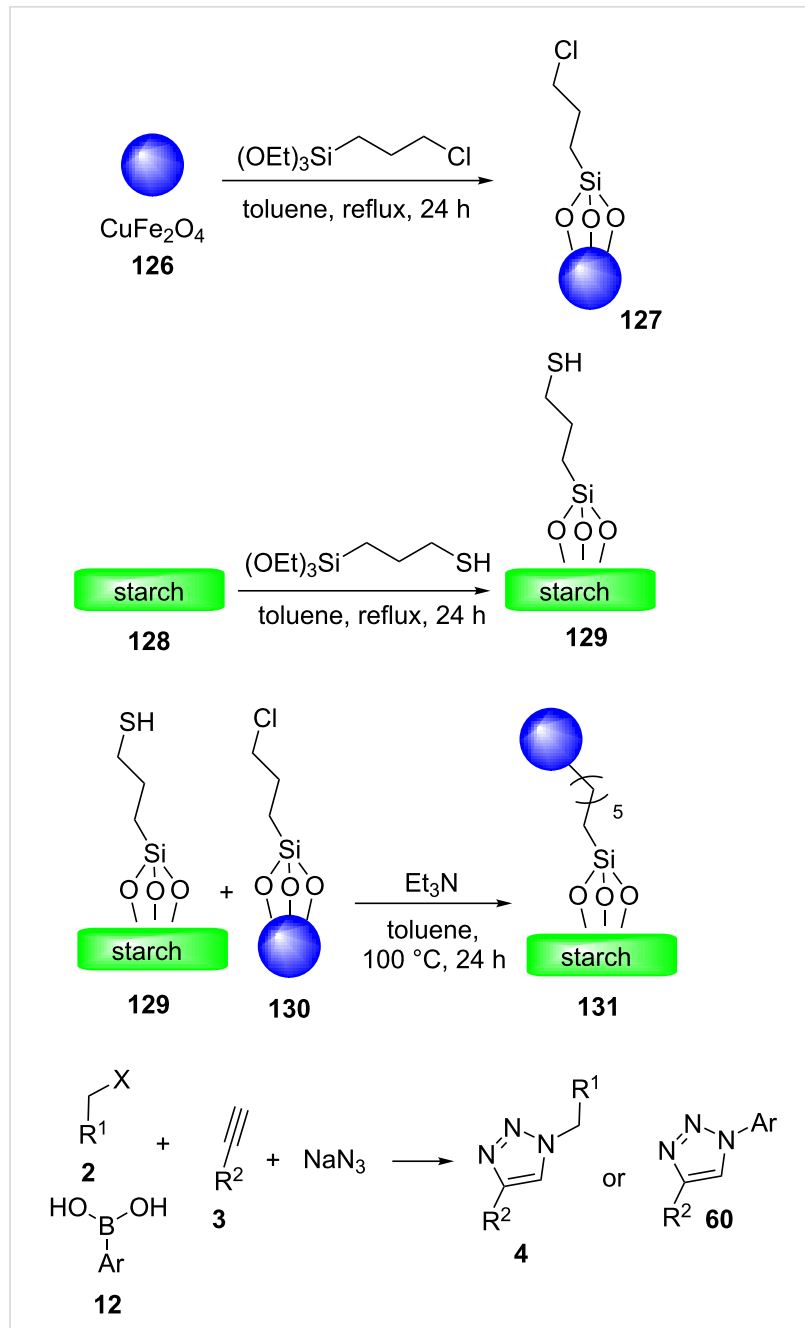

conditions for the triazole syntheses: $131(0.1 \mathrm{~mol} \%), 30^{\circ} \mathrm{C}, \mathrm{H}_{2} \mathrm{O}$ reaction time: $24 \mathrm{~h}$, yield: $76-95 \%$

$\mathrm{X}=\mathrm{Cl}, \mathrm{Br} ; \mathrm{R}^{1}=$ aryl, alkyl; $\mathrm{R}^{2}=$ aryl, alkyl

Scheme 28: Synthetic route to the catalyst 131 and catalytic application of 131 in "click" reactions.

starch (128) was reacted with (3-mercaptopropyl)triethoxysilane in dry toluene to afford the starch-containing thiol-functionalized nanoparticles SH@starch (129). Next, 127 was grafted onto 129 in toluene at reflux conditions for $24 \mathrm{~h}$ to form the magnetic nanoparticles $\mathrm{CuFe}_{2} \mathrm{O}_{4} @$ starch (131).

The catalytic activity of $\mathbf{1 3 1}$ was studied in the synthesis of 1,2,3-triazoles substituted at the 1- and 4-position by regioselective "click" reactions of benzyl/alkyl bromides or arylboronic acids, sodium azide, and aromatic/alkyl alkynes in the presence of low copper catalyst $\mathbf{1 3 1}$ loadings $(0.1 \mathrm{~mol} \%)$ at $30{ }^{\circ} \mathrm{C}$ for $24 \mathrm{~h}$ (Scheme 28). The heterogeneous catalyst 131 could be recycled eleven times, with only a small decrease in catalytic activity. After that, the yield of the riazole product significantly decreased. 


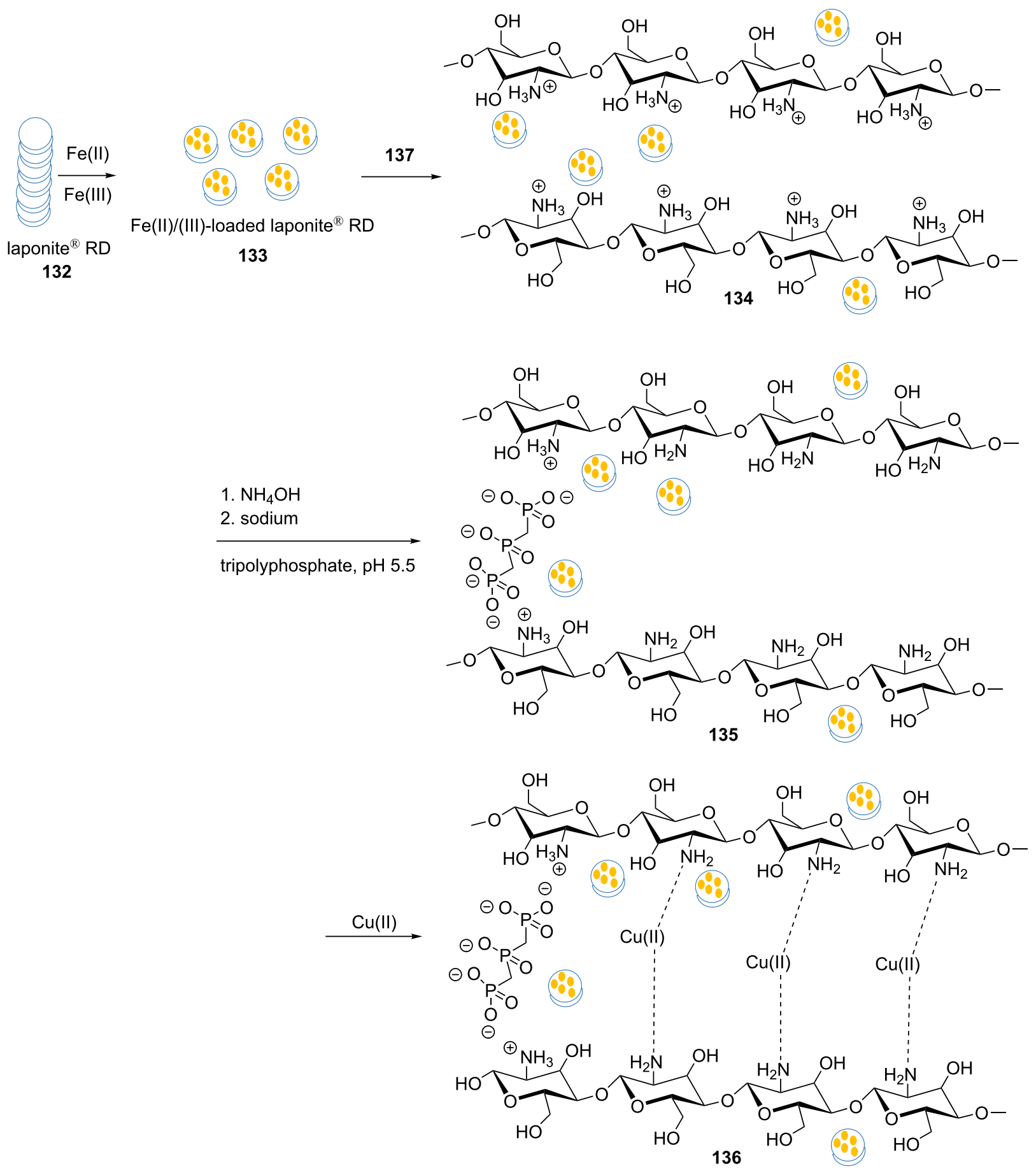

Scheme 29: Synthetic route to the catalyst 136.

A new magnetic catalyst $\mathbf{1 3 6}$ was prepared using a combination of chitosan (137) and laponite ${ }^{\circledR} \mathrm{RD}(\mathbf{1 3 2})$ [99]. The synthetic strategy to this catalyst is shown in Scheme 29. At first, $\mathrm{Fe}(\mathrm{II}) / \mathrm{Fe}$ (III)-loaded laponite RD, 133, was prepared by adding a solution of $\mathrm{Fe}(\mathrm{II}) / \mathrm{Fe}(\mathrm{III})$ ions to a dispersed solution of $\mathbf{1 3 2}$. In the next step, a solution of $\mathbf{1 3 7}$ was added to the previous solution and then, the $\mathrm{pH}$ value was adjusted to 11 , using ammonia solution, to achieve the magnetic nanocomposite. Sodium tripolyphosphate (138) was applied to create a crosslinked magnetic nanocomposite. It should be noted that $\mathbf{1 3 8}$ is a common crosslinker in the construction of 137-based materials. Due to the incorporation of $\mathbf{1 3 7}$ and $\mathbf{1 3 2}$, the capacity of the ob- 
tained magnetic nanocomposite $\mathbf{1 3 5}$ to complex $\mathrm{Cu}(\mathrm{II})$ ions was high. As such, copper ions were loaded into the magnetic nanocomposite, yielding 136. The most important benefit of the magnetic nanoparticles being situated within the laponite ${ }^{\circledR}$ discs was to prevent their aggregation.

Moreover, the catalytic activity of the nanocomposite $\mathbf{1 3 6}$ was explored in 1,3-dipolar cycloadditions of alkynes with in situgenerated organic azides. The reactions proceeded well in an aqueous medium at $70{ }^{\circ} \mathrm{C}$ with $0.004 \mathrm{~g}$ of the catalyst (Scheme 30).

In another study, Shaabani reported crosslinked chitosan nanoparticles-anchored magnetic multiwalled carbon nanotubes $\mathrm{Cu}-\mathrm{CS}$ NPs/MWCNT@ $@ \mathrm{Fe}_{3} \mathrm{O}_{4}(\mathbf{1 4 1})$ as a bionanoreactor catalyst, and the catalytic activity of $\mathbf{1 4 1}$ in 1,2,3-triazole syntheses was explored [100]. A schematic pathway for the creation of

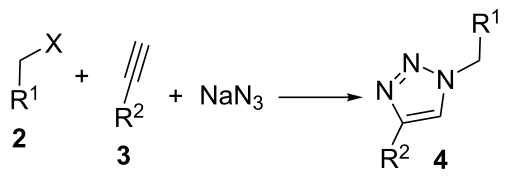

conditions for the triazole syntheses: $136(0.004 \mathrm{~g}), 70^{\circ} \mathrm{C}, \mathrm{H}_{2} \mathrm{O}$ reaction time: $4 \mathrm{~h}$, yield: $54-97 \%$

$\mathrm{X}=\mathrm{Cl}, \mathrm{Br} ; \mathrm{R}^{1}=\mathrm{Ph}, 4-\mathrm{MeC}_{6} \mathrm{H}_{4}, 2-\mathrm{MeC}_{6} \mathrm{H}_{4}, 4-\mathrm{NO}_{2} \mathrm{C}_{6} \mathrm{H}_{4}$ $\mathrm{R}^{2}=\mathrm{Ph}, 4-\mathrm{MeOC}_{6} \mathrm{H}_{4}, 4-\mathrm{MeC}_{6} \mathrm{H}_{5}, \mathrm{Me}_{2} \mathrm{COH}, \mathrm{CH}_{2} \mathrm{OH},\left(\mathrm{CH}_{2}\right)_{2} \mathrm{CH}_{3}$

Scheme 30: Application of the catalyst 136 in "click" reactions.

141 is presented in Scheme 31. In the first step, chitosan nanoparticles/multiwalled carbon nanotubes (CS NPs/MWCNT, 139) were prepared by the addition of MWCNT-COOH to an acetic acid solution of chitosan (CS, 137). Subsequently, a solution of sodium tripolyphosphate (138) was added to the
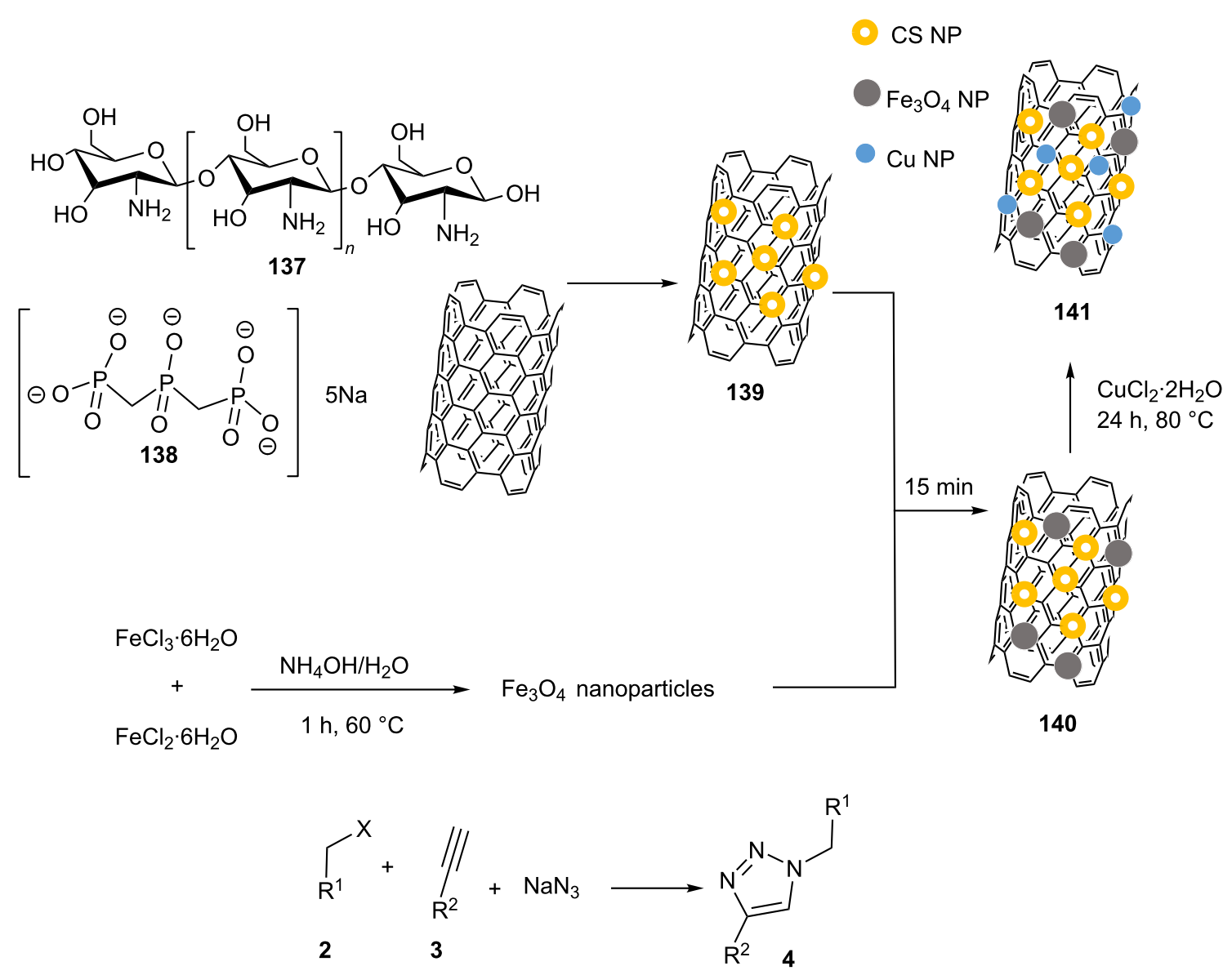

conditions for the triazole syntheses: $141(0.01 \mathrm{~g}), 70^{\circ} \mathrm{C}, \mathrm{H}_{2} \mathrm{O}$

reaction time: $30-120 \mathrm{~min}$, yield: $89-99 \%$

$\mathrm{X}=\mathrm{Br} ; \mathrm{R}^{1}=\mathrm{Ph}, 3-\mathrm{BrC}_{6} \mathrm{H}_{4}, 4-\mathrm{BrC}_{6} \mathrm{H}_{4}, 4-\mathrm{NO}_{2} \mathrm{C}_{6} \mathrm{H}_{4}, 4-\mathrm{MeC}_{6} \mathrm{H}_{4}, 3-\mathrm{IC}_{6} \mathrm{H}_{4}$

$\mathrm{R}^{2}=\mathrm{Ph}, 4-\mathrm{MeC}_{6} \mathrm{H}_{4}$ 
previous solution. After stirring for $5 \mathrm{~h}$, the mixture was sonicated at room temperature. The resulting nanomaterial was collected by centrifugation and rinsed with water. CS NPs/ MWCNT (139) was then added to sonicated $\mathrm{Fe}_{3} \mathrm{O}_{4}$ nanoparticles in water. The mixture was sonicated for $15 \mathrm{~min}$ at room temperature, and $\mathbf{1 4 0}$ was separated, washed with deionized water/ethanol, and dried. The material 140 was then sonicated in water for dispersion. An aqueous solution of $\mathrm{CuCl}_{2} \cdot 2 \mathrm{H}_{2} \mathrm{O}$ was added to the mixture and subsequently, ascorbic acid was applied. The resulting mixture was stirred at $80{ }^{\circ} \mathrm{C}$ for $24 \mathrm{~h}$. Finally, Cu-CS NPs/MWCNT@ $\mathrm{Fe}_{3} \mathrm{O}_{4}(\mathbf{1 4 1})$ was collected with a magnet and washed with deionized $\mathrm{H}_{2} \mathrm{O}$ /ethanol. Ultimately, the synthesized catalyst $\mathbf{1 4 1}$ was applied in the threecomponent synthesis of 1,2,3-triazole products in an aqueous solution at $70{ }^{\circ} \mathrm{C}$ (Scheme 31$)$.

8-Aminoquinoline (143) was immobilized on $\mathrm{Fe}_{3} \mathrm{O}_{4} @ \mathrm{SiO}_{2}$ functionalized with (3-glycidoxypropyl)trimethoxysilane (142) [101]. The supported quinoline ligand was used to coordinate copper ions. In this regard, (3-glycidoxypropyl)trimethoxysilane was added to a dispersed mixture of $\mathrm{Fe}_{3} \mathrm{O}_{4} @ \mathrm{SiO}_{2}$ in dry toluene, and this was heated at reflux for $72 \mathrm{~h}$. The resulting solid product was collected using a magnet. The obtained powdered material was washed with methanol and dried. The material 142 was dispersed in THF and then, 143 was added. The mixture was heated under reflux conditions for $24 \mathrm{~h}$ to afford aminoquinoline-functionalized ferrite (MNPs@FGly-8AQ). The MNPs@FGly-8-AQ material was collected from the reaction mixture. An aqueous solution of $\mathrm{Cu}(\mathrm{II})$ was added to dispersed MNPs@FGly-8-AQ in THF, and this was stirred for $24 \mathrm{~h}$. The synthesized material where $\mathrm{Cu}$ (II) ions were immobilized on 8-aminoquinoline-functionalized ferrite (MNPs@8-AQ· $\mathrm{CuCl}_{2}, \mathbf{1 4 4}$ ) was collected using a magnet and washed with methanol (Scheme 32).

MNPs@8-AQ· $\mathrm{CuCl}_{2}(\mathbf{1 4 4})$ has been applied as a recyclable and efficient nanocatalyst for the multicomponent one-pot synthesis of structurally diverse mono- and bistriazole products under green conditions. Reaction optimization result showed that a small amount of sodium ascorbate was needed to produce the desired triazoles. Although the reaction proceeded in the absence of an additive in water at $60{ }^{\circ} \mathrm{C}$, the surfactant SLS allowed for a lower reaction temperature and an increase of the reaction yield (Scheme 32). The reusability of the catalyst 144 was screened over five cycles of the synthesis of 1-benzyl-4phenyl-1H-1,2,3-triazole. Therein, the results indicated only a negligible decrease in the yield of the desired triazole.

A magnetic heterogeneous copper catalyst 149 was designed, and the material was prepared by supporting copper ions by polymer-functionalized $\mathrm{Fe}_{3} \mathrm{O}_{4}$ (Scheme 33) [102]. Therein, the

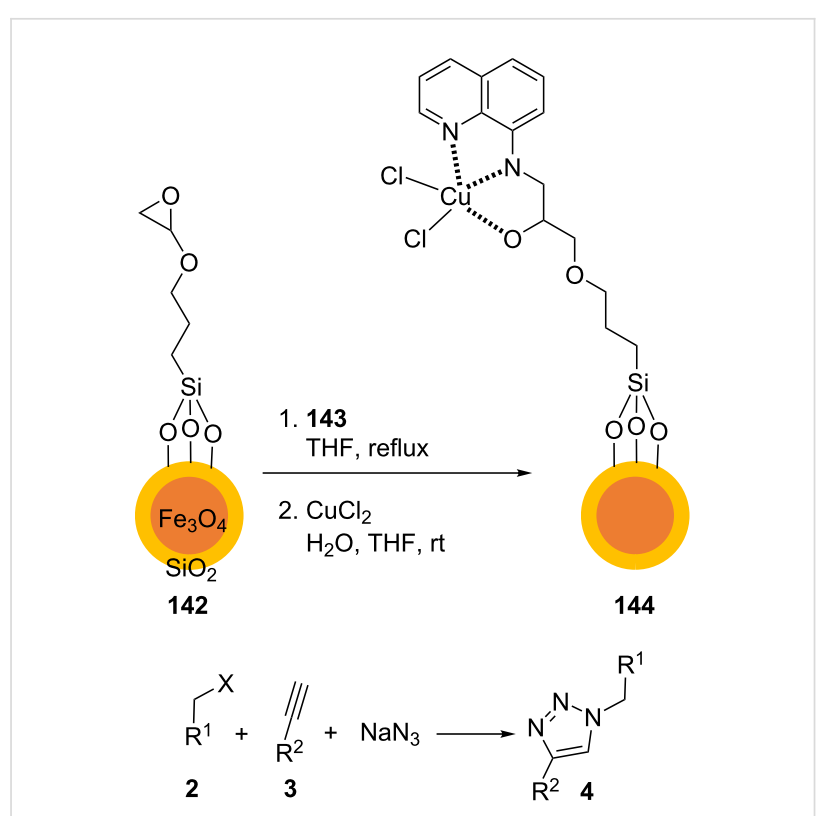

conditions for the triazole syntheses: $144(10 \mathrm{mg})$, sodium ascorbate (10 mol \%), sodium lauryl sulfosuccinate (SLS, $20 \mathrm{~mol} \%$ ), rt, $\mathrm{H}_{2} \mathrm{O}$ reaction time: $90-150 \mathrm{~min}$, yield: $85-98 \%$

$\mathrm{X}=\mathrm{Cl}, \mathrm{Br}$, OTs; $\mathrm{R}^{1}=$ aromatic/aliphatic groups

$\mathrm{R}^{2}=$ aromatic/aliphatic groups

Scheme 32: Synthetic route to the catalyst 144 and catalytic application of 144 in "click" reactions.

$\mathrm{SiO}_{2}$ shell was used to protect the $\mathrm{Fe}_{3} \mathrm{O}_{4}$ nanoparticles from agglomeration and oxidation. The surface of silica-coated $\mathrm{Fe}_{3} \mathrm{O}_{4}$ nanoparticles $\left(\mathrm{Fe}_{3} \mathrm{O}_{4} @ \mathrm{SiO}_{2} \mathrm{SMNP}\right.$ ) was modified with (3-mercaptopropyl)trimethoxysilane (145) to produce thiol-modified silica-coated magnetic nanoparticles (SMNP-SH, 146). Then, 146 was dispersed in ethanol with ultrasonication. Next, 4-vinylpyridine (147) and $N, N^{\prime}$-methylenebis(acrylamide) (MBA, 148) were added to the mixture, and this was stirred for $10 \mathrm{~min}$. Afterwards, ammonium persulfate (APS) was added, and the reaction mixture was heated at $60{ }^{\circ} \mathrm{C}$. The resulting product was magnetically collected, washed with ethanol and water, and dried. Subsequently, the synthesized material was ultrasonically dispersed in THF, and $\mathrm{CuCl}_{2}$ was added. Because of the presence of nitrogen-containing ligands, the polymer-functionalized $\mathrm{Fe}_{3} \mathrm{O}_{4}$ could immobilize copper ions. Finally, the catalyst $\mathbf{1 4 9}$ was collected with a magnet and dried before being used in reactions (Scheme 33).

A range of 1,4-disubstituted 1,2,3-triazole derivatives was prepared using $\mathrm{H}_{2} \mathrm{O} / t-\mathrm{BuOH}$ as the solvent system at $55^{\circ} \mathrm{C}$ and a catalytic amount of the catalyst 149 and alkyl halides, aryl/alkyl terminal alkynes, and sodium azide. The results showed that a small amount of sodium ascorbate was needed to reduce the oxidation state of the copper ions (Scheme 33). The catalyst 149 operated efficiently for nine circles in the Huisgen cycloaddi- 


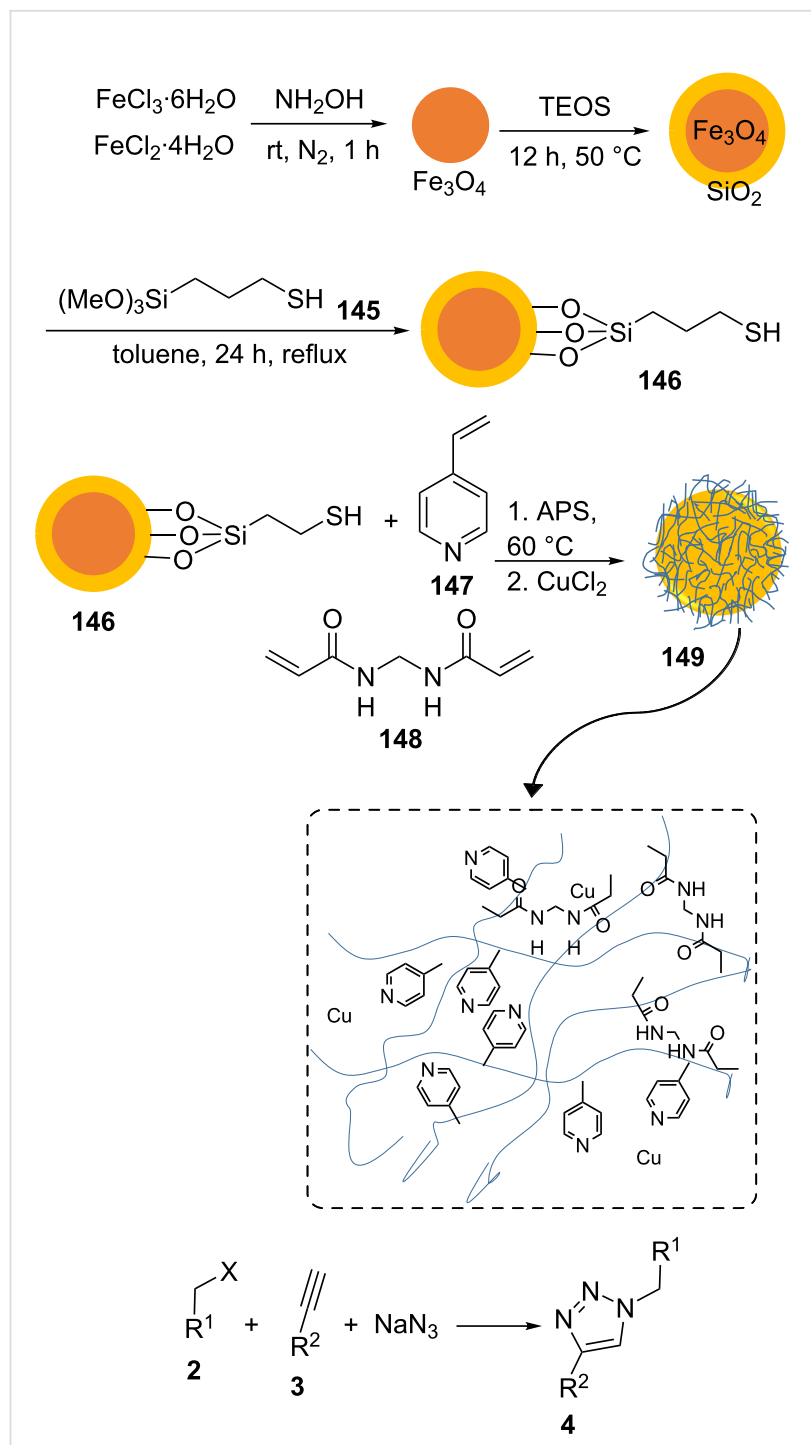

conditions for the triazole syntheses: $149(2.0 \mathrm{~mol} \%)$, sodium ascorbate $(10 \mathrm{~mol} \%), 55^{\circ} \mathrm{C}, \mathrm{H}_{2} \mathrm{O} / t-\mathrm{BuOH}, 4: 1$ reaction time: $3-7 \mathrm{~h}$, yield: $73-98 \%$

$\mathrm{X}=\mathrm{Cl}, \mathrm{Br}$, OTs; $\mathrm{R}^{1}=$ aromatic/aliphatic groups $\mathrm{R}^{2}=$ aromatic/aliphatic groups

Scheme 33: Synthetic route to the catalyst 149 and catalytic application of 149 in "click" reactions.

tion of phenylacetylene, benzyl bromide, and sodium azide without a considerable activity loss.

Shaabani and co-workers reported that copper supported on MWCNT-guanidine acetic acid@ $\mathrm{Fe}_{3} \mathrm{O}_{4}(\mathrm{Cu} / \mathrm{MWCNT}-\mathrm{GA}$ $\mathrm{A} @ \mathrm{Fe}_{3} \mathrm{O}_{4}, 152$ ) could be used as a catalyst for the "click" synthesis of triazole products [103]. In the synthesis of $\mathbf{1 5 2}$ (Scheme 34), thionyl chloride was used to convert MWCNT-COOH into the corresponding acid chloride. The reaction was stirred at reflux conditions for two days at $75{ }^{\circ} \mathrm{C}$.
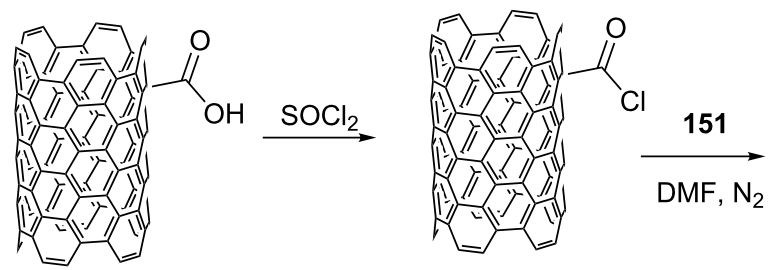

150

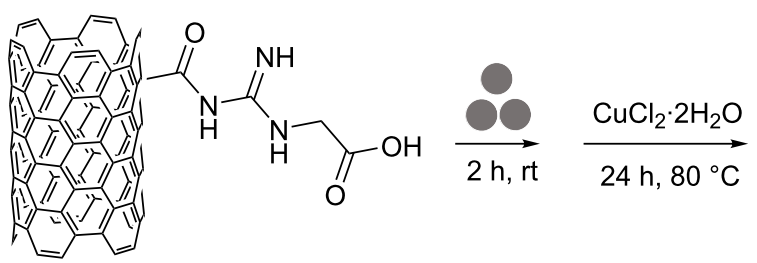

152
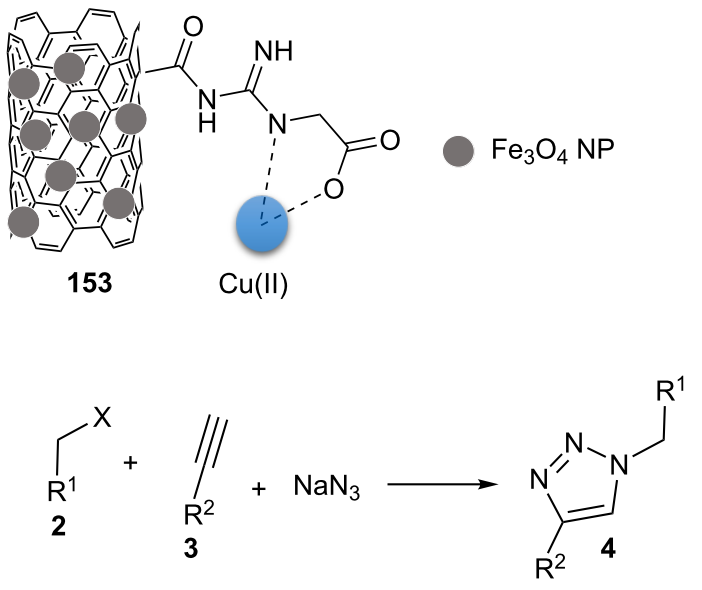

conditions for the triazole syntheses: 153 (0.4 mol \%),

$50{ }^{\circ} \mathrm{C}, \mathrm{H}_{2} \mathrm{O}$; reaction time:1-10 h, yield: $82-100 \%$ $\mathrm{X}=\mathrm{Br} ; \mathrm{R}^{1}=\mathrm{Ph}, 4-\mathrm{NO}_{2} \mathrm{C}_{6} \mathrm{H}_{4}, 3-\mathrm{IC}_{6} \mathrm{H}_{4}, 4-\mathrm{BrC}_{6} \mathrm{H}_{4}$, $2-\mathrm{MeC}_{6} \mathrm{H}_{4} ; \mathrm{R}_{2}=\mathrm{Ph}, 4-\mathrm{F}_{3} \mathrm{CC}_{6} \mathrm{H}_{4}, 4-\mathrm{MeC}_{6} \mathrm{H}_{4}, \mathrm{Me}_{2} \mathrm{NCH}_{2}$, $\mathrm{HOCMe}_{2}, \mathrm{HOCHPh}$

Scheme 34: Synthetic route to the catalyst 153 and catalytic application of 153 in "click" reactions.

Excess $\mathrm{SOCl}_{2}$ was removed, and MWCNT-COCl (150) was washed with anhydrous THF. Then, guanidine acetic acid (GAA, 151) was added to dispersed 150 in DMF, and this was stirred for $5 \mathrm{~h}$ at room temperature in an inert atmosphere. After evaporation of the solvent, the resulting solid was washed with acetone to yield MWCNT-GAA (152). A solution of $\mathrm{CuCl}_{2} \cdot 2 \mathrm{H}_{2} \mathrm{O}$ in water was added dropwise to dispersed 152 in water. Then, ascorbic acid was added, and the reaction mixture was stirred at $80{ }^{\circ} \mathrm{C}$ for $24 \mathrm{~h}$. After evaporation of the solvent, the precipitate was washed with deionized water and ethanol and dried to afford Cu/MWCNT-GAA (153). Species 153 was also prepared in situ: For this, 152 was added to dispersed 
$\mathrm{Fe}_{3} \mathrm{O}_{4}$ nanoparticles in water. The mixture was sonicated at room temperature for $2 \mathrm{~h}$. Subsequently, an aqueous solution of $\mathrm{CuCl}_{2} \cdot 2 \mathrm{H}_{2} \mathrm{O}$ was added to the mixture and then, ascorbic acid was added. After stirring at $80{ }^{\circ} \mathrm{C}$ for $24, \mathrm{Cu} /$ MWCNT-GAA@ $\mathrm{Fe}_{3} \mathrm{O}_{4}$ (153) was magnetically collected. The magnetic precipitate was washed with deionized water/ethanol and dried before being used in reactions (Scheme 34).

A low catalytic loading of $\mathbf{1 5 3}(0.4 \mathrm{~mol} \%)$ was required to afford 1,2,3-triazoles in a one-pot three-component reaction of aromatic/aliphatic alkynes, alkyl halides, and sodium azide in water at $50{ }^{\circ} \mathrm{C}$. The catalyst $\mathbf{1 5 3}$ was magnetically recovered from the mixture and recycled for subsequent reactions.

The magnetic core-shell material nanoFe ${ }_{3} \mathrm{O}_{4} @ \mathrm{TiO}_{2} / \mathrm{Cu}_{2} \mathrm{O}$ (155) was designed and constructed according to the procedure listed in Scheme 34 [104]. An aqueous ammonia solution was added to dispersed $\mathrm{Fe}_{3} \mathrm{O}_{4}$ nanoparticles in a mixture of absolute ethanol and acetonitrile. The resulting mixture was stirred for $30 \mathrm{~min}$, and an ethanol solution of tetrabutyl titanate (TBOT) was added dropwise to the above mixture under stirring at $30{ }^{\circ} \mathrm{C}$. The stirring was continued for $1.5 \mathrm{~h}$ to yield the core-shell nanoparticles $\mathrm{Fe}_{3} \mathrm{O}_{4} @ \mathrm{TiO}_{2}$ (154). The solid product was magnetically collected and washed with absolute ethanol. Following this, an aqueous solution of $\mathrm{CuCl}_{2}$ was added to $\mathbf{1 5 4}$ dispersed in water and then, an aqueous solution of $\mathrm{NaOH}$ was added dropwise under ultrasonication to obtain $\mathrm{Cu}(\mathrm{OH})_{2} \cdot \mathrm{NH}_{2} \mathrm{OH} \cdot \mathrm{HCl}$, which was immediately added to the previous solution over $5 \mathrm{~s}$. After $1 \mathrm{~h}$, the mixture was centrifuged. Finally, the top layer was decanted and the solid product was washed using water/ethanol to afford brown nanoFe $\mathrm{O}_{4} @ \mathrm{TiO}_{2} / \mathrm{Cu}_{2} \mathrm{O}(\mathbf{1 5 5})$.

The core-shell composite $\mathbf{1 5 5}$ was used as a nanomagnetic catalyst for the regioselective synthesis of 1,2,3-triazole products. A series of 1,4-disubstituted 1,2,3-triazoles was obtained through the one-pot three-component reaction of nonactivated aryl/alkyl alkynes, alkyl halides, and sodium azide using $0.02 \mathrm{~g}$ of the catalyst in $\mathrm{H}_{2} \mathrm{O}$ under reflux conditions (Scheme 35).

The nanomagnetic catalyst $\mathbf{1 5 5}$ could be kept in a tightly closed vessel for several months without any decrease in activity, without any color change, and was reused four times without suffering from activity loss.

Moghaddam et al. immobilized a $\mathrm{Cu}-1,2,3$-triazole complex on magnetic nanoparticles coated with silica (157) as a nanostructured heterogeneous catalyst [105]. The catalyst $\mathbf{1 5 7}$ was constructed in multiple steps, as shown in Scheme 36. First, 3-glycidoxypropyltrimethoxysilane on $\mathrm{Fe}_{3} \mathrm{O}_{4} @ \mathrm{SiO}_{2}, \mathbf{1 5 6}$, was formed using the reaction between $\mathrm{Fe}_{3} \mathrm{O}_{4} @ \mathrm{SiO}_{2}$ magnetic

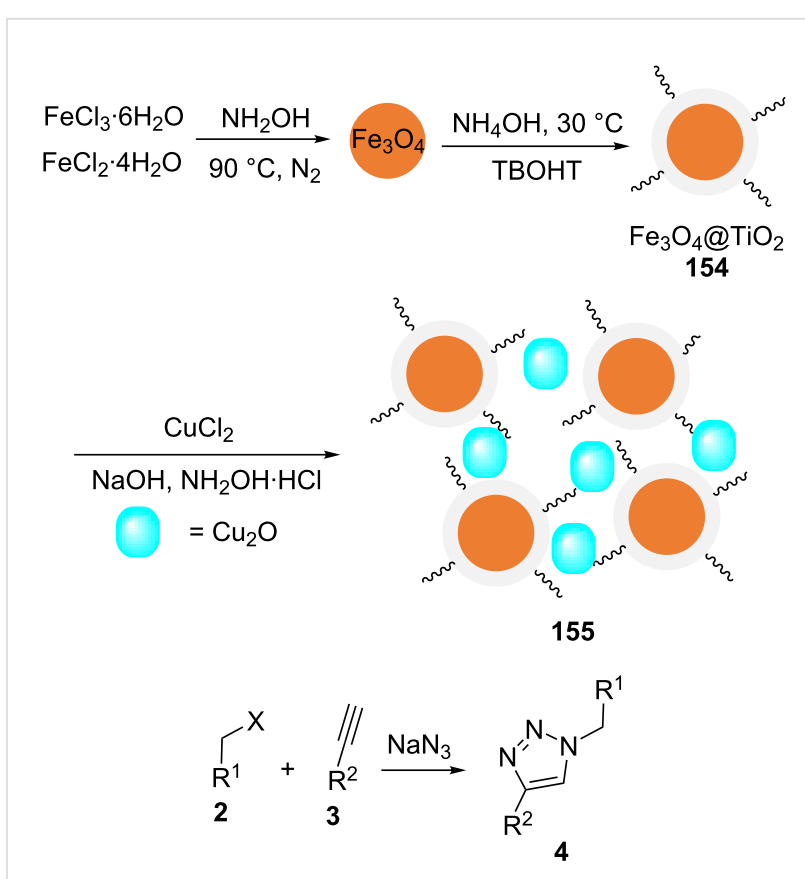

conditions for the triazole syntheses: $155(0.02 \mathrm{~g})$, reflux, $\mathrm{H}_{2} \mathrm{O}$ reaction time: $15-80 \mathrm{~min}$, yield: $75-93 \%$

$\mathrm{X}=\mathrm{Cl}, \mathrm{Br} ; \mathrm{R}^{1}=\mathrm{Ph}, 4-\mathrm{MeC}_{6} \mathrm{H}_{4}, 4-\mathrm{NO}_{2} \mathrm{C}_{6} \mathrm{H}_{4}$, $\mathrm{PhCO}, 4-\mathrm{BrC}_{6} \mathrm{H}_{3} \mathrm{CO}, 4-\mathrm{ClC}_{6} \mathrm{H}_{3} \mathrm{CO}, 4-\mathrm{MeC}_{6} \mathrm{H}_{3} \mathrm{CO}$ $\mathrm{R}^{2}=\mathrm{Ph}, \mathrm{CH}_{2} \mathrm{OH}, \mathrm{HOCMe}_{2}$

Scheme 35: Synthetic route to the catalyst 155 and catalytic application of 155 in "click" reactions.

nanoparticles and 3-glycidoxypropyltrimethoxysilane in refluxing toluene for $48 \mathrm{~h}$. The solid product was then washed with methanol and dried. In the next step, these modified magnetic nanoparticles and phenylacetylene were added to a mixture of copper(II) chloride, sodium ascorbate, and sodium azide dissolved in a THF/water mixture. This was heated at $60{ }^{\circ} \mathrm{C}$ for $10 \mathrm{~h}$ while stirring. The resulting nanomaterial 157 was collected using an external magnet, washed with methanol, and dried. Aryl-/alkylacetylenes, alkyl halides, and sodium azide, the catalyst, and monosodium ascorbate as well as a mixture of $\mathrm{H}_{2} \mathrm{O}$ and $t-\mathrm{BuOH}$ as the solvent were added to a glass tube and heated at $55^{\circ} \mathrm{C}$ for $4 \mathrm{~h}$ while stirring (Scheme 36).

In the synthetic route outlined above, no column chromatography was required, and the "click" products were purified by recrystallization from ethyl acetate/ $n$-hexane. A magnet was applied to recover the catalyst $\mathbf{1 5 7}$ from the reaction mixture, and the catalyst showed good reusability in these Huisgen cycloaddition reactions.

1,4-Disubstituted ß-hydroxy-1,2,3-triazoles were synthesized via a novel one-pot reaction between aliphatic/aromatic epoxides, aliphatic/aromatic alkynes, and $\mathrm{NaN}_{3}$ in water at $60{ }^{\circ} \mathrm{C}$ 

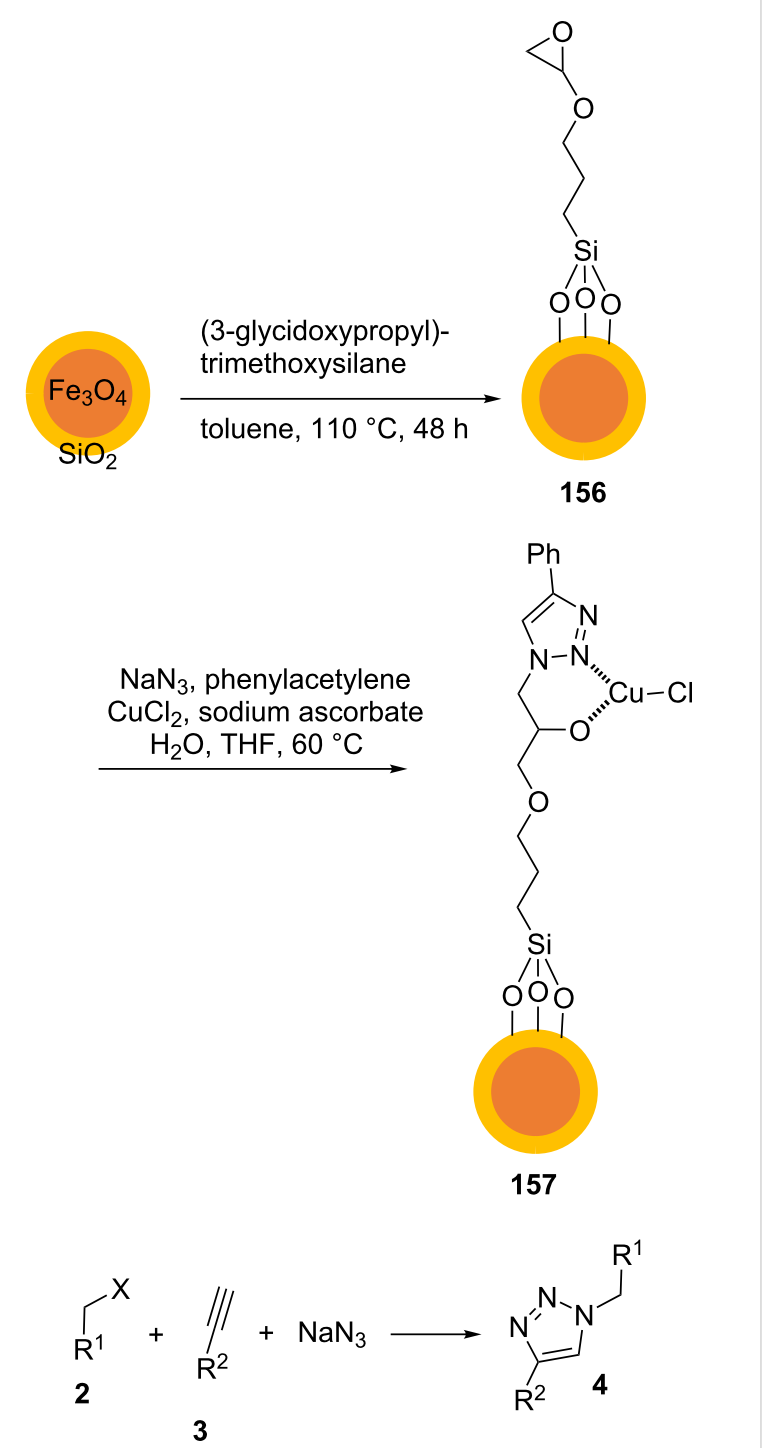

conditions for the triazole syntheses: $157(0.5 \mathrm{~mol} \%)$, sodium ascorbate $(10 \mathrm{~mol} \%), 55^{\circ} \mathrm{C}, \mathrm{H}_{2} \mathrm{O} / t-\mathrm{BuOH}$ (3:1); reaction time: $2-7 \mathrm{~h}$, yield: $85-97 \%$ $\mathrm{X}=\mathrm{Cl}, \mathrm{Br}$, OTs; $\mathrm{R}^{1}=$ aromatic/aliphatic groups $\mathrm{R}^{2}=$ aromatic/aliphatic groups

Scheme 36: Synthetic route to the catalyst 157 and catalytic application of 157 in "click" reactions.

using magnetic $\mathrm{CuFe}_{2} \mathrm{O}_{4}$ nanoparticles [106]. This procedure involved a reusable magnetic nanocatalyst, aqueous medium, no additives, and no requirement for the handling of organic azides as these were formed in situ during the reactions.

A nanomagnetic biocatalyst was prepared using isinglass (IG) as an attractive biopolymer [107]. IG consists predominantly of the protein collagen. The presence of various residues, includ- ing leucine, tyrosine, threonine, alanine, valine, hydroxyproline, proline, serine, arginine, aspartic acid, histidine, glycine, glutamic acid, phenylalanine, hydroxylysine, methionine, isoleucine, and lysine on the surface of IG renders it a natural, low-cost, and eco-friendly material for the coordination of metal ions.

IG was washed, dried, and ground in a ball mill machine. The obtained powder and $\mathrm{Fe}_{3} \mathrm{O}_{4}$ nanoparticles were treated using glutaraldehyde (GA) to form the magnetic isinglass nanoparticles IG@ $@ \mathrm{Fe}_{3} \mathrm{O}_{4}$. Then, IG@ $@ \mathrm{Fe}_{3} \mathrm{O}_{4}$ and $\mathrm{Cu}(\mathrm{OAc})_{2}$ were reacted in water at $\mathrm{rt}$ for $8 \mathrm{~h}$. Finally, the $\mathrm{Cu}-\mathrm{IG} @ \mathrm{Fe}_{3} \mathrm{O}_{4}$ nanocatalyst was washed with water, ethanol, and acetone and dried. The synthesized nanocatalyst was applied for the "click" synthesis of triazoles from organic halides, organic alkynes, and sodium azide using $\mathrm{K}_{2} \mathrm{CO}_{3}$ in water at $70{ }^{\circ} \mathrm{C}$. The reusability of the magnetic material $\mathrm{Cu}-\mathrm{IG} @ \mathrm{Fe}_{3} \mathrm{O}_{4}$ was analyzed, confirming good reusability. The $\mathrm{Cu}-\mathrm{IG} @ \mathrm{Fe}_{3} \mathrm{O}_{4}$ nanocatalyst could be separated from the reaction mixture using a magnet and was recycled for use in five reactions.

A practical, efficient, and simple strategy for the immobilization of $\mathrm{Cu}(\mathrm{II})$ on functionalized $\gamma-\mathrm{Fe}_{2} \mathrm{O}_{3} @ \mathrm{TiO}_{2}(\mathbf{1 6 2})$ and the application of $\mathbf{1 6 2}$ in the synthesis of 1,2,3-triazole derivatives substituted at the 1- and 4-position was described [108]. An aqueous solution of $\mathrm{FeCl}_{3} \cdot 6 \mathrm{H}_{2} \mathrm{O}$ and $\mathrm{FeCl}_{2} \cdot 4 \mathrm{H}_{2} \mathrm{O}$ was magnetically stirred in deionized water under an argon atmosphere at room temperature for $5 \mathrm{~min}$. Afterwards, titanium tetrachloride was added to this solution. The $\mathrm{pH}$ value was increased to 9 by adding a $\mathrm{NH}_{4} \mathrm{OH}$ solution while stirring at ambient temperature. Then, deionized water was added for dilution of the mixture. After vigorously stirring at $50{ }^{\circ} \mathrm{C}$ for $30 \mathrm{~min}$, the magnetic nanoparticles were collected from the solution. The particles were washed with deionized water, crushed, calcinated at $400{ }^{\circ} \mathrm{C}$ for $60 \mathrm{~min}$ under an argon atmosphere, and then calcinated at $250{ }^{\circ} \mathrm{C}$ for $2 \mathrm{~h}$ under an oxygen atmosphere to obtain 162. The material 162 was dispersed in epibromohydrin (E, 158) using sonication, and this was stirred at $60{ }^{\circ} \mathrm{C}$ for $24 \mathrm{~h}$ to afford $\gamma-\mathrm{Fe}_{2} \mathrm{O}_{3} @ \mathrm{TiO}_{2}-\mathrm{E}$ (159). The obtained material was separated using an external magnet and washed with $\mathrm{MeOH}$. Sodium bicarbonate and guanidine hydrochloride (160) were added to $\mathbf{1 5 9}$ dispersed in dry toluene. The mixture was heated at reflux for 2 days and then, the guanidinated epibromohydrinfunctionalized compound $\gamma-\mathrm{Fe}_{2} \mathrm{O}_{3} @ \mathrm{TiO}_{2}-\mathrm{EG}$ (161) was magnetically collected, washed with dry dichloromethane, and dried. The material 161 was added to an EtOH solution of $\mathrm{Cu}(\mathrm{OAc})_{2} \cdot \mathrm{H}_{2} \mathrm{O}$, and this was stirred for $4 \mathrm{~h}$ under an argon atmosphere. $\mathrm{Cu}$ (II) supported on guanidinated epibromohydrinfunctionalized $\gamma-\mathrm{Fe}_{2} \mathrm{O}_{3} @ \mathrm{TiO}_{2}, \gamma-\mathrm{Fe}_{2} \mathrm{O}_{3} @ \mathrm{TiO}_{2}-\mathrm{EG}-\mathrm{Cu}(\mathrm{II})$ (162), was collected, washed with acetone and ethanol, and dried (Scheme 37). 


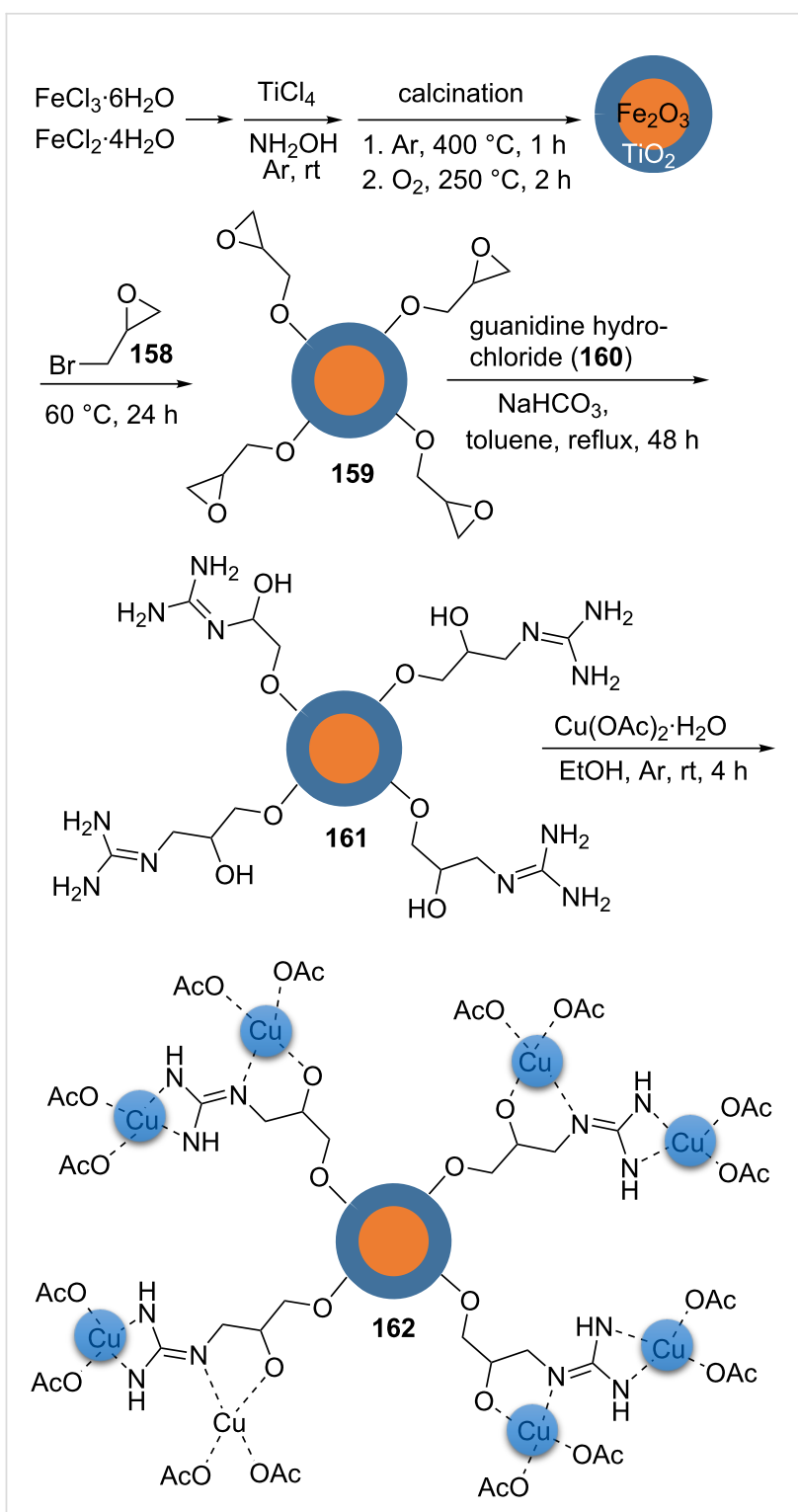

Scheme 37: Synthetic route to the catalyst 162.

The catalyst displayed robust catalytic activity in the synthesis of triazole derivatives via "click" reactions. A variety of terminal alkyl/aryl alkynes was treated with organic halides and sodium azide in water at $50{ }^{\circ} \mathrm{C}$ using $4 \mathrm{~mol} \%$ of the catalyst to generate the corresponding 1,2,3-triazole products substituted at the 1- and 4-position (Scheme 38).

The magnetic nanocatalyst $\mathbf{1 6 2}$ was easily recycled using an external magnet, and could be reused in six consecutive cycles applying the mentioned reaction conditions, without considerable loss of catalytic activity.

The $\mathrm{Fe}_{3} \mathrm{O}_{4}$-supported thiourea-copper(I) complex 167 was designed and prepared as a new magnetically separable material

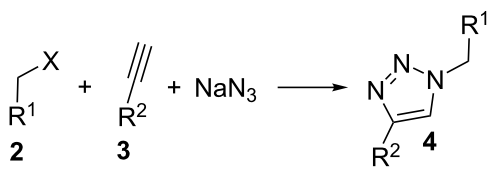

conditions for the triazole syntheses: $162(4.0 \mathrm{~mol} \%), 50^{\circ} \mathrm{C}, \mathrm{H}_{2} \mathrm{O}$ reaction time: $5-75 \mathrm{~min}$, yield: $85-97 \%$

$\mathrm{X}=\mathrm{Br} ; \mathrm{R}^{1}=\mathrm{Ph}, 4-\mathrm{ClC}_{6} \mathrm{H}_{4}, 4-\mathrm{NO}_{2} \mathrm{C}_{6} \mathrm{H}_{4}, \mathrm{CH}_{2} \mathrm{CH}$

$\mathrm{R}^{2}=\mathrm{Ph}, 4-\mathrm{MeC}_{6} \mathrm{H}_{4}, 4-t-\mathrm{BuC}_{6} \mathrm{H}_{4}, 4-\mathrm{ClC}_{6} \mathrm{H}_{4}, 4-\mathrm{BrC}_{6} \mathrm{H}_{4}$, 4- $\mathrm{NO}_{2} \mathrm{C}_{6} \mathrm{H}_{4}$, 2-pyridine, 4- $\mathrm{MeOC}_{6} \mathrm{H}_{4}$

Scheme 38: Application of the catalyst 162 in "click" reactions.

[109]. Initially, $\mathbf{1 6 4}$ was created as shown in Scheme 39. In the next step, isothiocyanate 165 and 164 were reacted in dry dichloromethane in the presence of DBU at $0{ }^{\circ} \mathrm{C}$ for $20 \mathrm{~min}$. Then, 166 was obtained by shaking the mixture for $24 \mathrm{~h}$. The obtained solid 166 was washed with dry dichloromethane and dried. 166 was dispersed in dry dichloromethane and then, $\mathrm{CuI}$ as a copper source was added. After shaking under an argon atmosphere for 2 days, the final material 167 was separated using a magnet and washed with absolute ethanol.

The supported thiourea-copper(I) catalyst $\mathbf{1 6 7}$ exhibited an excellent catalytic activity in the synthesis of triazole derivatives through the "click" reaction of halides, alkynes, and sodium azide in water at room temperature (Scheme 39).

Shaabani et al. reported magnetic casein as a biosolid to support copper(I) oxide nanoparticles [110]. To immobilize copper(I) oxide nanoparticles on magnetic casein, casein (168) was stirred in water for $5 \mathrm{~min}$. In the next step, an aqueous solution of $\mathrm{FeCl}_{2} \cdot 4 \mathrm{H}_{2} \mathrm{O} / \mathrm{FeCl}_{3} \cdot 6 \mathrm{H}_{2} \mathrm{O}$ was added to the previous solution, and the reaction mixture was subsequently heated to $80{ }^{\circ} \mathrm{C}$ for $1 \mathrm{~h}$. The $\mathrm{pH}$ value of the solution was adjusted to $8-9$ by the dropwise addition of an aqueous ammonia solution (25\%). Casein (168), as a biosolid, was dissolved in the previous solution and continuously stirred at $80{ }^{\circ} \mathrm{C}$ for $1 \mathrm{~h}$. After cooling, an aqueous solution of $\mathrm{CuCl}_{2} \cdot 2 \mathrm{H}_{2} \mathrm{O}$ was slowly added to the reaction mixture. Then, an aqueous solution of $\mathrm{HCl}$ was used to neutralize the reaction mixture. Subsequently, an aqueous solution of ascorbic acid was added to this. The mixture was heated to $80{ }^{\circ} \mathrm{C}$ under continuous stirring for $24 \mathrm{~h}$. The magnetic nanoparticles $\mathrm{Cu}_{2} \mathrm{O} /$ casein $@ \mathrm{Fe}_{3} \mathrm{O}_{4}(\mathbf{1 6 9})$ were collected with a magnet, washed with deionized water and ethanol, and dried (Scheme 40).

The 1,4-disubstituted 1,2,3-triazole products were obtained with excellent yields in a regioselective manner using an aqueous medium (Scheme 40). The recyclability of the magnetic catalyst $\mathrm{Cu}_{2} \mathrm{O} /$ casein@ $\mathrm{Fe}_{3} \mathrm{O}_{4}(\mathbf{1 6 9})$ was examined as well. After each cycle, the catalyst was easily recovered, washed with 


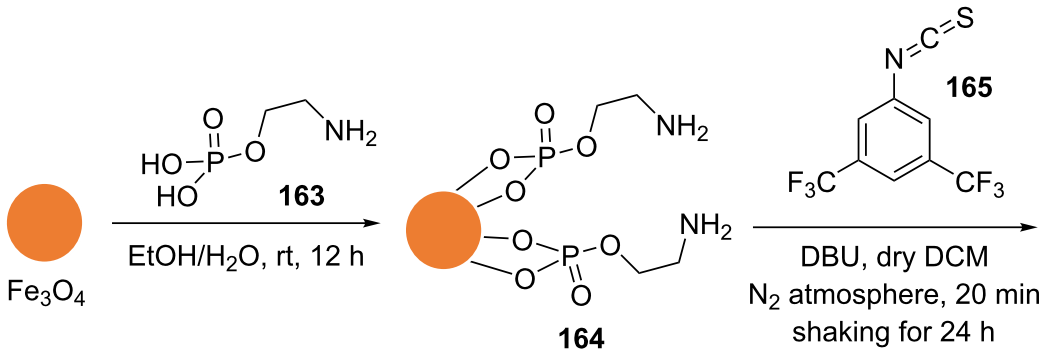<smiles>O=P1(OCCNC(=S)Nc2cc(C(F)(F)F)cc(C(F)(F)F)c2)OC2CCCC(O1)C1OP(=O)(OCCNC(=S)Nc3cc(C(F)(F)F)cc(C(F)(F)F)c3)OP1(=O)O2</smiles>

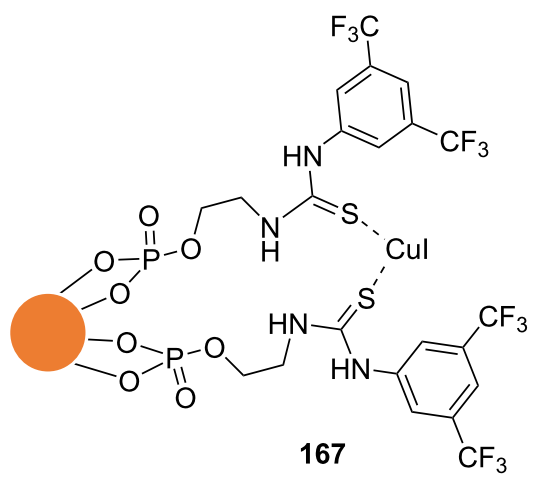

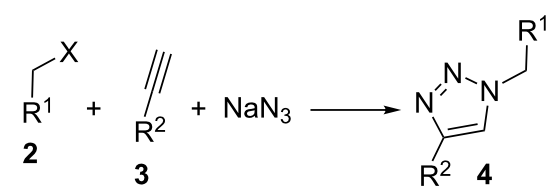

conditions for the triazole syntheses: $167(0.02 \mathrm{~g}), \mathrm{rt}, \mathrm{H}_{2} \mathrm{O}$

reaction time: $0.5-7 \mathrm{~h}$, yield: $85-92 \%$

$\mathrm{X}=\mathrm{Cl}, \mathrm{Br} ; \mathrm{R}^{1}=\mathrm{Ph}, 4-\mathrm{NO}_{2} \mathrm{C}_{6} \mathrm{H}_{4}, \mathrm{MeCH}_{2} \mathrm{CO}_{2}, \mathrm{H}_{2} \mathrm{NCO}$

$\mathrm{R}^{2}=\mathrm{Ph}, 4-\mathrm{MeOC}_{6} \mathrm{H}_{4}, \mathrm{CO}_{2} \mathrm{Et}, \mathrm{C}_{5} \mathrm{H}_{11}$

Scheme 39: Synthetic route to the catalyst 167 and catalytic application of 167 in "click" reactions

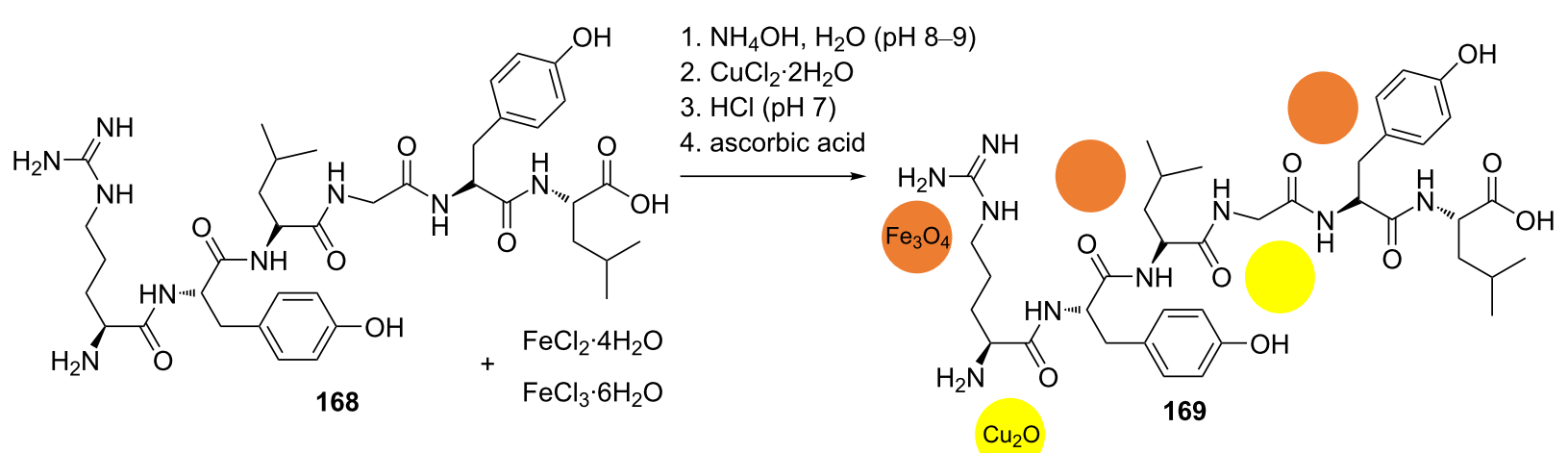

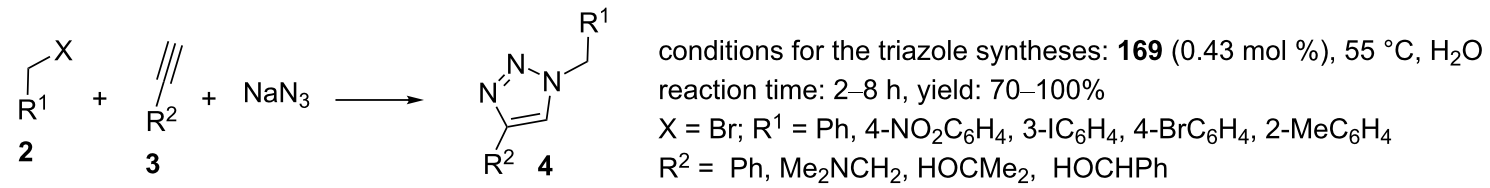

Scheme 40: Synthetic route to the catalyst 169 and catalytic application of 169 in "click" reactions. 
chloroform, and dried before being used in the next cycle. This process was carried out at least three times without any significant decrease in catalytic activity.

Nemati et al. synthesized a modified cellulose-based nanomagnetite composite to support copper(I) iodide [111] Cellulose- $\mathrm{NH}_{2}$ (171) was prepared by the reaction of microcrystals of cellulose (170) with APTES in anhydrous dimethylformamide by stirring at room temperature for $2 \mathrm{~h}$. The material 171 was gathered by centrifugation and washed with anhydrous DMF. The magnetic nanoparticles $\mathrm{Fe}_{3} \mathrm{O}_{4} @$ @cellulose- $\mathrm{NH}_{2}-\mathrm{CuI}(\mathbf{1 7 2})$ were produced by the addition of an aqueous solution of amino-functionalized cellulose, 171, to an aqueous mixture of the magnetic $\mathrm{Fe}_{3} \mathrm{O}_{4}$ nanoparticles and copper iodide. The resulting mixture was magnetically stirred under a nitrogen atmosphere at $80{ }^{\circ} \mathrm{C}$ for $5 \mathrm{~h}$. The resulting solid 172 was magnetically collected, washed with water, and dried (Scheme 41).
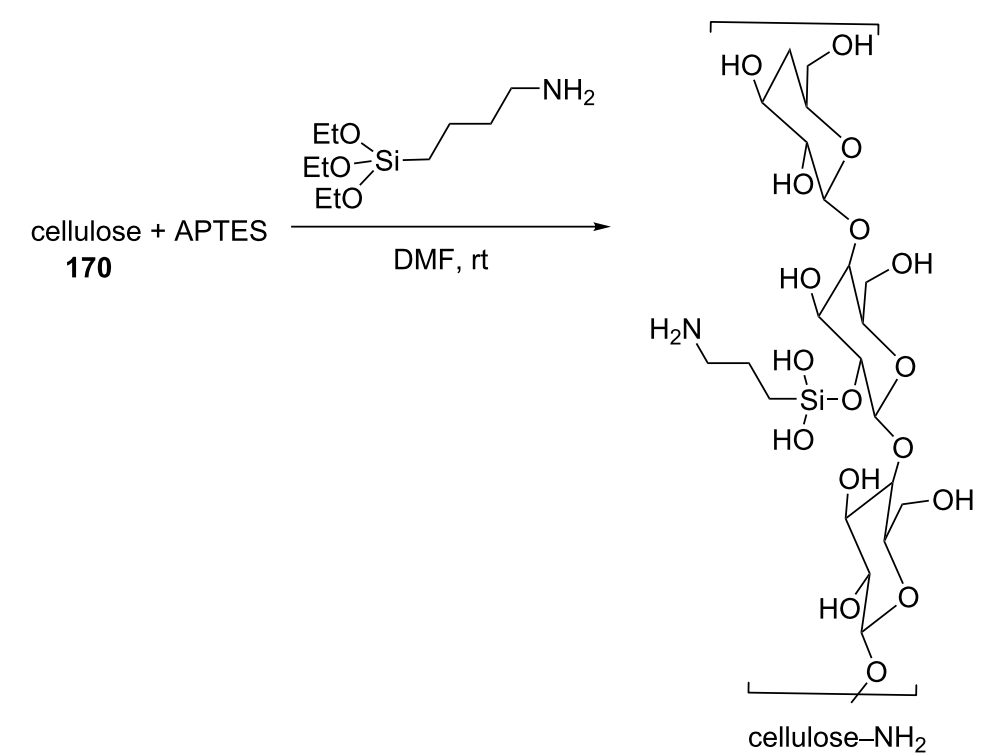

171

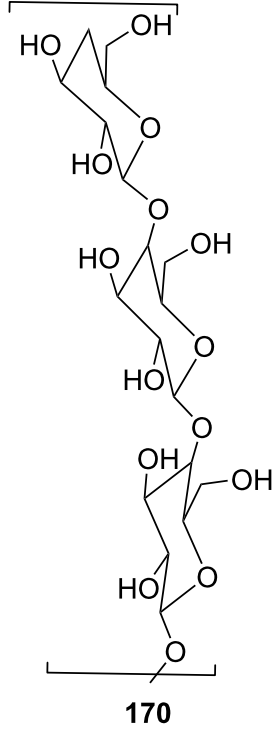

170

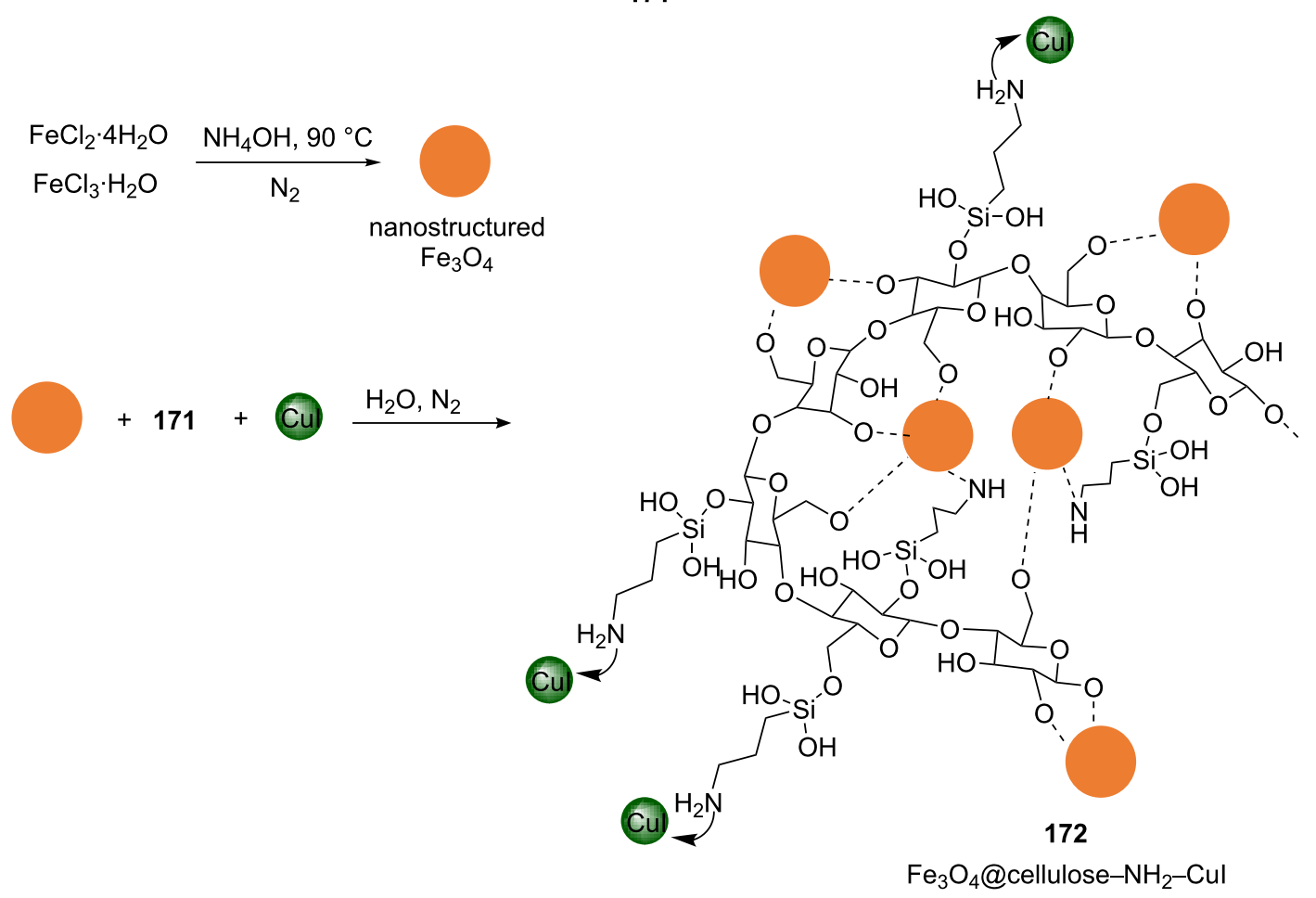

Scheme 41: Synthetic route to the catalyst 172. 
The magnetic nanoparticles $\mathbf{1 7 2}$ were applied in the multicomponent reaction of a range of substituted propargylic alcohols or phenylacetylenes, different benzyl halides, and sodium azide to regioselectivity obtain the desired 1,2,3-triazole derivatives substituted at the 1- and 4-positions in an aqueous medium with high yields (Scheme 42).

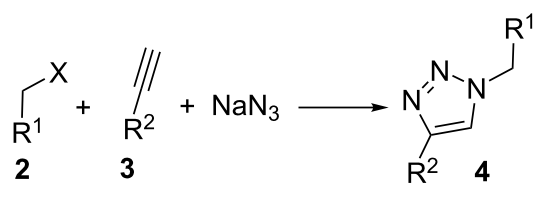

conditions for the triazole syntheses: $172(0.01 \mathrm{~g})$, reflux, $\mathrm{H}_{2} \mathrm{O}$ reaction time: $20-180 \mathrm{~min}$, yield: $66-95 \%$

$\mathrm{X}=\mathrm{Cl}, \mathrm{Br}, \mathrm{I} ; \mathrm{R}_{1}=\mathrm{Ph}, 4-\mathrm{NO}_{2} \mathrm{C}_{6} \mathrm{H}_{4}, 4-\mathrm{MeC}_{6} \mathrm{H}_{4}, 4-\mathrm{ClC}_{6} \mathrm{H}_{4}, \mathrm{H}$

$\mathrm{R}^{2}=\mathrm{Ph}, 4-\mathrm{MeC}_{6} \mathrm{H}_{4}, \mathrm{CH}_{2} \mathrm{OH}, \mathrm{C}(\mathrm{Me})_{2} \mathrm{OH}$

Scheme 42: Application of the catalyst 172 in "click" reactions.

To determine the reusability of the magnetic ctalyst $\mathrm{Fe}_{3} \mathrm{O}_{4} @$ cellulose- $\mathrm{NH}_{2}-\mathrm{CuI}$ (172), the compound was used for several cycles in the synthesis of 1-benzyl-4-phenyl-1H-1,2,3triazole derivatives. After the first "click" reaction, the magnetic catalyst was simply recovered with an external magnet and washed with water and ethyl acetate, respectively. The magnetic nanocatalyst could be recycled at least four times with only negligible change in its catalytic activity.

\section{Conclusion}

As emphasized in this review article, a wide variety of functionalized silica/carbon/magnetic material-based supports and their catalytic application in Sharpless-Meldal C-N bond-forming reactions are reported in the literature. The functionalized silica/ carbon/magnetic material-based supports demonstrated usefulness in catalysis owing to their diverse structures, chemical/ thermal/mechanical stability, facile synthesis, and reusability as well as low toxicity and, in some cases, porous structures and uniform pore sizes. Moreover, from economic and environmental perspectives, these nanocatalysts have advantages over other heterogeneous and homogeneous nanocatalysts. There are a variety of possibilities in this area that require the design and synthesis of ligands and inorganic supports. This review should serve as a starting point for further syntheses of a variety of highly active copper-supporting materials.

\section{ORCID ${ }^{\circledR}$ iDs}

Pezhman Shiri - https://orcid.org/0000-0003-0071-6570

\section{References}

1. Sharghi, H.; Aboonajmi, J.; Aberi, M.; Shekouhy, M. Adv. Synth. Catal. 2020, 362, 1064-1083. doi:10.1002/adsc.201901096

2. Yadav, P.; Lal, K.; Kumar, L.; Kumar, A.; Kumar, A.; Paul, A. K.; Kumar, R. Eur. J. Med. Chem. 2018, 155, 263-274. doi:10.1016/j.ejmech.2018.05.055

3. Pandeya, S. N.; Sriram, D.; Nath, G.; de Clercq, E. Arzneim. Forsch. 2000, 50, 55-59. doi:10.1055/s-0031-1300164

4. Kumar, R.; Yar, M. S.; Chaturvedi, S.; Srivastava, A. Int. J. PharmTech Res. 2013, 5, 1844-1869.

5. Lee, Y.-S.; Kim, B. H. Bioorg. Med. Chem. Lett. 2002, 12, 1395-1397. doi:10.1016/s0960-894x(02)00182-8

6. Al-Harbi, N. O.; Bahashwan, S. A.; Fayed, A. A.; Aboonq, M. S.; Amr, A. E.-G. E. Int. J. Biol. Macromol. 2013, 57, 165-173. doi:10.1016/j.ijbiomac.2013.03.019

7. Martorana, A.; Giacalone, V.; Bonsignore, R.; Pace, A.; Gentile, C.; Pibiri, I.; Buscemi, S.; Lauria, A.; Palumbo Piccionello, A. Curr. Pharm. Des. 2016, 22, 3971-3995. doi:10.2174/1381612822666160518141650

8. Boros, F. A.; Klivényi, P.; Toldi, J.; Vécsei, L. Expert Opin. Ther. Targets 2019, 23, 39-51. doi:10.1080/14728222.2019.1549231

9. Chen, M.; Lu, S.; Yuan, G.; Yang, S.; Du, X. Heterocycl. Commun. 2000, 6, 421-426. doi:10.1515/hc.2000.6.5.421

10. Mashayekh, K.; Shiri, P. ChemistrySelect 2019, 4, 13459-13478. doi:10.1002/slct.201902362

11. Kolb, H. C.; Sharpless, K. B. Drug Discovery Today 2003, 8, 1128-1137. doi:10.1016/s1359-6446(03)02933-7

12. Himo, F.; Lovell, T.; Hilgraf, R.; Rostovtsev, V. V.; Noodleman, L.; Sharpless, K. B.; Fokin, V. V. J. Am. Chem. Soc. 2005, 127, 210-216. doi:10.1021/ja0471525

13. Zhang, L.; Chen, X.; Xue, P.; Sun, H. H. Y.; Williams, I. D.; Sharpless, K. B.; Fokin, V. V.; Jia, G. J. Am. Chem. Soc. 2005, 127, 15998-15999. doi:10.1021/ja054114s

14. Wu, P.; Fokin, V. V. Aldrichimica Acta 2007, 40, 7-17.

15. Chan, T. R.; Hilgraf, R.; Sharpless, K. B.; Fokin, V. V. Org. Lett. 2004, 6, 2853-2855. doi:10.1021/ol0493094

16. Hein, J. E.; Fokin, V. V. Chem. Soc. Rev. 2010, 39, 1302-1315. doi:10.1039/b904091a

17. Khalili, D.; Evazi, R.; Neshat, A.; Aboonajmi, J.; Osanlou, F. Inorg. Chim. Acta 2020, 506, 119470. doi:10.1016/j.ica.2020.119470

18. Sharghi, H.; Aberi, M.; Doroodmand, M. M.; Shiri, P. J. Iran. Chem. Soc. 2017, 14, 1557-1573. doi:10.1007/s13738-017-1097-x

19. Sharghi, H.; Aboonajmi, J.; Aberi, M.; Shiri, P. J. Iran. Chem. Soc. 2018, 15, 1107-1118. doi:10.1007/s13738-018-1308-0

20. Sharghi, H.; Aberi, M.; Shiri, P. Appl. Organomet. Chem. 2019, 33, No. e4974. doi:10.1002/aoc.4974

21. Rajabzadeh, M.; Khalifeh, R.; Eshghi, H.; Sorouri, M. Catal. Lett. 2019, 149, 1125-1134. doi:10.1007/s10562-019-02666-1

22. Ebadi, A.; Rajabzadeh, M.; Khalifeh, R. ChemistrySelect 2019, 4, 7211-7218. doi:10.1002/slct.201901237

23. Rezaei, F.; Amrollahi, M. A.; Khalifeh, R. Inorg. Chim. Acta 2019, 489, 8-18. doi:10.1016/j.ica.2019.01.039

24. Ramazani, A.; Asiabi, P. A.; Aghahosseini, H.; Gouranlou, F. Curr. Org. Chem. 2017, 21, 908-922. doi:10.2174/1385272820666161021103415

25. Lim, M.; Lee, H.; Kang, M.; Yoo, W.; Rhee, H. RSC Adv. 2018, 8, 6152-6159. doi:10.1039/c8ra00306h 
26. Sharghi, H.; Aberi, M.; Shiri, P. Appl. Organomet. Chem. 2018, 32, No. e4446. doi:10.1002/aoc.4446

27. Koishybay, A.; Shantz, D. F. Appl. Catal., A 2018, 563, 196-203. doi:10.1016/j.apcata.2018.07.007

28. Khajehzadeh, M.; Moghadam, M.; Jamehbozorgi, S. Inorg. Chim. Acta 2019, 485, 173-189. doi:10.1016/j.ica.2018.09.042

29. Dehbanipour, Z.; Moghadam, M.; Tangestaninejad, S.; Mirkhani, V.; Mohammadpoor-Baltork, I. Polyhedron 2017, 138, 21-30. doi:10.1016/j.poly.2017.08.032

30. Sharghi, H.; Shiri, P.; Aberi, M. Catal. Lett. 2017, 147, 2844-2862. doi:10.1007/s10562-017-2173-7

31. Nunes, A.; Djakovitch, L.; Khrouz, L.; Felpin, F.-X.; Dufaud, V. Mol. Catal. 2017, 437, 150-157. doi:10.1016/j.molcata.2016.11.017

32. Tavassoli, M.; Landarani-Isfahani, A.; Moghadam, M.; Tangestaninejad, S.; Mirkhani, V.; Mohammadpoor-Baltork, I. ACS Sustainable Chem. Eng. 2016, 4, 1454-1462. doi:10.1021/acssuschemeng.5b01432

33. Mirsafaei, R.; Heravi, M. M.; Ahmadi, S.; Moslemin, M. H.; Hosseinnejad, T. J. Mol. Catal. A: Chem. 2015, 402, 100-108. doi:10.1016/j.molcata.2015.03.006

34. Diz, P.; El Pernas, P.; Maatougui, A.; Tubio, C. R.; Azuaje, J.; Sotelo, E.; Guitián, F.; Gil, A.; Coelho, A. Appl. Catal., A 2015, 502, 86-95. doi:10.1016/j.apcata.2015.05.025

35. Roy, S.; Chatterjee, T.; Pramanik, M.; Roy, A. S.; Bhaumik, A.; Islam, S. M. J. Mol. Catal. A: Chem. 2014, 386, 78-85. doi:10.1016/j.molcata.2014.01.027

36. Ting, J.-M.; Lin, W.-C. Nanotechnology 2008, 20, No. 025608. doi:10.1088/0957-4484/20/2/025608

37. Geim, A. K.; Novoselov, K. S. The rise of graphene. In Nanoscience and Technology: A Collection of Reviews from Nature Journals; Rodgers, P., Ed.; World Scientific: Singapore, 2009; pp 11-19. doi:10.1142/9789814287005_0002

38. Tsakadze, Z. L.; Levchenko, I.; Ostrikov, K.; Xu, S. Carbon 2007, 45, 2022-2030. doi:10.1016/j.carbon.2007.05.030

39. Fejes, D.; Hernádi, K. Materials 2010, 3, 2618-2642. doi:10.3390/ma3042618

40. Shaikjee, A.; Coville, N. J. J. Adv. Res. 2012, 3, 195-223. doi:10.1016/j.jare.2011.05.007

41. Sharghi, H.; Khalifeh, R.; Mansouri, S. G.; Aberi, M.; Eskandari, M. M. Catal. Lett. 2011, 141, 1845-1850. doi:10.1007/s10562-011-0671-6

42. Abbaspour, A.; Tashkhourian, J.; Ahmadpour, S.; Mirahmadi, E.; Sharghi, H.; Khalifeh, R.; Shahriyari, M. R. Mater. Sci. Eng., C 2014, 34, 326-333. doi:10.1016/j.msec.2013.09.013

43. Sharghi, H.; Jokar, M.; Doroodmand, M. M. Adv. Synth. Catal. 2011, 353, 426-442. doi:10.1002/adsc.201000365

44. Abbaspour, A.; Khoshfetrat, S. M.; Sharghi, H.; Khalifeh, R. J. Hazard. Mater. 2011, 185, 101-106. doi:10.1016/j.jhazmat.2010.09.002

45. Shamsipur, M.; Shirmardi Dezaki, A.; Akhond, M.; Sharghi, H.; Khalife, R. Int. J. Environ. Anal. Chem. 2011, 91, 33-48. doi:10.1080/03067310903194998

46. Abbaspour, A.; Norouz-Sarvestani, F.; Sharghi, H.; Moeini, F. Anal. Methods 2010, 2, 1522-1527. doi:10.1039/c0ay00268b

47. Sharghi, H.; Khalifeh, R.; Salimi Beni, A. R. J. Iran. Chem. Soc. 2010, 7, 275-288. doi:10.1007/bf03245889

48. Sharghi, H.; Beyzavi, M. H.; Safavi, A.; Doroodmand, M. M.; Khalifeh, R. Adv. Synth. Catal. 2009, 351, 2391-2410. doi:10.1002/adsc.200900353

49. Shamsipur, M.; Najafi, M.; Hosseini, M. M.; Sharghi, H. Pol. J. Chem. 2009, 83, 1173-1183.
50. Sharghi, H.; Khalifeh, R.; Doroodmand, M. M. Adv. Synth. Catal. 2009, 351, 207-218. doi:10.1002/adsc.200800612

51. Sharghi, H.; Aberi, M.; Doroodmand, M. M. Adv. Synth. Catal. 2008, 350, 2380-2390. doi:10.1002/adsc.200800317

52. Sharghi, H.; Khalifeh, R. Can. J. Chem. 2008, 86, 426-434. doi:10.1139/v08-026

53. Sharghi, H.; Hosseini-Sarvari, M.; Eskandari, R. Synthesis 2006, 2047-2052. doi:10.1055/s-2006-942384

54. Abbaspour, A.; Izadyar, A.; Sharghi, H. Anal. Chim. Acta 2004, 525, 91-96. doi:10.1016/j.aca.2004.07.074

55. Dabiri, M.; Kashi, S. R. B.; Lehi, N. F.; Bashiribod, S. Appl. Organomet. Chem. 2018, 32, No. e4189. doi:10.1002/aoc.4189

56. Zhai, Y.; Dou, Y.; Zhao, D.; Fulvio, P. F.; Mayes, R. T.; Dai, S. Adv. Mater. (Weinheim, Ger.) 2011, 23, 4828-4850. doi:10.1002/adma.201100984

57. Patrick, J. W., Ed. Porosity in Carbons: Characterization and Applications; John Wiley \& Sons, Inc: Hoboken, NJ, 1995.

58. Kinoshita, K. Carbon: Electrochemical and Physicochemical Properties; John Wiley \& Sons, Inc.: Hoboken, NJ, 1988.

59. Kyotani, T. Carbon 2000, 38, 269-286. doi:10.1016/s0008-6223(99)00142-6

60. Zheng, Y.; Liu, J.; Liang, J.; Jaroniec, M.; Qiao, S. Z. Energy Environ. Sci. 2012, 5, 6717-6731. doi:10.1039/c2ee03479d

61. Rodríguez-reinoso, F. Carbon 1998, 36, 159-175. doi:10.1016/s0008-6223(97)00173-5

62. Lam, E.; Luong, J. H. T. ACS Catal. 2014, 4, 3393-3410. doi:10.1021/cs5008393

63. Tiwari, J. N.; Tiwari, R. N.; Kim, K. S. Prog. Mater. Sci. 2012, 57, 724-803. doi:10.1016/j.pmatsci.2011.08.003

64. Li, Y.; Fan, X.; Qi, J.; Ji, J.; Wang, S.; Zhang, G.; Zhang, F. Nano Res. 2010, 3, 429-437. doi:10.1007/s12274-010-0002-z

65. Diyarbakir, S.; Can, H.; Metin, Ö. ACS Appl. Mater. Interfaces 2015, 7, 3199-3206. doi:10.1021/am507764u

66. Liu, H.; Chen, J.; Chen, L.; Xu, Y.; Guo, X.; Fang, D. ACS Sustainable Chem. Eng. 2016, 4, 3140-3150. doi:10.1021/acssuschemeng.6b00156

67. Gao, Y.; Ma, D.; Wang, C.; Guan, J.; Bao, X. Chem. Commun. 2011, 47, 2432-2434. doi:10.1039/c0cc04420b

68. Sharghi, H.; Ebrahimpourmoghaddam, S.; Doroodmand, M. M. J. Organomet. Chem. 2013, 738, 41-48. doi:10.1016/j.jorganchem.2013.04.013

69. Sharghi, H.; Khoshnood, A.; Khalifeh, R.; Doroodmand, M. M. Mol. Diversity 2015, 19, 481-500. doi:10.1007/s11030-015-9585-3

70. Sharghi, H.; Ebrahimpourmoghaddam, S.; Doroodmand, M. M. Tetrahedron 2013, 69, 4708-4724. doi:10.1016/j.tet.2013.03.073

71. Sharghi, H.; Khalifeh, R.; Moeini, F.; Beyzavi, M. H.; Salimi Beni, A.; Doroodmand, M. M. J. Iran. Chem. Soc. 2011, 8, S89-S103. doi:10.1007/bf03254285

72. Sharghi, H.; Sarvari, M. H. Synthesis 2003, 243-246. doi:10.3184/030823403103173408

73. Sharghi, H.; Shiri, P.; Aberi, M. Beilstein J. Org. Chem. 2018, 14, 2745-2770. doi:10.3762/bjoc. 14.253

74. Sharghi, H.; Mozaffari, M.; Aboonajmi, J.; Doroodmand, M. M.; Shiri, P.; Aberi, M. ChemistrySelect 2018, 3, 13534-13540. doi:10.1002/slct.201802381

75. Sharghi, H.; Aboonajmi, J.; Mozaffari, M.; Doroodmand, M. M.; Aberi, M. Appl. Organomet. Chem. 2018, 32, No. e4124. doi:10.1002/aoc.4124

76. Payra, S.; Saha, A.; Banerjee, S. ChemCatChem 2018, 10 , 5468-5474. doi:10.1002/cctc.201801524 
77. Gupta, A.; Jamatia, R.; Dam, B.; Pal, A. K. ChemistrySelect 2018, 3, 8212-8220. doi:10.1002/slct.201801724

78. Naeimi, H.; Ansarian, Z. Inorg. Chim. Acta 2017, 466, 417-425. doi:10.1016/j.ica.2017.06.057

79. Nandi, D.; Taher, A.; UI Islam, R.; Siwal, S.; Choudhary, M.; Mallick, K. R. Soc. Open Sci. 2016, 3, No. 160580. doi:10.1098/rsos. 160580

80. Dabiri, M.; Kasmaei, M.; Salari, P.; Kazemi Movahed, S. RSC Adv. 2016, 6, 57019-57023. doi:10.1039/c5ra25317a

81. Naeimi, H.; Shaabani, R.; Moradian, M. Appl. Organomet. Chem. 2017, 31, No. e3626. doi:10.1002/aoc.3626

82. Prakash, S. P.; Gopidas, K. R. ChemistrySelect 2016, 1, 4803-4813. doi:10.1002/slct.201601127

83. Reddy, V. H.; Reddy, Y. V. R.; Sridhar, B.; Reddy, B. V. S. Adv. Synth. Catal. 2016, 358, 1088-1092. doi:10.1002/adsc.201501072

84. Shaygan Nia, A.; Rana, S.; Döhler, D.; Jirsa, F.; Meister, A.; Guadagno, L.; Koslowski, E.; Bron, M.; Binder, W. H. Chem. - Eur. J. 2015, 21, 10763-10770. doi:10.1002/chem.201501217

85. Pourjavadi, A.; Safaie, N.; Hosseini, S. H.; Bennett, C. Appl. Organomet. Chem. 2015, 29, 601-607. doi:10.1002/aoc.3336

86. Roy, I.; Bhattacharyya, A.; Sarkar, G.; Saha, N. R.; Rana, D.; Ghosh, P. P.; Palit, M.; Das, A. R.; Chattopadhyay, D. RSC Adv. 2014, 4, 52044-52052. doi:10.1039/c4ra08127g

87. Rossy, C.; Majimel, J.; Delapierre, M. T.; Fouquet, E.; Felpin, F.-X. J. Organomet. Chem. 2014, 755, 78-85. doi:10.1016/j.jorganchem.2014.01.006

88. Shaygan Nia, A.; Rana, S.; Döhler, D.; Noirfalise, X.; Belfiore, A.; Binder, W. H. Chem. Commun. 2014, 50, 15374-15377. doi:10.1039/c4cc07774a

89. Baig, R. B. N.; Varma, R. S. Chem. Commun. 2013, 49, 752-770. doi:10.1039/c2cc35663e

90. Atalay, S.; Kolat, V. S.; Atalay, F. E.; Bayri, N.; Kaya, H.; Izgi, T. J. Magn. Magn. Mater. 2018, 465, 151-155. doi:10.1016/j.jmmm.2018.05.108

91. Martinez-Boubeta, C.; Simeonidis, K. Nanoscale Materials in Water Purification. In Nanoscale Materials in Water Purification; Thomas, S.; Pasquini, D.; Shao-Yuan, L.; Gopakumar, D. A., Eds.; Elsevier: Amsterdam, Netherlands, 2019; pp 521-552. doi:10.1016/b978-0-12-813926-4.00026-4

92. Frey, N. A.; Peng, S.; Cheng, K.; Sun, S. Chem. Soc. Rev. 2009, 38, 2532-2542. doi:10.1039/b815548h

93. Xie, J.; Liu, G.; Eden, H. S.; Ai, H.; Chen, X. Acc. Chem. Res. 2011, 44, 883-892. doi:10.1021/ar200044b

94. Wu, M.; Huang, S. Mol. Clin. Oncol. 2017, 7, 738-746. doi:10.3892/mco.2017.1399

95. Misztalewska-Turkowicz, I.; Markiewicz, K. H.; Michalak, M.; Wilczewska, A. Z. J. Catal. 2018, 362, 46-54. doi:10.1016/j.jcat.2018.03.015

96. Salamatmanesh, A.; Kazemi Miraki, M.; Yazdani, E.; Heydari, A. Catal. Lett. 2018, 148, 3257-3268. doi:10.1007/s10562-018-2523-0

97. Doustkhah, E.; Heidarizadeh, M.; Rostamnia, S.; Hassankhani, A.; Kazemi, B.; Liu, X. Mater. Lett. 2018, 216, 139-143. doi:10.1016/j.matlet.2018.01.014

98. Bonyasi, R.; Gholinejad, M.; Saadati, F.; Nájera, C. New J. Chem. 2018, 42, 3078-3086. doi:10.1039/c7nj03284f

99. Mahdavinia, G. R.; Soleymani, M.; Nikkhoo, M.; Farnia, S. M. F.; Amini, M. New J. Chem. 2017, 41, 3821-3828. doi:10.1039/c6nj03862j
100.Shaabani, A.; Afshari, R.; Hooshmand, S. E. New J. Chem. 2017, 41, 8469-8481. doi:10.1039/c7nj01150d

101. Mogaddam, F. M.; Eslami, M.; Ayati, S. E. ChemistrySelect 2017, 2, 11942-11948. doi:10.1002/slct.201701988

102. Banan, A.; Bayat, A.; Valizadeh, H. Appl. Organomet. Chem. 2017, 31, No. e3604. doi:10.1002/aoc.3604

103.Shaabani, A.; Afshari, R.; Hooshmand, S. E.; Tabatabaei, A. T.; Hajishaabanha, F. RSC Adv. 2016, 6, 18113-18125. doi:10.1039/c5ra23294e

104. Nemati, F.; Heravi, M. M.; Elhampour, A. RSC Adv. 2015, 5, 45775-45784. doi:10.1039/c5ra06810j

105. Moghaddam, F. M.; Ayati, S. E. RSC Adv. 2015, 5, 3894-3902. doi:10.1039/c4ra13330g

106. Anil Kumar, B. S. P.; Harsha Vardhan Reddy, K.; Satish, G.; Uday Kumar, R.; Nageswar, Y. V. D. RSC Adv. 2014, 4, 60652-60657. doi:10.1039/c4ra12061b

107.Dolatkhah, Z.; Javanshir, S.; Bazgir, A.; Mohammadkhani, A. ChemistrySelect 2018, 3, 5486-5493. doi:10.1002/slct.201800501

108. Jahanshahi, R.; Akhlaghinia, B. RSC Adv. 2016, 6, 29210-29219. doi:10.1039/c6ra05468d

109.Mohammadi, L.; Zolfigol, M. A.; Khazaei, A.; Yarie, M.; Ansari, S.; Azizian, S.; Khosravi, M. Appl. Organomet. Chem. 2018, 32, No. e3933. doi:10.1002/aoc.3933

110.Shaabani, S.; Tavousi Tabatabaei, A.; Shaabani, A. Appl. Organomet. Chem. 2017, 31, No. e3559. doi:10.1002/aoc.3559 111.Sabaqian, S.; Nemati, F.; Heravi, M. M.; Nahzomi, H. T. Appl. Organomet. Chem. 2017, 31, No. e3660. doi:10.1002/aoc.3660

\section{License and Terms}

This is an Open Access article under the terms of the Creative Commons Attribution License (http://creativecommons.org/licenses/by/4.0). Please note that the reuse, redistribution and reproduction in particular requires that the authors and source are credited.

The license is subject to the Beilstein Journal of Organic Chemistry terms and conditions: (https://www.beilstein-journals.org/bjoc)

The definitive version of this article is the electronic one which can be found at: $\underline{\text { doi: } 10.3762 / \text { bjoc. } 16.52}$ 